Portland State University

PDXScholar

Fall 12-13-2013

\title{
Sexting Unleashed: The Social Phenomenon According to Youth Sexters
}

Jessica Marie McGraw

Portland State University

Follow this and additional works at: https://pdxscholar.library.pdx.edu/open_access_etds

Part of the Gender, Race, Sexuality, and Ethnicity in Communication Commons, and the Social Media Commons

Let us know how access to this document benefits you.

\section{Recommended Citation}

McGraw, Jessica Marie, "Sexting Unleashed: The Social Phenomenon According to Youth Sexters" (2013). Dissertations and Theses. Paper 1491.

https://doi.org/10.15760/etd.1490

This Thesis is brought to you for free and open access. It has been accepted for inclusion in Dissertations and Theses by an authorized administrator of PDXScholar. Please contact us if we can make this document more accessible: pdxscholar@pdx.edu. 
Sexting Unleashed: The Social Phenomenon According to Youth Sexters

\author{
by \\ Jessica Marie McGraw
}

A thesis submitted in partial fulfillment of the requirements for the degree of

\author{
Master of Science \\ in \\ Communication
}

\begin{abstract}
Thesis Committee:
Leslie A. Rill, Chair

Priya Kapoor

Alma M. O. Trinidad
\end{abstract}

Portland State University

2013 
(C)2013 Jessica Marie McGraw 


\begin{abstract}
What is missing from academia and society at large is a more holistic picture of youth sexting. Not adequately understanding youth sexting has stunted previous attempts to effectively educate young people on its potential consequences. As such, the social and legal consequences of sexting gone viral have negatively impacted countless individuals. This study offers a preliminary glimpse of the sexting phenomenon by highlighting the experiences of 20 young people. I explore emergent themes regarding the nature of youth sexting as well as the interrelations amongst privacy, relationships, and sexting. Two distinct forms of sexting emerged from participant narratives, opening the door for more open-minded discussions and social policies cognizant of both the positive and negative outcomes of electronic forms of sexual communication. In general, participant discourse on youth sexting demonstrates a need for more research on the topic as well as updated forms of sexting education in schools and amongst families.
\end{abstract}




\section{Dedication}

I dedicate my Master's thesis to my Grandpa, my biggest academic fan and the one that never stopped encouraging me to pursue higher education. I love you Grandpa. 


\section{Acknowledgements}

First and foremost, I would like to thank my thesis advisor, Dr. Leslie A. Rill, for being the most challenging and encouraging professor I have ever had the pleasure of working with. Your advice regarding all facets of life will always stick with me as I move forward. You have impacted my life in so many wonderful ways, and I hope you know that I will always be grateful. Thank you for being my mentor and my friend.

I would also like to thank my remaining committee members, Dr. Priya Kapoor and Dr. Alma M. O. Trinidad. Thank you for committing to this project, for encouraging me, and for sharing with me your knowledge and insights. I am forever appreciative.

I thank my cohort—Kalistah, Jason, Johanna, Bobby Awesome, and Veronicafor all of your support within and outside of our classrooms together. I will never forget my time with you. To Kalistah, thank you for being my best friend, supporter, partner in crime, and fellow explorer of P-town. To Jason, thank you for being my research partner time and time again. It could only be you. To Johanna, thank you for always being the first to check in on me and make sure my head was above water. I have your words of encouragement pinned to my wall and they won't ever come down. To Bobby Awesome, you'll always be my gay husband and, no matter how far apart our lives take us, the thought of you will always put a smile on my face. To Veronica, thank you for all of your encouragement and for introducing me to the Tanqueray and tonic.

I also thank my participants, whose willingness to share their experiences made this project possible. Thank you so much for your time and honesty!

And, as always, I thank my family. You will always be my rock, and I am where I am today because of all of you. I love you so much! 


\section{Table of Contents}

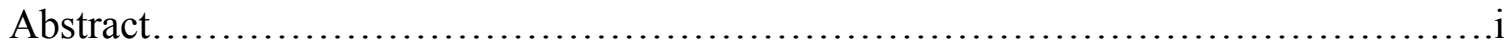

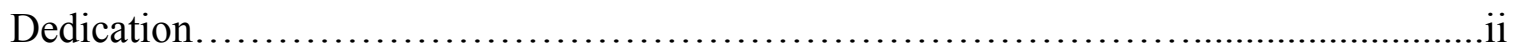

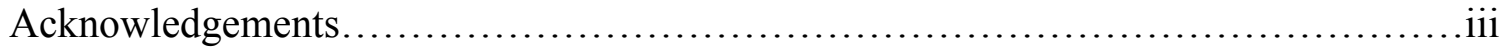

Chapter 1

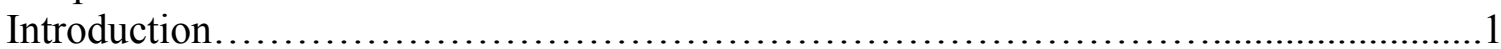

Chapter 2

Literature Review............................................................... 8

Chapter 3

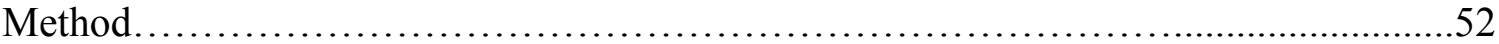

Chapter 4

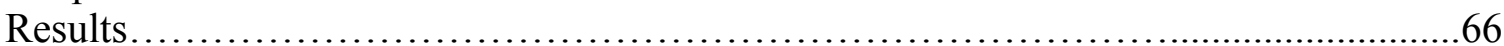

Chapter 5

Discussion.................................................................... 104

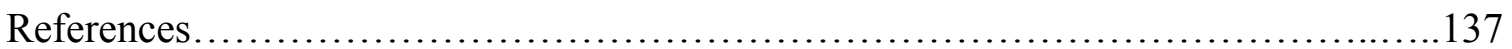

Appendices

A. Table 1: Participant Demographics................................. 142

B. Recruitment Script...............................................143

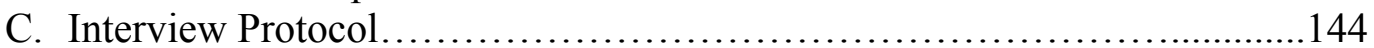

D. Informed Consent.................................................... 146

E. Table 2: Theme Tallies...........................................147 


\section{CHAPTER 1: INTRODUCTION}

Dina Van Cleve was young and bright, a successful high school athlete with top college prospects and a boyfriend she loved. At just 17 years of age, Dina had already planned out the next four years of her life. She had recently accepted a field hockey scholarship to her favorite college and planned to graduate with honors. Yet, for reasons initially unbeknownst to her mother, Rachel Van Cleave, Dina returned home from school one cold autumn day, walked the single flight of stairs to her second floor bedroom, and hung herself from a ceiling fan in her room. Dina's actions were seemingly without cause, prompting her mother to investigate why her young, beautiful, successful daughter with a bright, open future would choose to end her life (Moody Independent, 2012).

Rachel's investigation would ultimately reveal that Dina's tragic suicide was the result of intense bullying and sexual harassment from her peers, actions precipitated by the mass dissemination of a naked picture of Dina throughout the school and the community just weeks before. Dina had taken the picture of herself, smiling and standing naked in front of a full-length mirror, with her mobile phone prior to sending it to her boyfriend. The same picture was found by Dina's friend, forwarded to another friend, found by a parent, and, finally, sent en masse to hundreds of students. Consequentially, and despite the fact that she was still a virgin, Dina was labeled a 'slut' by her peers, who then chose to perpetually taunt her, call her names, and even vandalize her locker. Eventually, the harassment became too persistent and intense for Dina to tolerate (Moody Independent, 2012). 
Though reminiscent of, and perhaps even inspired by, the more extreme cases of sexting and cyberbullying touted in the media in the past couple of years, this anecdote is not a true story. Instead, it is the brainwork of screenwriters and video producers, a Lifetime Movie Network Original suitably titled Sexting in Suburbia and released to television on January 14, 2012. The movie cover features several of the high school characters, with Dina in the forefront next to what is presumably the headstone of her own grave. "A harmless text turned deadly" is inscribed on the headstone, foregrounding the potentially fatal consequences of a seemingly normal adolescent activity. If this inscription is not foreboding enough, the personal and social consequences of Dina's actions are clearly displayed in the movie (Moody Independent, 2012).

The recent release of a Lifetime movie reflecting the perils of youth sexting seems germane to the environment of current media, legal, and academic responses to the practice. Some of the key themes regarding sexting that are depicted in the movie appear to align with current understandings of the phenomenon in reality, which include: the amplified role of the mobile phone in youth subculture (Bond, 2011; Bosch, 2011; Oksman \& Turtiainen, 2004; Thompson \& Cupples, 2008; Thulin \& Vilhelmson, 2007; Yoon, 2006); the use of sexting as a means to facilitate romantic attachment (Drouin \& Landgraff, 2012); the purported increased likelihood of girls to be the initiators and victims of sexting (Bailey \& Hanna, 2011; Brown, Keller, \& Stern, 2009; Hasinoff, 2010; Karaian, 2012); and the social and legal nature of the consequences associated with sexting as well as young people's inability to adequately comprehend their magnitude (Dake, Price, Maziarz, \& Ward, 2012; Stone, 2011; Theodore, 2011; Walker, Sanci, \& Temple-Smith, 2011). 
Indeed, Sexting in Suburbia stands as an amalgamation of most, if not all, of the components to be discussed in a review of academic literature on the topic, which demonstrates the interrelations between social realities (contrived or not), media representations, and academic pursuits. In these various contexts, sexting is a risky form of sexual communication. As such, it is one of many outcomes of enhancements to mobile phones that warrants deeper consideration given its consequential, controversial and much-debated nature.

Sexting, or the sending and receiving of sexually explicit or implicit content (e.g. What are you wearing?) via text, photo, or video messaging, has received considerable attention in the popular press over the past seven years (Kiesbye, 2011). Social science researchers interested in the effects of new media technologies on popular opinion and practice have examined sexting as a communication behavior, including its function within and outside of romantic relationships and consequences, which demonstrates its existence as a social issue important to academia as well (Barkacs \& Barkacs, 2010; Drouin \& Landgraff, 2012; Ferguson, 2011; Parker, Blackburn, Perry, \& Hawks, 2013; Weiss \& Samenow, 2010; Weisskirch \& Delevi, 2011; Wysocki \& Childers, 2011). The nationwide focus on sexting, especially among teenagers and young adults, reflects the moral and social importance of this activity to authority figures attempting to control teenage-cell phone interaction (Kiesbye, 2011). How teens may use new technologies and media for either sexual expression or exploitation is especially relevant now, as federal and state authorities are struggling to clearly define and legally control the act and consequences of sexting (Bailey \& Hanna, 2011; Stone, 2011; Theodore, 2011). 
As a form of sexual communication and behavior, sexting is a social outcome enabled by enhancements in the field of new media technology, specifically in the contexts of computer-mediated communication (CMC), or technology-mediated communication (TMC), and information-communication technologies (ICTs) such as the mobile phone. Given the fact that sexting is enabled by CMC/TMC and ICT technologies, its prevalence among members of the digital generation, or people between the ages of 12 and 25, is unsurprising and yet concerning. For instance, sexting was ranked in the top ten health concerns for children in the 2011 Mott's Children's Hospital National Poll on Children's Health, with $20 \%$ of adults rating it as a big problem in modern society (Hua, 2012).

Furthermore, in light of the apparent rise in sexting, individual states within the U.S. have enacted their own legislation on the practice based on the 2008 child pornography federal statute. For example, sexting is illegal in Nebraska and a felony in Virginia regardless of the age of those involved. As of 2011, Ohio was considering a new bill to make sexting a misdemeanor (Theodore, 2011). Statistics and legislative actions such as these suggest three things: first, sexting is perceived as a health issue and problem; second, parents, educators, and various other social authorities view teenage engagement with advancements in new media technologies, like the mobile phone, with a watchful eye; and lastly, the consequences of sexting are alarming enough to social authorities to invoke state legislation on and regulation of the practice.

How sexting is perceived, valued, and potentially controlled by efforts to align the use of ICTs and CMC with social standards in a particular society or culture speaks to the tenuous nature of technological advancements. This is especially relevant when 
considering how they may or may not disrupt what is considered acceptable sexual communication and expression in American society. As such, sexting is an important practice for communication scholars to consider in light of its implications for social morality and conduct. Furthermore, it is an important research endeavor for social researchers interested in the relationship between new media and cultural relations broadly, and young people and sexual communication specifically. By virtue of their specialization in communication studies, communication scholars are particularly well equipped to examine the potential utilities, associated behaviors, and consequences of youth sexting as well as the moral and legal responses to the practice from authority figures. Interestingly, few communication scholars have examined the sexting phenomenon, with much of the research on the topic stemming from youth studies and sexuality education journals, adolescent health and behavior professionals, and legal scholars (Bailey \& Hanna, 2011; Brown et al., 2009; Dake et al., 2012; Farber, Shafron, Hamadani, Wald, \& Nitzburg, 2012; Hua, 2012; Parker et al., 2013; Stone, 2011; Theodore, 2011; Walker et al., 2011, 2013).

Much of what we currently know about youth sexting, namely that sexting is a widespread phenomenon with very important social and cultural implications, stems from these sources. It is clear, however, that we have not yet taken the time to construct a more comprehensive picture of sexting by engaging the perspective of youth sexters. By excluding the voices of youth sexters from discussions on the topic, current research has failed to adequately conceptualize sexting. This exclusion is consequential in that it restricts both understandings of the social impact of sexting as well as attempts to educate individuals about its potential consequences. 
With this gap in mind, this thesis aims to contribute a holistic perspective on sexting as a prominent practice in contemporary society by examining the perspectives of young adults on the topic. Given the emergence of sexting in the media in 2008 (Hasinoff, 2010), young adults between the ages of 18-25 are the ideal age group to contribute to current understandings of the phenomenon because they can be considered the first generation of texters in accordance with this timeline. This means that when members of this age group were in high school, they were in a crucial position to learn the behaviors and habits of adolescent texters, and thus potential sexters, at a time when little was known about the nature of sexting. In this sense, young adults could provide both reflections of their more formative sexting experiences as well as observations on the existence and role of sexting in their lives now. As such, young adults could contribute a comparative foundation for understanding sexting that could shed light on how age may or may not impact the use of technology or notions of acceptable technology use and the nature of privacy for those immersed in the digital lifestyle. In light of recent research outlining the consequences of sexting, a study of this nature is not only justified but absolutely necessary.

The goals of this project are threefold. My primary goal is to learn about the nature of youth sexting from members of the first generation of sexters, all of whom are now young adults. Furthermore, I hope to flesh out youth perspectives of privacy and how these notions manifest in the practice of sexting. Consequently, my results may have important practical application for researchers interested in collaborating with members of the youth subculture to develop effective solutions to potential social 
problems stemming from sexting. Subsequent chapters further explicate the nature of current understandings of sexting and details of the present study.

In chapter two, I synthesize relevant literature on sexting to date, with specific regard for several topical areas: definitions of sexting, who sexts and how often, and the relationship between sexting and other behavioral and relational variables. Furthermore, I explore general notions of privacy and how sexting, as a form of sexual communication, may impact interpersonal relationships. I also consider the legal, media, and critical responses to youth sexting to provide social context for the phenomenon. Finally, I briefly discuss Petronio and Durham’s (2008) Communication Privacy Management (CPM) theory and its relevance to the context of youth sexting. This review of the literature culminates in three refined research questions, which guide the remainder of the study. Chapter three outlines the methodology of this project, and includes four primary components: method; sample; procedures; and data analysis. Each component includes details on and justification for how I conducted this study. Chapters four and five explore and discuss the results of this study. 


\section{CHAPTER 2: LITERATURE REVIEW}

To achieve a diverse and well-rounded understanding of my research topic, specifically youth sexting, I broadly examine sexting in form and function before narrowing my focus to its use in the social sphere. First, I identify the mechanism, specifically the cellular phone, that facilitates sexting and briefly discuss its role in the lives of contemporary youth. Secondly, I define the practice, or what constitutes sexting, according to the popular press and academia prior to examining its prevalence among young people. Furthermore, I examine some of the research and theoretical perspectives concerning the construct of sexting and associated behaviors. Specifically, I consider sexting from a functional perspective, noting its role as a communicative tool in both interpersonal and sexual communication and how it may impact social relations and interpersonal relationships. To provide social context for my study, I examine various social, legal, and alternative responses to the practice as well as experts' opinions on how to prevent and control youth sexting. Finally, I consider theoretical approaches that may be useful to future investigations of sexting to help fill the gaps left by previous research. This review culminates in several refined research questions concerning the phenomenon that are investigated over the course of this study and added to the overall conversation on sexting.

\section{Explication: "Youth" and "youth sexting"}

Explication of the term "youth" necessarily precedes a discussion and study of youth sexting. Research on sexting and mobile phones use several terms, such as "youth," adolescents," "teenagers," and "young adults," to refer to the young people that comprise the digital generation. Members of the digital generation may range along an 
age spectrum of 11 to 25 (Bond, 2010; Thulin \& Vilhelmson, 2007; Thurlow, 2003;

Yoon, 2006). For example, Thulin and Vilhemlsom (2007) cite research that conceptualizes young people as those between 15 and 24 years of age; for their own study, they sample high school students and refer to them as both "young people" and "teenagers." Thurlow (2003) uses the terms "adolescents," "teenagers," and "young people" synonymously. Bond (2010) similarly uses the terms "young people" and "children" interchangeably; the age range of her study sample is 11-17. Thurlow and McKay (2003) discuss statistics regarding the "net generation of cyberkids" (p. 94). Here, the net generation includes teenagers, older teenagers, youth, and young people ranging in age from 11 to 25.

These examples demonstrate how terms used to denote childhood, adolescence, and youth are loosely and perhaps even arbitrarily defined. More importantly, they reflect a broad age spectrum of what constitutes youth. For purposes of clarity, throughout this paper I will use the term "youth" to refer to members of the digital generation, or anyone between the ages of 11-25. Furthermore, I will work with the latter end of this spectrum, specifically young adults between the ages of 18 and 25 , to construct youth narratives on sexting. In the context of my study, I will refer to the latter half of the digital generation as "young adults" and "young people" and their engagement in sexting as "youth sexting."

\section{The mechanism: Mobile communication and information sharing}

The ubiquitous nature of text messaging, also known as Short-Messaging Service (SMS), as a primary and secondary means of communication for people with cellular phones exemplifies the changes in communication patterns inherent in a society 
characterized by rapid technological advancement, particularly in the area of ICTs. With these advancements in communication mediums comes transformation in the ease and manner in which individuals may communicate with others. Texting has been cited for its functionality, especially in facilitating mass communication quickly and relatively effortlessly. Cross-cultural research demonstrates commonality in users' preferences and utilization of SMS as a communication tool (Oksman \& Turtiainen, 2004; Thompson \& Cupples, 2008; Thulin \& Vilhelmson, 2007; Yoon, 2006). Furthermore, advances in the photographic capabilities of cellular phones permit the taking and sending of picture and video messages in a manner similar to texting, thus broadening the way in which individuals can communicate non-verbally with others outside of face-to-face interactions. In this manner, cellular phone users are afforded the opportunity to communicate and network in a manner that satisfies their personal and social expectations and desires in a variety of contexts.

Qualitative research further validates the cellular phone as a significant component of contemporary youth culture. Bond's (2011) study of 30 young people between the ages of 11 and 17 reveals the importance of the mobile phone in providing youth with a digital space in which they may explore and construct their sexual identities with the help of others. She describes the phone as a "prop" that adolescents use in their “everyday performances" of self (p. 599). Bosch's (2011) work exploring South African women's use of social networking sites (SNSs), like Facebook and MXit, via the cell phone similarly presents social media as a means through which adolescents and young adults navigate global youth culture. Both authors recognize that the spaces created by new digital technology available through mobile phones afford these users a "space for 
play," in which they can explore and express their sexual identity without fear of parental control (Bosch, 2011, p. 75).

This research demonstrates that, for members of the digital generation, the phone is a significant outlet for participating in youth culture. In this sense, young people use phones to present images of themselves in everyday life. They achieve self-presentation in two primary ways: first by their use of the phone in public and concurrently via the content (i.e. messages, photos, and videos) they send to and receive from others or post on their SNS pages. With the exception of these studies, however, little research has been conducted with the goal of highlighting the voices of the primary insiders, or youth, of the digital culture and lifestyle.

Thurlow (2003) acknowledges the general lack of research addressing adolescent communication from the viewpoint of young people. He suggests that research exploring what adolescents know about communication and how they do communication in a variety of contexts may contribute to a better understanding of youth culture. Sexting is one of those contexts in need of exploration. For adolescents in particular, sexting enables sexual self-expression and communication at unprecedented levels and thus exists as one aspect of youth culture available for investigation and reflection. In line with Bosch (2011) and Bond's (2011) work, sexting can be understood as the sharing of sexual stories and materials that aid in adolescents' construction of their sexual identities. Furthermore, sharing in this manner is inherently risky based on the perceived social consequences of the phenomenon and its representation in the media, as demonstrated by Cumming (2009), Draper (2012), and Kiesbye (2011) and numerous other researchers 
from multiple disciplines. As such, youth sexting is both theoretically open to and in need of exploration.

\section{What is sexting?: Definitions}

A discussion of sexting as a social phenomenon as well as its prominence amongst various generations necessarily precedes examination of its social function. Notably missing in research on the topic is unanimity in what constitutes sexting. Definitions of sexting vary. Kiesbye's (2011) compendium of popular opinion on the practice suggests that sexting "involves a person transmitting pictures of themselves, scantily clad or in the nude, via cell phone or other media" (p. 7), such as via instant messaging. Numerous studies also limit the act of sexting to the sending of sexually explicit images via cellular phones (Draper, 2012; Lenhart, 2009; Strassberg, McKinnon, Sustaita, \& Rullo, 2012; Walker et al., 2011, 2013). In contrast, some definitions stretch to include sexually suggestive videos (Gordon-Messer, Bauermeister, Grodzinski, \& Zimmerman, 2013; Hurdle, 2009) and texting content (Bailey \& Hanna, 2011; Weisskirch \& Delevi, 2011), or what Hudson (2011) calls "sexy messages" (p. 11) as well.

Bailey and Hanna (2011) further extend previous definitions that involve sending and receiving sexts to include "forwarding, and/or posting sexualized images and/or text through a variety of digital platforms including text messaging, social networking sites, email, and blogging" (p. 409). This definition is the most comprehensive given its inclusion of a variety of media (e.g. mobile phones, SNS, e-mail, blogging) and actions (e.g. sending, receiving, forwarding, posting). As such, it extends future sexting research foci beyond the cellular phone. However, given the term's origin from mashing the 
words 'text' and 'sex' (Hudson, 2011), sexting would logically appear to be limited to actions achieved via the mobile phone. Bailey and Hanna's (2011) extension may have been precipitated by the fact that people are engaging in various forms of sexting via numerous social media technologies (e.g. SNSs, e-mail, chat rooms).

These differences in how sexting is defined have important implications for how the practice is investigated by social researchers and perceived in the popular press. Differing definitions are especially problematic when evaluating statistics on the prevalence of sexting. If researchers are defining sexting differently in their respective studies, reliably interpreting and cross-comparing results is nearly impossible. For example, Weisskirch and Delevi (2011) define sexting as the activity of "sending and receiving sexually-laden images and messages" via cellular phone (p. 1697), thus providing a more inclusive definition of what specific activities or actions constitute sexting. Definitions limiting sexting to the transmission of photos and videos are geared more toward operationalizing the phenomenon so as to make it a social practice with the potential to be controlled and prevented. However, more comprehensive definitions may be more reflective of the realities of the phenomenon among young people. Additionally, more inclusive definitions may include components based on subjective criteria that differ across perspectives. For instance, what constitutes a message or image that is “sexually laden?” (Weisskirch \& Delevi, 2011, p. 1697).

In the realm of social research committed to media ethics and issues of digital abuse, answering these questions is paramount to discussions on how sexting affects youth and what social institutions and parents should and can do about it. Furthermore, conceptualizing the practice of sexting may influence and even proscribe subsequent 
legal actions attempted or pursued by police and lawmakers. Stone (2011) articulates the problematic nature of defining sexting in his examination of criminal justice responses to the practice. He calls sexting an "unsatisfactory" term given its limited ability to encompass the full spectrum of behaviors under its umbrella. For example, these behaviors may range in valence (positive versus negative), typology (private exchange versus "sextortion;" explicit images versus conventional depictions), and psychological motivation (e.g. attention-seeking, low self-esteem, disinhibition due to intoxication) (p. 267).

Here, Stone (2011) achieves several notable distinctions that must be considered. First, sexting can be achieved privately between people or it can be a form of extortion, specifically "sextortion" if sexts are sent or forwarded on without consent from the person who initiated them. Secondly, Stone's "spectrum of behaviors" involves a spectrum of intentions ranging from "attention-seeking" to "malicious or mischievous intent" or even "reluctant compliance," with some people sexting to flirt, to satisfy peer pressures or expectations of the opposite or same sex, or to hurt others. Finally, the nature of sexts varies in intensity or explicitness, with some more benign and playful versus those tantamount to "pornographic images." Similar attempts at categorizing the practice are unearthed in Lenhart's (2009) mixed methods study on how and why teenagers sext, with sexting emerging as one of three potential categories: between romantic partners; between partners and shared with others; between people where at least one person hopes to be in a relationship with the other.

Both Stone's (2011) contentions and Lenhart's (2009) typology serve as cursory understandings of youth sexting that can be compared to the results of the current study 
to see if similar findings emerge or if the nature of youth sexting can be further expanded upon. It is clear that the assortment of behaviors that constitute sexting may occur along a continuum as dictated by the intentions of those engaging in the practice. Furthermore, the abovementioned distinctions confuse and conflict attempts to define and thus regulate the practice of youth sexting, particularly in terms of identifying perpetrators and victims of sexting. Problematic definitions of youth sexting may have substantial social implications for how legal authorities deal with cases of selfvictimization versus self-produced pornography and instances of cyberbullying.

As such, clarifying what constitutes sexting is paramount with regard to current understandings of the practice and how these interpretations of sexting manifest in social discourse on the topic. Some research distinguishes between consensual and nonconsensual sexting, the latter defined as "where an image is misused and sent on without permission" and considered a form of sexual violence (Walker et al., 2011, p. 13). In contrast, consensual sexting refers to voluntary engagement in the practice with others in any variety of interpersonal contexts (i.e. friends, partners, etc.). Dake et al. (2012) suggest that sexting can be conceptualized as cyberbullying when it is involuntary and harmful, which follows this line of thought involving intention. The legal issues incurred by conflicting definitions of sexting will be examined in detail in future sections. For now, it is important to note all of the potential nuances of sexting in practice, as how specific details associated with the activity affect public responses to and the nature of consequences of youth sexting are important components of the social context underlying the current study. 
While young people's use of a variety of mediums to engage in sexual exploration activities is increasingly important to consider and investigate, the following study isolates the practice of sexting to the realm of mobile phone SMS services. Youth definitions of sexting may be far different than those suggested in social research and in the media. These differences are important to consider given the fact that authority figures in a variety of contexts (i.e. homes, schools, police stations, courtrooms, etc.) are attempting to regulate the phenomenon. With this in mind, how youth define sexting is a necessary first step to better understanding the practice.

\section{Prevalence: Who sexts and how often?}

Regardless of how sexting is defined, its prominence among cellular phone users is garnering attention in the mass media (Ahmed, 2013; Barry, 2012; Dvorak, 2013; Hurdle, 2008; Wortham, 2013). With headlines like "Teens, nude photos and the law; Ask yourself: should the police be involved when tipsy teen girls e-mail their boyfriends naughty Valentine's Day pictures?" and "Sexting scandal: Elite private school kids in video wildfire," the explosion of popular press articles on sexting demonstrates American society's and other nations' increased preoccupation with the practice (Barry \& Harris, 2012; Lithwick, 2009). As previously mentioned, Lifetime recently aired Sexting in Suburbia, a movie reflecting the extreme consequences of sexting gone wrong (Moody Independent, 2012). In late 2012, Samsung released a set of commercials highlighting the video-sending capabilities of one of their mobile phones featuring various women (e.g. Mrs. Claus, typical housewife) sending self-made videos to their husbands by merely touching the screen of one phone to the other. Afterward, the women verbally imply the sexual nature of the content of the videos (e.g. "you may not want to watch this 
in the sleigh;" "you might not want to watch this on the plane") to their husbands prior to them leaving. Most recently, Jack in the Box’s "Jack's Big Stack" commercial satirizes the sexting phenomenon by substituting pictures of hamburgers, or "Big Stacks," for pictures of male genitalia.

Kiesbye's (2011) compendium is a testament to the ubiquity of sexting; it includes social, cultural, legal, and educational perspectives on the phenomenon that vary in both scope and suggestion for social and legal policy. The bulk of research and opinions on sexting live in education, sexuality, adolescent health, behavior prevention, and legal journals, thus demonstrating the importance of the topic to social policy debates, adolescent health, and legal actions. Additionally, research and legislation on sexting transcends the national boundaries of the United States, with work done in Australia (Walker et al., 2011, 2013), the United Kingdom (Stone, 2011), and Canada (Bailey \& Hanna, 2011). The cross-cultural nature of sexting suggests that the phenomenon is associated with developed countries that are heavily invested in technological advancements and thus digitally inclined.

Similar to increased media representation, statistics imply an increase in youth engagement with others via sexting. Barkacs and Barkacs (2010) cited the statistics of youth surveys (no age range was given) attesting to the prominence of youth sexting, explaining that approximately $44 \%$ of boys reported viewing sexual images of their female peers, with $15 \%$ of them transmitting nude images of their girlfriends to others after their romantic relationships had ended. In Strassberg et al.'s (2012) survey of 606 high school students, approximately $20 \%$ of participants reported sending sexual images while almost twice as many participants reported receiving them. More recent surveys 
conducted amongst youth, grades 6-12, in 35 different schools in a Midwestern state resulted in a lower engagement rate of $17 \%$ and showed increases in the prevalence based on age, with $3 \%$ of 12 -year-olds reporting engagement in the practice versus $32 \%$ of 18 year-olds (Dake et al., 2012). The age range of these statistics is especially important in establishing a baseline age for individuals who sext given the lack of survey data from even younger populations, such as elementary schoolers, in the literature.

Hudson's (2011) overview of the 2008 national youth surveys conducted by The National Campaign to Prevent Teen and Unplanned Pregnancy further reflects the ubiquity of sexting amongst teenagers between the ages of 13 and 19 and young adults between the ages of 20 and 26 . Of 1,262 respondents, $20 \%$ of teens and $33 \%$ of young adults reported having sent or posted nude or semi-nude images in either photos or videos of themselves while $31 \%$ of teens and $46 \%$ of young adults reported having received sexual images. Notably, sexting statistics increase in the realm of sexually suggestive content, with over half (58\%) of the young adult respondents between the ages of 20 and 26 reporting having sent or posted messages and $64 \%$ reporting having received them (The National Campaign, 2008). More recent research further suggests that sexting rates may increase with age, with $30 \%$ of $18-24$ year-olds reporting having sent and $41 \%$ reporting having received sexts (Gordon-Messer et al., 2013).

The National Campaign (2008) study also found trends in sexting across the gender divide, with more teenage girls and young women sending images than teenage boys or young men, and vice versa for the sending of sexually suggestive messages that did not include images. These results have been regurgitated and interpreted in light of constructing public policy on regulating sexting in various studies in legal and adolescent 
health journals (Bailey \& Hanna, 2011; Farber et al., 2012; Theodore, 2011; Walker et al., 2011). Bailey and Hanna (2011) similarly suggest that girls are more likely to send sexts and "suffer" the social consequences due to their "unauthorized secondary redistribution" (p. 440). Qualitative work on youth sexting, specifically discourse from experts on adolescent behavior and young people between the ages of 15-20, also suggest that sexting is a behavior that involves gendered expectations of how young people should engage in the practice (Walker et al., 2011, 2013). However, Lenhart (2009), Dake et al. (2012), and Reyns, Burek, Henson, and Fisher (2013) reported non-significant relationships between gender and sexting, thus demonstrating a disconnect amongst results on the practice that is difficult to pinpoint solely on methodological differences.

The results of the aforementioned studies demonstrate two important findings: first, males are more likely to engage in sexting via the transmission of content while females are more likely to send images; second, the definition of what constitutes sexting depends on its inclusivity, with reported sexting statistics increasing if sexually suggestive content is included. It appears that further research is needed to either corroborate or negate the existence of a gender divide within the sexting phenomenon, as results suggesting the prevalence of the practice among certain genders over others have important implications for constructing educational materials on the practice. For example, if females are more likely to send naked pictures than males, future research beyond the context of this study would need to focus on why this is the case.

Furthermore, preventative materials and campaigns would need to be audience-specific to certain demographics, such as gender, age, race, etc. The current study may elicit 
SEXTING UNLEASHED

findings regarding a potential gendered component of sexting, and thus may serve as a preliminary investigation useful to future considerations of education on the practice.

It is important to note the variations inherent in statistics on the prevalence of sexting given the conflicting nature of how the practice is defined and investigated. With an engagement rate ranging anywhere from $4-20 \%$ of U.S. teenagers sexting, Bailey and Hanna (2011) contend that studies on the prevalence of youth sexting vary so dramatically—specifically regarding the questions used to investigate the technologies used, the behaviors considered, and their specificity — that they are not comparable. Brown, Keller, and Stern (2009) similarly argue that studies on prevalence do not use true probability samples, which means their results cannot be interpreted as representative of the frequency of sexting among the general population. Validity of statistical analyses and comparability of results could be increased by standardizing the definition of sexting used in future studies and utilizing appropriate sample types dependent on the methodology employed. More importantly, the definition of sexting that is used should be generated from qualitative research on the perspectives of youth so that researchers are speaking the same language as those actually engaging in the practice.

Because current research may not accurately reflect the prevalence of youth sexting, youth opinions regarding how common youth sexting is, where it is occurring, who is sexting and how often may contribute to a more comprehensive picture of the phenomenon. Regardless of the abovementioned inconsistencies in definitions, the statistics cited above show that young people are sexting, and thus validate the importance of exploring this social phenomenon. This is especially so given the potential consequences of sexting outlined in later sections. 
SEXTING UNLEASHED

\section{Why are youths sexting?: Sexting and sexual communication}

An examination of the social functions of sexting is useful in understanding its suggested pervasiveness in society and how this particular phenomenon has become popular amidst increasing attempts to regulate it. Given advancements in CMC technology, the cell phone can now be viewed as a communicative tool that enables both sexual expression and interpersonal communication via sexting. CMC technology, specifically cell phones in this case, stretches the boundaries of when, where, and how people can engage in sexual communication. In this manner, $\mathrm{CMCs}$ permit the slippage of private activities into public domains. Van Manen (2010) explains that social networking technologies unlock the potential for the "exteriorizing of the interiorities of inner life" (p. 1024) and thus serve as "Momus" technologies, so-called windows of Greek mythology that provide inside access to people's innermost thoughts, feelings, and desires (p. 1023). In this sense, the mobile phone, when used for publicizing the private in the case of sexting, can be conceptualized as a "Momus" technology with its own potential advantages, disadvantages, benefits and risks. It is with this pedagogical understanding in mind that I turn to an examination of the utilities and consequences of youth sexting according to social researchers, experts on adolescent behavior, and the few existing studies that examine sexters' self-reported behaviors and reasons for those behaviors.

Utility. Prior research adopting a functionalist perspective of sexting has examined its utility in a variety of contexts, including the initiation or maintenance of romantic relationships among adults and college students (Drouin \& Landgraff, 2012) as well as the use of cyberspace to seek out new sexual partners outside of current 
relationships and marriages (Wysocki \& Childers, 2011). Clinical research illustrates how sexting may serve as an intervention tool that enhances relationship and sexual satisfaction among intimate couples (Parker et al., 2013). Lenhart (2009) discusses how sexting fulfills numerous functions in interpersonal engagement and can be seen as a component of physical sexual activity, an extension of sexual relationships, or a way to gain sexual experience via digital exploration. Specific to youth culture, Curnutt (2012) suggests that teens remediate their sexuality through sexting in order to generate cultural capital, which further underscores the importance of the practice as a form of cultural production in a digital environment.

Here, research demonstrates how sexting is an important facilitator of both interpersonal and sexual communication. Lenhart's (2009) educational component is especially important in considering youth sexting, as it may serve a learning and socialization function in the context of personal sexual education. Brown et al. (2009) relate the time-intensive nature of adolescents' relationship with new media to the educational role of said media. For example, in the U.S., adolescents between the ages of 12 and 17 spend six to seven hours a day with some form of media. Furthermore, various media act as sex educators in that they "include frequent discussion and portrayals of sexual behavior that affect adolescents' conceptions of sexual attractiveness, romantic relationships, and sexual behavior" (p. 12). The authors explain that many adolescents choose to use new media, or digital media specifically, to put their sexuality on display as well as learn about sex from others' displays. In this sense, media can provide an abundance of sexual information and has the potential to increase knowledge and learning and thus acts as what one youth and family psychologist calls a "third parent" in 
and outside of the home (Walker et al., 2011, p. 12). Van Manen (2010) also suggests that young people may take and send pictures and videos that "reflect less who they are than who they want to be" (p. 1025) as a means of experimenting with their sexual identity construction.

As a specific form of virtual sexual communication and component of interpersonal communication, sexting may influence and encourage processes involved in relating to others. Van Manen (2010) suggests that young peoples' engagement in digital intimacy in general is a result of their cravings for closeness and desires to belong as well as their need for keeping a safe distance and saving face in potentially awkward social situations. This view is reinforced in the context of texting and sexting specifically. Farber et al. (2012) suggest that texting allows adolescents to be social yet keep a safe emotional distance from their peers and further explain that young people use SNSs to avoid face-to-face communication that could be uncomfortable or embarrassing. Specific to sexting, Hudson (2011) explains that the practice may "help facilitate a sense of closeness, a greater sense of control in being able to compose responses, and courage to be more open with feelings and desires" (p. 23).

Brown et al. (2009) further reinforce these contentions by describing sexting as just another form of sexual expression that can be both functional and healthy given its capacity to validate users' feelings and increase their sexual agency via permitting adolescents to: share information; form bonds with others based on their similarities; and express their sexual desires for a partner or specific activities, etc. According to Dake et al. (2012), sexting can be conceptualized as a "natural outgrowth of sexual experiences" (p. 13). However, it is important to consider sexting as "natural" in light of the idea that 
sexuality is socially constructed (this is explored in the next section). In all of these cases, CMC is used to bridge users' desires for both the rewards of closeness and the safety of nearness and permits sexters to engage in what Van Manen (2010) calls "distant intimacy," or "intimacy at a distance mediated through texting" (p. 1028).

Here, academic discourse highlights the underlying psychological components involved in predicting certain behaviors from expressed attitudes and intentions. For example, Weisskirch and Delevi's (2011) study on the relationship between attachment anxiety and sexting attitudes and behaviors underscores the existence of specific psychological components that may predict likelihood to sext. Attachment anxiety levels predicted positive attitudes toward using texts for propositioning sex, thus prompting the notion of the cell phone as a "novel technological means" for the expression of attachment anxiety, specifically via sexting (p. 1700). The authors explain that sexting, as a "technological form of flirting," can be a part of both relationship formation and maintenance (p. 1700). However, for those with attachment anxiety, sexting can be a compulsion precipitated by feelings that sexting is a necessary component of preserving a relationship.

Drouin and Landgraff (2011) also found correlations between attachment styles in relationships and sexting levels among 744 college students ages 18 to 36 , with high attachment avoidance predicting greater likelihood to sext. Hudson's (2011) overview of sexting research similarly emphasizes the importance of examining the relationship between multiple psychological variables (e.g self-esteem levels, subjective norms toward sexting, sexting attitudes, and sexting behavior intentions) and sexting behaviors, as such predictors are useful in formulating social and education policies aimed at the 
prevention of digital abuse. Finally, recent preliminary research has demonstrated a positive correlation between levels of self-esteem and likelihood to sext (Gauz \& McGraw, 2011). The potential psychology behind sexting, as demonstrated by the results of these studies, are important for two reasons: first, they situate sexting within the context of interpersonal relationships and thus demonstrate the social component of the practice; second, they have important implications for why youth may sext, and thus can contribute to the construction of educational materials on the benefits and consequences of the practice. As such, these results contribute to the current study by providing more reasons for why youths sext. These reasons can serve as comparison points to be considered in light of emerging emic discourse from my participants.

Associated behaviors. Shifting across the digital divide to a focus on youth sexting engenders a discursive shift as well, with research investigating the functional aspects of sexting as a communicative tool giving way to research examining its association with risky and problematic behaviors, such as uninhibited sexual activity, cyberbullying, and drug use as well as emotional health problems like depression (Dake et al., 2012; Ferguson, 2011; Weiss \& Samenow, 2010). From this perspective, sexting is another type of sexual behavior enabled and encouraged by a hypersexual socio-cultural environment and the peer pressure and social norms operating within it (Bailey \& Hanna, 2011; Curnutt, 2012; Dake et al., 2012; Walker et al., 2011, 2013). Van Manen (2010) suggests that Momus technologies can be dangerous given their capacity to "seduce" young people to give away private information, such as pictures, in a social environment where extensive personal disclosure is expected. Bailey and Hanna (2011) propose that youth sexting is just one result of a "mass-mediated society that immerses children and 
youth in, and encourages the early adoption of, pre-packaged conceptions of femininity and sexuality as keys to social success" (p. 414). Consideration of more dystopian views of sexting are necessary to contextualizing the practice, as it is clear that the positive or negative potential of sexting to either enhance or ruin interpersonal relationships depends on how and why people engage in the practice.

Expert discourse on the topic also reflects the hypersexualized nature of the social environment in which sexting is taking place, which further suggests that sexting is a cultural issue (Walker et al., 2011). In the first phase of their two-part, qualitative study, Walker et al. (2011) interviewed experts on adolescent behavior to generate insight as to why adolescents engage in sexting, the potential consequences of such activities, and solutions. Participants suggest that youth sexting is a sexualization issue stemming from a sexualized culture in which girls "face pressure to present themselves in sexual ways, and young men are expected to be interested..." (p. 12). Some informants expressed concern that sexting was the result of youth's desensitization to sex and sexual behavior due to the "mainstreaming of pornography" (p. 12). Multiple participants discussed the newness of the mechanism, such as the mobile phone, for old behaviors, in this case sharing images of naked men and women.

During the second phase of their two-part qualitative study, Walker et al. (2013) asked young people to share their perspectives on others' sexting experiences, making this study the most useful and important first step in research on youth sexting to date. Similar to expert perspectives, young people corroborated the gendered nature of sexting (e.g. more stigma attached to female sexting) and the role of peer pressure in encouraging youth to engage in the practice. Both themes further implicate sexting as a cultural issue 
for youth in Australia, results that stand as important comparison points for the current study.

Here, sexting is considered a "new manifestation" of youth behaviors that have always existed and, given enhancements to mobile phone technologies, is "inevitable" (Walker et al., 2011, p. 11). According to expert sources, digital media merely increases and enhances the capacity for adolescents to engage in behaviors of sexual exploration with others. It is precisely this increased access and capability that is worrisome for parents and other authority figures attempting to control the practice and mitigate the consequences of digital abuses such as 'sextortion' and other forms of cyberbullying. Because expert discourse on sexting mediates social understandings of the practice, these contentions better clarify the nature and expectations of youth sexting in the U.S. in general and among the participants of this study more specifically.

Weiss and Samenow (2010) discuss the dangers inherent in the development of technology that facilitates quick and easy access to sex, specifically citing phone applications like GRINDR (which allows users to find others in their geographic location that are interested in quick, gratuitous sex), especially among youth and adults with addictive tendencies. The authors contend that increases in individuals' capacities to anonymously access sexual content and sexual partners via digital media result in increases in personal and work-associated problems, including sexual health risks, reputation issues, and psychological distress:

While most of us find comfort in our increasing interconnectivity, those who struggle with sexual problems are capable of turning our technological advances into the kinds of personal nightmares from which there is little escape and even less understanding. (Weiss \& Samenow, 2010, p. 245) 
This passage reflects the dialectical tension inherent in the development of consumer technology meant to enable mass communication and unlimited access to digital information and content. On the one hand, research demonstrates the utility of these media, especially in their ability to enhance communicative processes and interpersonal relationships. However, the same capabilities that enhance communicative processes and interconnection may also enable the manifestation of risky behaviors as well as make them harder to prevent and control. This is especially so for youth engaging with mobile technologies that permit activities outside of the home and away from parents and other authority figures. In conjunction with expert discourse on the topic, Weiss and Samenow's (2010) consideration of the potential dangers of technological advancements provides a more comprehensive picture of the positives and negatives of CMC use for sexual communication purposes. Other behaviors associated with the practice function similarly for this discussion.

Ferguson's (2011) investigation of sexting and associated behaviors amongst a sample of Hispanic adolescents and young adults, ages 16 to 25, revealed correlations between sexting and engaging in unprotected sex without the intention of getting pregnant. Other high-risk sexual behaviors, such as having sex with multiple partners, contracting sexually transmitted diseases, unwanted pregnancy, and abortion, were not significantly correlated with sexting behaviors. It is important to note the preliminary nature of Ferguson's (2011) study; while it may be useful for cross-referencing sexting behaviors across gender and cultural divides, larger, more representative quantitative studies are needed to determine significant relationships between sexting and high risk behaviors. This is especially so in light of recent findings of non-significant relationships 
among sexting, sexual behavior, and psychological wellbeing within a sample of 3,447 young adults (Gordon-Messer et al., 2013).

Research committed to this task is especially important for two reasons. Generally, results suggesting that sexting is associated with risky behaviors may promote baseless (with regard to their true significance), more negative perceptions of the practice that inhibit a discussion of it positives. More specifically, understanding the connection between sexting and other sexual or risky behaviors can better shape productive social discourse and educational materials on the practice.

Though limited in geographical scope, Dake et al.'s (2012) investigation of the prevalence and correlates of youth sexting provides a larger sample size and more extensive examination of the relationship between sexting and a host of other demographic and behavioral variables. For example, the authors found statistically significant correlations between sexting and engaging in other sexual behaviors (e.g intercourse, oral, and anal sex, sex with four or more sexual partners, not using contraceptives), substance use (e.g. marijuana, smoking one or more cigarettes in the past 30 days, binge drinking), and, finally, emotional health behaviors (e.g. attempting suicide in the past year, contemplating suicide in the past year, feeling hopeless for two continuous weeks in the past year). These results certainly reinforce the appropriateness of parental, legal, and other authorities harboring concern about the practice of sexting, as they suggest that sexting can be a "public health problem" (Walker et al., 2011, p. 10) with severe and potentially fatal physical, social, mental, and emotional consequences. Indeed, the potential relationship between sexting and risky health behaviors reveals the importance of considering how communication practices are connected to human actions. 
Consequences. In general, youth obsession with social media may have numerous "dire" consequences, such as depression, sleep deprivation, Internet addiction, social anxiety, aggression, social isolation, cyberbullying, susceptibility to online advertising, harassment, sexual solicitation, and over-sharing of personal information (Farber et al., 2012, p. 1225). Specific to sexuality, Theodore (2011) contends that technology is "changing the way adolescents develop sexually" and can lead to the early sexualization of teens, which is linked to lower self-esteem and other mental health issues such as self-image problems and eating disorders (p. 3). As Van Manen (2010) notes, adolescent use of Momus technologies to publicize the private has the potential to destroy the "inner values of the private," with digital lifestyles capable of enriching or eroding past conceptions of intimacy and privacy (p. 1024).

Sexting, as a form of computer-mediated interpersonal communication, is a clear contributor to this rapidly changing landscape, particularly for adolescents who are digitally inclined. Consequences of sexting are abundant in current social research, which speaks to the controversial nature of the phenomenon and the rising propensity for authority figures to control youth engagement in it. The following section offers a glimpse into the dark side of sexting, a necessary endeavor that provides a more holistic picture of current understandings regarding the practice.

Potential negative consequences of sexting range in intensity along a continuum of emotional, physical, social, and legal punishment. For instance, youth sexting may result in minimal forms of punishment, such as parents confiscating phones from their children for a set period of time or school authority figures temporarily suspending students caught in the act. In stark contrast, however, youth sexting can initiate more 
severe consequences, such as cyberbullying, emotional health problems, and even suicide (Hua, 2012).

Distinguishing between different types of sexting may be of consequence here. Consensual sexting in interpersonal relationships that is non-exploitative may lack any negative repercussions. On the other hand, non-consensual sexting, such as forwarding sexts to others without permission from the original sender, often has considerable social consequences, such as expulsion from school, psychological damage in the form of extreme shame, embarrassment, humiliation, emotional trauma, depression, sexual solicitation from child predators, cyberbullying, and harassment (Bailey \& Hanna, 2011; Farber et al., 2012). Regardless of definitions, Brown et al. (2009) contend that youth sexting has the potential to normalize objectification, of self and of others, may result in violations of trust that can ruin individuals' relationships, friendships, and reputations, and can affect how individuals who sext are treated in the future. Finally, given the research that shows sexting is associated with other risky behaviors, youth sexters may be more likely to acquire sexually-transmitted diseases (STDs), get pregnant, engage in substance abuse, and have mental health issues. (Brown et al., 2009; Dake et al., 2012; Ferguson, 2011).

Bailey and Hanna (2011) suggest that girls who sext are more likely to be held to a double standard concerning the appropriateness and social acceptability of their actions. Here, girls who sext are considered slutty, while boys with sexts in their phones or who forward sexts to others may not suffer social consequences, such as shaming and humiliation, from their peers. Brown et al. (2009) elaborate: "So, for example, a teen girl who presents herself as very sexual through a provocative picture and content 
indicating interest in sex may find herself labeled a 'slut' by some and be more likely to encounter sexual solicitations" (p. 14). Stone (2011) similarly asserts that sexually explicit visual depictions, such as more sexually overt sexts, increase the likelihood of pedophiles to gain access to such images and use them to seduce children into physical sexual activity, thus increasing chances for adolescents to suffer from online victimization. Reyns et al.’s (2013) work corroborates Stone's (2011) assertions. The authors found significant relationships between engaging in sexting and likelihood to experience some form of cybervictimization, with odds increasing for females versus males.

Given the potential for youth sexting to have harmful consequences, legal action is a possible and increasingly explored response. According to one study investigating how often teenagers are arrested for sexting, more than 3,400 youth sexting cases were handled by law enforcement authorities nationwide during a two-year period (2008-2009), thus demonstrating how youth sexting is perceived as a social problem in need of intervention (Wolak, Finkelhor, \& Mitchell, 2012). As such, youth sexting can result in potentially serious legal consequences and youth sexters may be criminally liable for their actions. Depending on the circumstances of the action and the setting (state statutes on child pornography and responses to youth sexting vary considerably), youths who engage in sexting can be arrested, charged with misdemeanors or felonies, and even required to register as sex offenders (Stone, 2011; Theodore, 2011; Walker et al., 2011).

An overview of the literature on the utilities, associated behaviors, and consequences of sexting provides some insight as to why youth engage in the practice according to social researchers and professionals in such fields as adolescent health, 
behavior, and education. However, youth perspectives on the hows and whys of youth sexting are glaringly missing, and surprisingly so given the fact that youth sexters are in the position to provide the most relevant and valuable insights into youth sexting. Perhaps the most important piece to the sexting puzzle yet to be investigated remains the question of why youths sext. Here, it is important to note the role of intimacy and privacy in the context of sexting. While engaging in sexting is, by nature, an intimate act, exploitative sexting may be enhanced in its potential destructiveness because it violates expectations of privacy in the digital context. The previous section demonstrates that, similar to research on youth sexting, research on youth conceptions of privacy, specifically in the context of sexting, is notably absent.

Finally, it is especially important to consider the warbled and conflicted nature of social responses to youth sexting, as these serve three important functions for the current study. First, responses to youth sexting, legal and otherwise, are reflections of social understandings regarding the practice and thus contextualize the environment in which my own participants live and act. Secondly, youth commentary on the nature of this environment is missing, which means there may be a disconnect in how older generations view youth sexting versus the opinions of the actual practitioners. In this manner, youth perspectives on the topic have the potential to enhance current educational strategies that could limit the occurrence and thus harm of nonconsensual sexting. This latter component is especially important in light of the negative consequences and associated behaviors of youth sexting detailed above. It is important to note that this study is not designed to generate solutions that may mitigate the negative consequences of sexting. However, the results of this study may indirectly contribute to these efforts by providing 
fresh perspectives on the practice from youth sexters. The following section will

briefly examine educational, media, legal, and alternative responses to youth sexting with a focus on the problematic nature of current attempts in the United States and other countries to construct legislation to address this phenomenon.

\section{Responses to youth sexting: Legal and otherwise}

Meanwhile, sexual stimuli bombarded the young so incessantly and intensely they were inflamed with a randy itch long before reaching puberty. At puberty the dams, if any were left, burst...From age thirteen, American girls were under pressure to maintain a façade of sexual experience and sophistication. Among girls, "virgin" was a term of contempt. The old term "dating" -referring to a practice in which a boy asked a girl out for the evening and took her to the movies or dinner-was now deader than "proletariat" or "pornography" or "perversion." (Wolfe, 2000, p. 6)

Given its ubiquity and potentially harmful consequences, sexting has birthed a diversity of opinion, particularly regarding the engagement of youth in the practice. Wolfe's (2000) passage underscores the seemingly typical assessment of teenage sexuality as the out-of-control manifestation of desires promulgated to youth via their exposure to mass media. As a potential consequence of a hypersexualized culture, sexting has been labeled an "epidemic" among members of the digital youth culture, one in need of prevention and control given its potential to lead to other risky and dangerous behaviors such as sexual intercourse, cyberbullying, and suicide (Kiesbye, 2011).

Debates concerning the legality of sexting involve how to negotiate First Amendment rights that protect sexual speech while attempting to control the use of technology that facilitates the practice in order to protect youth. Sexting was even featured as one aspect of the 2009 MTV campaign "A Thin Line," which was developed and aired with the goal of generating awareness to the dangers of digital abuse (Hudson, 2011). 
Issues of morality and appropriate use of ICTs, SMS specifically, appear to be divided based on the age of the user. While the use of sexting amongst adults is perceived as an acceptable and valuable dating instrument or tool for keeping relationships fresh and exciting, the proliferation of sexting amongst adolescents is regarded as a "symptom" of a hyper-sexualized American culture and has generated discussion on its relationship to child pornography (Kiesbye, 2011, p. 73). As one commentator puts it, "Teenagers today are obsessed with watching and creating pornography, and the practice of sexting is a new and dangerous symptom" (Kiesbye, 2011, p. 63). Bailey and Hanna (2011) offer reasons for this purported obsession, specifically implicating the seemingly worldwide "commercial agenda that profits from promoting hypersexualized understandings of girlhood" (p. 441). Curnutt's (2012) examination of celebrity sexting as a form of self-publicization and manufacturing of stardom further demonstrates the value of sexting proffered by the media industry. Here, teens pose and take pictures of themselves in manners reminiscent of what they see in magazines and movies. In this sense, it is difficult to reconcile the criminalization of youth sexting with prevailing social norms that encourage such behavior. However, media responses seem to ignore this double standard.

Media coverage of sexting. United State's news coverage of youth sexting reflects the negative reaction to the practice amongst members of the public, with broadcast discourse emphasizing and even conflating the risks and consequences of sexting as well as reporting the need for surveillance and control of youth activities (Cumming, 2009; Draper, 2012; Hasinoff, 2010, 2012). Dominant discourse regarding sexting in various cultural texts, such as news pieces and online safety campaigns, often 
dichotomizes the appropriateness of the practice based on age and problematizes youth sexting in particular (Hasinoff, 2012). Due to the dimensions of social uproar concerning youth sexting in recent years, Lumby and Funnell (2011) view the phenomenon as a case study that could provide opportunities for moral panic scholars to investigate dominant discourse on the subject and develop "strategic interventions" for engaging in debates on sensitive issues generally and the use of technology for sexual experimenting specifically (p. 282).

Here, dominant discourse that encourages moral panic may not only exacerbate the problem, but negate the potential for effective and participatory discussions between authority figures and youth. Participants of Walker et al.'s (2011) study, which includes various professionals (i.e. a cyber safety expert, education policy academic, secondary school teacher, sexual violence prevention researcher), similarly advocate strategic interventions that involve talking "with rather than at" young people and avoiding discussions that purely emphasize, or frame, negative aspects of youth sexting (p. 13). Notably, Hasinoff (2012) proposes a media production model as a theoretical lens for examining sexting that is more open to the potential benefits of the practice and shifts the focus from abstinence to the reduction of unauthorized distribution of sexts. Both enacting successful strategic interventions and exploring the positives of sexting require first investigating what young people have to say about the phenomenon, the results of which could positively infuse legal debates regarding the practice with more accurate understandings of youth engagement as well as more reasonable legislative strategies to prevent harm. 
Legal responses to sexting. January 15, 2009 - "Sexting” Shockingly Common Among Teens...Latest Case Involves Three Teen Girls In PA Who Sent Nude Pics To Three Boys: This week, three teenage girls who allegedly sent nude or semi-nude cell phone pictures of themselves, and three male classmates in a western Pennsylvania high school who received them, are charged with child pornography. (Hurdle, 2008)

Legal considerations are important components of the social world surrounding youth sexting, as they reflect attempts to control technology use that may engender negative consequences, although perhaps at the expense of inhibiting more positive forms of interpersonal communication. Unsurprisingly, legal debates on the nature of sexting similarly have pejorative undertones, with legal experts arguing over how to handle sexting cases and whether or not youth transmitting nude pictures of themselves or others should be charged as child pornographers (Bailey \& Hanna, 2011; Barkacs \& Barkacs, 2011; Kiesbye, 2011; Stone, 2011; Theodore, 2011). The CBS news brief on sexting presented at the beginning of this section marked the end of a significant legal battle between Wyoming County District Attorney George Skumanick and over 20+ students from Pennsylvania's Tunkhannock School District that were caught sexting and threatened with charges of either possessing or distributing child pornography (Hurdle, 2008). The U.S. District Judge on the case ultimately barred Skumanick from filing the charges in the name of protecting the students' constitutional rights.

This case, which garnered substantial national media attention, exemplifies both the social concerns surrounding the phenomenon and the rise in media attention to youth sexting that necessarily precedes legal debates on how to handle the issue. While some, like Skumanick, believe the harmful emotional and physical ramifications that may result from sexting practices demand strict legal action, others view felony and other charges as 
too harsh, "ill-fitted," and even "Draconian" in terms of punishment for minors (Hasinoff, 2012; Hurdle, 2008; Stone, 2011, p. 278). Furthermore, Bailey and Hanna (2011) suggest that prosecuting instances of youth sexting in both Canada and the U.S. may disproportionately punish young girls who send sexual images of themselves to boys with the hopes of garnering their attention and initiating a relationship.

Despite the uprising of sexting issues and legal debates in recent years, federal legislation specific to sexting has not been enacted on the practice to date. Instead, states within the U.S. specifically have grappled with the issue of interpreting and evaluating youth sexting in light of Congress's federal enactment of the Protection of Children Against Sexual Exploitation Act in 2008 (see Theodore, 2011 for a full overview of the act and current attempts to legislate against sexting). Ultimately, prevention education is a preferred measure. Theodore (2011) advocates for laws, parents, and schools to coordinate their responses for youth sexting in a manner that allows for education, regulation, deterrence, and punishment of the practice and integrates youth perspectives on the practice. Likewise, Hua (2012) recommends that parents set guidelines for their children's responsible use of social media and further suggests that prevention and intervention strategies should utilize the same forms of media so prominent in adolescent culture to ensure that youth get the message.

Most notably, Theodore (2011) proposes incorporating sexting discussions in health education curricula in schools as early as middle school, a recommendation that is reinforced by Walker et al.'s (2011) compilation of opinions from experts on adolescent health and behavior. Dake et al. (2012) similarly recommend extending sex education for 
youths to include information on sexting, paying attention to the following areas specifically:

1) Students should not assume anything they send is going to remain private and that it may affect how others perceive them in the future; 2) Sexually explicit messages sent in cyberspace will never truly go away and may impact the students years from now; 3) Sexting is not truly anonymous and engaging in such behaviors could leave students vulnerable to sexual harassment; 4) There are potentially serious legal consequences associated with sending and/or receiving sexting messages. (p. 12-13)

This passage outlines several considerations of youth sexting that Dake et al. and other researchers and experts on adolescent health and behavior assume young people are not adequately grasping. First, discourse from these sources implies that adolescents conceptualize privacy similar to older generations, an assumption that Van Manen (2010) questions in light of the ubiquitous nature of adolescent engagement in digital lifestyles. Secondly, it appears that adolescents are not understanding the permanence of sexts or the damage to their reputations that sexting could elicit. Finally, adolescents are not fully aware of the legal consequences that could be precipitated by sexting and may need to be educated about state and federal statutes that apply to the practice.

These assumptions serve as important points of comparison for this study. Exploring the nature of youth sexting from the perspectives of youth may provide insight into young peoples' conceptions of privacy as well as their understandings of the potential consequences of sexting. While I agree that incorporating expert assumptions and considerations into sexting education discussions with adolescents is an important first step in curbing digital abuses such as sextortion, cyberbullying, and other forms of sexual violence, I also agree with the abundance of research calling for the use of youth perspectives and opinions in crafting education measures, public policy, and local and 
federal legislation. Here, insider discourse on sexting attitudes and behaviors, or micro-narratives, may reflect a generational disconnect in how the phenomenon is perceived and engaged in.

Alternative responses to sexting. Cumming's (2009) commentary on the intersection of adolescence, sexuality, and technology provides a useful foundation for understanding the aforementioned disconnect. He questions the legitimacy of "sledgehammer-like" (p. 4) legal responses to youth sexting, primarily arguing that they infringe on the rights of adolescents: "When, we must ask, in Western culture, did nudity become pornography, youth sexuality perverse, digital technologies the tail wagging the dog, and when and how and why have we forgotten children's participatory rights as sexual beings?" (Cumming, 2009, pp. 10-11). Lumby and Funnell (2011) similarly question the appropriateness of criminalizing sexting, specifically citing the specious practice of lumping "sexually curious teenagers together with convicted paedophiles" (p. 286). They also suggest permitting those engaged in sexting to define the practice themselves.

Additionally, some critical research has investigated media and legal responses to youth sexting with results suggesting that dominant discourse in the mainstream media is, like current legislation efforts, more harmful than beneficial to adolescents (Hasinoff, 2010, 2012; Karaian, 2012). Hasinoff's (2010) examination of the relationship between how sexting is represented in mass media and how subsequent policy is formulated to combat the practice suggests that both serve to undermine teenage girls' sexual agency. Karaian (2012) echoes this contention, suggesting that the censoring of adolescent discourse, particularly that of girls, serves as a form of oppression that reifies a sense of 
female powerlessness in the context of sexual expression and agency. Finally, Hasinoff (2012) recently conducted a critical analysis of the so-called commonsense assumptions regarding sexting in the media and other cultural texts. Her analysis demonstrates how dominant discourses criminalize female youth expressions of sexuality by highlighting the risks associated with anonymity and the disinhibition that it encourages in digital environments (Hasinoff, 2012).

Ultimately, alternative responses to youth sexting underscore how media rhetoric may actively strip individuals of their capacity to evaluate and respond to specific social conditions based on their personal desires. Girls are viewed as sexual objects, incapable of pursuing and achieving their own forms of sexual expression and empowerment. Though not addressed in either critical piece, it is important to note that this stripping of agency goes both ways, as boys who are more commonly portrayed as perpetrators of sexting crimes are, too, diminished of their capacity to engage in healthy sexual relationships that do not victimize women. These types of portrayals may implicate boys more often than girls in criminal prosecutions, despite girls initiating sexting or engaging in secondary redistribution themselves, which may suggest that boys are more likely to use new technologies for inappropriate and even harmful activities.

It appears that current media and legal responses to sexting lump youth into a single category of problematic binaries. All young people are in need of protection via surveillance from authorities, some more than others. The dichotomous relationships included in this category are primarily perpetrator/victim in nature. Youth sexting is seen as harmful and thus bad. Positives and benefits of the practice are often ignored, regardless of the fact that, given statistics suggesting the ubiquity of youth sexting, cases 
of 'sextortion' or sexual exploitation among adolescents are strikingly uncommon.

Instead, instances of young people curiously exploring their sexuality with their peers, with sexting as a "natural outgrowth" of their experiences (Dake et al., 2012, p. 13), may be far more frequent. As Hua (2012) so adequately puts it, sexting, as a form of sexual exploration, should be evaluated carefully "to prevent pathologizing potentially normal adolescent behavior" (p. 6), as this may thwart attempts to educate and encourage teens to practice safe sexting. In this sense, sexting is risky, but may also be developmentally appropriate for digital natives growing up in a digital world. As demonstrated by a review of the literature thus far, we need to know more about this world to better grapple with its various components, sexting specifically.

While an examination of the various social responses to youth sexting provides context for the current study, more questions than answers arise from this overview. For example, research has yet to investigate how youth perceive sexting in all of its forms. Because the social context of sexting includes various legal responses, youth perspectives may include how youth feel about current attempts to legislate against the practice. Although the main purpose of this study is to offer a more holistic understanding of youth sexting from the perspective of young people, the discourse of my participants may answer some of these questions. As such, it is important to consider potential indirect utilities of the results of this study. For example, answers to these questions may shed light on the apparent disconnect in appropriateness between youth and adult sexting. Insight from young people could also help mitigate the impact of dominant discourse that effectively disempowers youth by stripping them of their agency, sexual and otherwise, specifically their capacity to think, speak, and be sexual through their use of new media 
technologies. Finally, from a practical standpoint, youth discourse on sexting could help facilitate more intensive and productive discussions on how to prevent harmful digital abuses in the future.

One over-arching research question emerges from an in-depth overview of definitions, prevalence, motivations for, and responses to sexting:

RQ1) What is the nature of the youth sexting experience?

This research question encompasses the broadness of the phenomenon yet focuses the investigative perspective that will be utilized to young people, or members of the digital generation, who are in the best position to offer answers on their practices.

\section{Theoretical framework}

Given the need for further research into sexting, particularly among youth populations and members of the digital population, the following section considers a theoretical approach that may be useful in examining the phenomenon. Petronio and Durham's (2008) communication privacy management theory (CPM) could shed light on how young people negotiate the sharing of sexts either interpersonally (one on one sexting) or en masse (what I call 'mass sexting'). Furthermore, it may provide insight into young peoples' values concerning privacy and potentially expose generational or gender differences in this domain, an idea previously proposed by Van Manen (2010) in his exploration of Momus technologies and the outcomes of digital intimacy. A brief overview of the theory, as well as how it has been used to examine privacy management via computer-mediated communication $(\mathrm{CMC})$, will precede a discussion of its application to sexting specifically. 
Communication privacy management theory. Originally grounded in research and developed to examine how people manage private information through processes of revealing and concealing, CPM is a dialectically-based theory that is primarily concerned with how people use management systems to regulate self-disclosure of private information. This distinction is necessarily dependent upon what individuals consider private as well as how they view the nature of boundaries associated with either private or public domains or between individuals and society. In the case of digital intimacy, these distinctions may vary considerably based on the age and desires of those balancing closeness and nearness through the use of CMC/TMC to achieve what Van Manen calls “distant intimacy” (p. 1028).

The methodological versatility of CPM allows its theoretical propositions and assumptions to be tested by both post-positivist and interpretivist researchers alike. CPM research has primarily concerned itself with exploring communication in a variety of interpersonal and group contexts, such as between or amongst family members, married couples, and within doctor-patient relationships (Petronio \& Durham, 2008). More recently, researchers have investigated privacy management in CMC contexts, such as in e-commerce relationships (Metzger, 2007) and on Facebook (FB) (Waters \& Ackerman, 2011), as well as how privacy rules are valued, developed and utilized in the activities of blogging (Child \& Agyeman-Budu, 2010) and instant messaging (Lowry, Cao, \& Everard, 2011). Current CPM research reflects its relevance to CMC/TMC contexts, thus making it a prime candidate for approaching the phenomenon of youth sexting. As such, the nuts and bolts of the theory will be considered below. 
$\mathrm{CPM}$ is based on the idea that individuals possess private information about themselves (and potentially others) and control it through information management processes that are governed by what Petronio and Durham (2008) call "privacy rules" (p. 312). Privacy rules are intrinsically subjective and thus vary depending on different criteria, with at least 5 assumption maxims suggested by the authors: cultural, gendered, motivational, contextual, and risk-benefit ratio. The importance and impact of each criteria on privacy rule development and utilization will vary based on the needs, values, and desires of the culture(s), group(s), and individual(s) involved in private information regulation. This permits privacy rules to be inductively developed from fieldwork conducted among any variety of groups, which further demonstrates the versatility and usefulness of CPM in communication studies generally and investigating sexting specifically. Van Manen's (2010) contention that young peoples' propensity for using Momus technologies suggests that they may not experience or conceptualize privacy like their elders do or even desire or feel a need for privacy is foundational in asserting the use of CPM to explore youth sexting. In light of this, a complementary research question to this study is:

RQ2) What is the youth perspective on privacy in the context of sexting?

As a communication theory, CPM is based on three interaction maxims that consider both the discloser and recipient of private information: shared boundaries, boundary coordination, and boundary turbulence (For a complete overview of each maxim and their subsequent processes, see Petronio and Durham, 2008.). In line with the conceptualization of private information as something that is owned and controlled, shared information similarly becomes an object, or resource, that is then co-owned and 
co-managed by any number of "shareholders" (p. 314) and thus subject to differing

forms of value and control depending on the nature of the person holding that information. Shared information stretches boundaries of privacy and requires both implicit and explicit coordination between or amongst shareholders.

For example, intimates within an interpersonal relationship may disclose information to each other, perhaps via sexting, with either implicit or explicit instructions that it remains between them. Some couples may require no specific explication of instructions; mutual protection of the information, specifically that it stays between them, is implied. Others may either precede or conclude their discussions with the qualification that any disclosed information must stay between partners. Boundary turbulence, then, can be expected when shareholder values and intentions regarding resource control do not align. In the case of sexting, one-to-one sexting may evolve into mass sexting when one or more intimates redistribute sexts originally shared within the contexts of the dyadic relationship, either consensually or without permission. The use of CMC/TMCs to distribute information is a particularly risky endeavor given the potential permanence of texts and sexts and the ease and speed at which they can spread or go "viral" (Kiesbye, 2011), which suggests that this context may require stricter explication and/or enforcement of privacy rules but may also be subject to more intense boundary turbulence.

CPM and CMC/TMC research. CMC research utilizing CPM highlights the development and use of privacy rules online. Metzger (2007) examines how consumers navigate between revealing and concealing personal information based on their purchasing desires and needs and the requests of "etailers" (p. 4) and according to 
privacy management strategies, such as withholding, falsifying information, and seeking. In the context of blogging, researchers revealed a relationship between certain personality dispositions, such as self-monitoring skills and concern for appropriateness, that dictate blogging frequency and the nature of self-disclosure via blogging (Child \& Agyeman-Budu, 2010). Waters and Ackerman (2011) found all five of CPM's criteria for privacy rule development present in college students' use of Facebook for selfdisclosure, with findings that suggest individuals who use FB do so because they believe it helps them improve relationships with others, especially distant friends. Finally, Lowry et al. (2011) develop and empirically test a model for predicting the use of selfdisclosure technologies that considers various elements, including cultural dimensions, privacy concerns, and desire for online awareness. Their results suggest that selfdisclosure use is influenced by motivations and concerns that are culturally based, thus giving credence to CPM's culture-criterion of privacy rule development.

Some research suggests the superficial nature of electronic disclosures, which implies that users are aware of the potentially enduring nature of information sharing via digital outlets and regulate their use of them for purposes of self-disclosure (Farber et al., 2012; Van Manen, 2010). For example, young people have reported keeping their social interaction on SNSs, such as Facebook, "superficially positive," with communication that is more likely to be "insincere" and "phony" as opposed to face-to-face disclosing (Farber et al., 2012). While Van Manen (2010) contends that the lack of physical presence involved in instances of digital, or distant, intimacy may make people feel more open to express their vulnerabilities, he also suggests that adolescents using digital outlets 
to construct and diffuse their identities take and send pictures and videos that reflect who they want to be and not necessarily who they are.

Regardless of the accuracy of personal images and information transmitted electronically, the ease with which they diffuse to others increases the chances of what Walker et al. (2011) call "e-crimes" and other breaches of intimacy (p. 14). These authors suggest that users of digital media, adolescents especially, need to "develop skills in ethical intimacy" (p. 14) in order to diminish the occurrence and mitigate the consequences of such crimes. Ethical intimacy is especially relevant to a discussion on youth sexting, as adolescents may not fully comprehend the consequential nature of mass sexting or consider mass sharing of sexual information and images as a "big deal" (Hua, 2012, p. 6).

CPM and sexting. Current research utilizing CPM in the CMC context is mostly quantitative and has considered various social-networking sites and the use of Internet in facilitating self-disclosure and relating generally. How CPM may be used to investigate sexting as a form of sexual disclosure is missing from this discussion, demonstrating a gap in the literature to-date that could contribute to the larger social debate on youth engagement in the phenomenon. Consider the following example of sexting in a hypothetical dyadic relationship that illustrates CPM concepts in practice. Two partners, Jack and Jill, may sext, or share visual or textual sexual information about themselves to each other via cell phone. Specifically, Jill may send Jack a nude picture of herself under the implicit expectations that the picture will remain between them. However, as demonstrated by cases of sexting gone awry, or "mass sexting," sexts shared between relational partners may be further shared (e.g. forwarded) with others outside of the 
relationship for various reasons (e.g. break-up). Continuing with this example, Jack, under pressure from his friends, may forward Jill's picture to them. Furthermore, Jack's friends may forward Jill's picture to various others. In this manner, Jill's picture far surpasses the boundaries of Jack and Jill's relationship and ownership.

This situation may result in several outcomes. First, trust may be violated, especially if Jill assumed that her picture would remain within the confines of her relationship with Jack. Second, the shared boundaries surrounding Jill's picture have been stretched to accommodate a larger number of people (e.g. Jack's friends, Jack's friends' friends) and are thus subjected to a larger, more diverse pool of values regarding boundary permeability. Thirdly, this increase in shareholders makes Jill's picture more difficult to control and regulate, thus increasing the amount of boundary turbulence experienced by shareholders, especially Jill as the initial discloser.

The digital component of this process magnifies the effects of sharing; more people can receive private information at the click of a button. Furthermore, in the case of sexting, the information is transformed into a visual artifact that can be digitally stored and visually displayed, as opposed to remaining in oral form and solely talked about. The permanence of sexts is often cited as a reason for why sexting is so dangerous, with some research suggesting young people do not fully comprehend the potency of these digitally-enabled features of the practice (Dake et al., 2012; Stone, 2011; Theodore, 2011; Walker et al., 2011). I examine these digital transformations of private information, especially at sites of turbulence, under the CPM lens to see how they impact interpersonal and group relationships among youth, which may shed light on how communication is generally and specifically shaped by new media of transmission. Because sexting is 
situated in the context of interpersonal relationships, intimate and otherwise, the final research question of this study explores the nature of sexting in these contexts:

RQ3) How does sexting manifest in interpersonal relationships?

Answers to research questions 2 and 3 may shed light on young peoples' sexual values, use of digital technology to enhance their interpersonal communication, express their sexuality, and manage their desires to present themselves and maintain their privacy. Most importantly, the youth perspective could help adults better understand their children's desires to use technology for sexual expression and develop ways to engage in an ongoing dialogue with them on the responsible use of new technology in the context of sexual communication.

\section{Overview of the literature}

Much of the research on youth sexting is quantitative and primarily concerned with its prevalence and consequences, often citing damage to reputation, emotional and mental health, and suicide as potential outcomes of the phenomenon. These studies lack any emic perspective and insight from youth sexters on the positives of sexting, and thus fail to adequately investigate or flesh out the hows and whys of youth sexting. All of the research included in this review, especially Hasinoff $(2010,2012)$ and Karaian's $(2012)$ critical pieces, speak to the need for future research investigating youth discourse in the realm of sexting.

With few exceptions, how youth actually engage in and view sexting is missing from academic discussion and is a site for further exploration of the topic. Walker et al.'s (2013) work is the first to qualitatively explore young peoples' perceptions on sexting. However, this study solely investigates young peoples' perspectives of others' sexting 
experiences and does not uncover the personal motivations for sexting as expressed by youth sexters themselves. From an intervention standpoint, this missing perspective is invaluable to the development of prevention materials geared toward educating adolescents on the potential risks and consequences of sexting. Walker et al. (2011, p. 15) call for future research efforts to "identify how young people define sexting, the role it plays in their lives and their suggestions for how best to intervene." Investigating these elements of sexting may contribute to the development of effective measures that may prevent or minimize the harm of digital abuses such as cyberbullying on youth.

The following study is a qualitative endeavor utilizing a social constructionist approach to explore youth sexting. My goal is to provide a more holistic picture of youth sexting. A secondary impact of this study is that it may contribute results that potentially aid in the development and implementation of social policy and educational measures that more effectively curb digital abuses. The following chapter delineates my choice of methodology, its relevance to and appropriateness for investigating the context of youth sexting, and how I conducted this study. This chapter includes discussion of my sample, sampling technique, and research protocol, or what specific methods I used to conduct my study and how I analyzed the data I collected. 


\section{CHAPTER 3: METHOD}

An overview of recent literature on sexting proffers few emic answers from youth outside of existing research on the topic. Instead, sexting research to date foregrounds academic assumptions on the nature of the practice. Furthermore, Petronio and Durham's (2008) CPM theory is a useful framework for conducting qualitative research to address the gap in the literature on youth conceptions of privacy proposed by Van Mannen (2010). To bring these missing voices and perspectives to the forefront, the three research questions driving this study were designed to tap into the nature of youth sexting (i.e. how youth define sexting, how prevalent it is to them, why they sext, and why they think their peers sext), its potential impact on relationships, and how youth conceptualize and negotiate privacy in the context of sexting. The following chapter outlines the methodology, method, sample, and data analysis of this study. This includes specification of the procedures, or the specific details of how I conducted a qualitative study on youth sexting.

\section{Methodology}

The qualitative, also known as inductive, paradigm of communication is the philosophical and theoretical foundation of this study, and is an appropriate strategy for investigating new phenomena (Walker et al., 2011) such as youth sexting. According to Becker (2001), qualitative research tries to "see how society works, to describe social reality, to answer specific questions about specific instances of social reality” (p. 317). Inductive perspectives are based on Blumer's (1969) methodological position of symbolic interactionism, which defines social interaction as a formative process whereby humans take action to designate, indicate, and interpret the meanings of objects. As such, 
inductive perspectives underscore the agency of humans in their engagement with others in the process of socially constructing their world. In this sense, they are more sensitive to how meaning is constructed within social interaction, as opposed to the dominant sociological and psychological conceptions of social interactions as a space, setting, or medium for the "release of human conduct" (p. 8). This project seeks to describe a specific social phenomenon, youth sexting, and thus engages with youth sexters to find answers.

Several ontological, epistemological, and axiological assumptions undergird this endeavor. I invoke a social constructionist ontology, which means I believe that individuals" "ideas about reality are constructed through societal and interpersonal communication" (Davis, Gallardo, \& Lachlan, 2010, p. 27). This means our thoughts and behaviors are contingent on our interpretation of the thoughts and behaviors of others, and the meanings we ascribe to things, objects such as the cell phone or sexts included, are socially constructed throughout interactions with others and ourselves via selfinteraction. Because reality is socially constructed and not objectively available to be perceived or found, human knowledge is subjective and dependent on numerous life factors. To properly investigate human knowledge, then, requires what Bernard (2006) describes as "trained subjectivity," or "using our own feelings, values, and beliefs to achieve insight into the nature of human experience" (p. 22). In terms of epistemology, this means I adopt a subjectivist stance; I acknowledge that knowledge is relative, appreciate the uniqueness of the human experience, and look to individuals' points of view or lived experiences to discern what they know. As Becker (2001) notes, "qualitative methods insist that we should not invent the viewpoint of the actor, and 
should only attribute to actors ideas about the world they actually hold, if we want to understand their actions, reasons, and motives" (p. 323). Finally, the theoretical and methodological process of research is value-laden and emphasizes the importance of considering multiple voices and perspectives.

The primary advantage of utilizing the qualitative paradigm for this study — which also stands as the most important justification for using a qualitative over a quantitative approach — is investigating the emic perspective, or what Becker (2001) calls the "point of view of the actor" (p. 321). This is especially so in light of research that suggests that existing interventions for mass sexting and cyberbullying have failed because various social authorities are not targeting the youth audience appropriately or effectively (Brown et al., 2009). To remedy this, a plethora of expert opinion on youth behavior and health calls for learning from the youth perspective to inform the development of education and prevention materials, and discussion (Theodore, 2011; Walker et al., 2011). Clearly, there is a social need to learn more about youth sexting from the youth perspective. This would require taking a social constructivist metatheoretical perspective to adopt the view of the actual practitioners of youth sexting, which are youth.

The goals of this study are to amplify the youth perspective, to listen to and learn the language of young people who have engaged in or know about youth sexting, so as to provide a more accurate reflection of the reality of youth sexting. Approaches to research that are based on these premises and thus sensitive to members' meanings and interpretations stand in opposition to pre-constructing frameworks of investigation that may constrain the data that is produced. In this manner, they offer more holistic investigations of social phenomena and may produce work that is both insightful and 
practical to social researchers, the social sciences in general, and people engaging with youth on a daily basis. This is primarily because emic-oriented approaches give proper attention to the reflexivity of cultural processes and meanings as dynamic occurrences.

While the qualitative approach is time and energy intensive and can be subject to issues of reliability and researcher bias from a deductivist standpoint, it allowed me to let youths speak for themselves and the nature of the activities they engage in, specifically sexting. By tapping into the youth perspective, I produced results that differed from popularized understandings of "sexting" (what parents and authority figures say in the media, court cases, past quantitative studies in academic literature) and thus provided new insights into the social phenomenon. The following section outlines the specific qualitative method I used to conduct this study.

\section{Method}

The following project is a qualitative study informed by phenomenological qualities and methods. Notably, extensive and varied explications of the meaning of phenomenology have followed its initial inception as a philosophical tradition developed by Edmund H. Husserl (Patton, 2002). Thus, it is necessary to clarify that this study adopts an existential phenomenological goal of deriving participants' experiences and perceptions of the sexting phenomenon. According to Bernard (2006), "phenomenologists seek to sense reality and to describe it in words, rather than numbers-words that reflect consciousness and perception" (p. 23). The goal of a phenomenological approach is to study individuals, groups, and artifacts via the use of interviews, focus groups, and artifact analysis to generate themes and descriptions of the meanings of a particular phenomenon (Davis et al., 2010). Here, the focus is on 
exploring how humans make sense of their lived experiences and, in Patton's (2002)

words, "transform experience into consciousness" (p. 104).

In line with the metatheoretical goals of qualitative research, phenomenology

allows researchers to learn from the viewpoints of others and adopt their views when interpreting a social phenomenon. Most importantly, Van Manen (2010) contends that phenomenology is the "study of the hidden" (p. 1030), which reinforces its appropriateness as a tool to investigate youth sexting in particular because little is known or understood about young individuals' choices and motivations to engage in the practice. The main advantage of conducting a qualitative study informed by phenomenology to study youth sexting is that it allowed me to focus on the meanings of, or within, the lived experiences of young people who sext, have sexted, or know about sexting, from their more formative years to now. In this manner, I was able to flesh out some of what Patton (2002) describes as the "essence," or "core meanings," of sexting as mutually experienced and understood by my participants (p. 106).

Although phenomenological inquiries typically underscore the importance of directly observing phenomena, the mobility and sensitive nature of sexting make it a social phenomenon that is difficult to observe. For example, sexting involves sexual communication and behavior and could include sexual imagery, in the forms of pictures of people, which could infringe on the privacy of others. As such, artifact analysis would have been limited to textual words and not images/video sent via the cell phone. These considerations made in-depth interviews the most appropriate data collection technique of phenomenology to use to study youth sexting, which is specified in the procedures. A discussion of my sample and sampling techniques precedes a more detailed description of 
the procedures of this study.

\section{Sample}

I used quota and snowball sampling, both non-random sampling techniques appropriate for the qualitative approach, to generate participants for this study with the hopes of acquiring "information-rich cases” (Wengraf, 2011, p. 103) suitable to investigating youth sexting. Specifically, I recruited young people between the ages of $18-25$, some of whom I had worked with in the past to co-construct an ethnography of texting. Sexting emerged from this initial study with the first group as a common practice in these particular individuals' lives, which means they were able to contribute their perspective on the phenomenon as they had experienced it. This initial sample consisted of 10 young adults, five males and five females. To achieve a broader sample size of 20 individuals, I used a snowball sampling technique. This involved asking members of my initial sample to recruit more participants who they know have experience with sexting. The specifics of how I sampled, including my recruitment scripts, are in the procedures.

The purpose and advantage of sampling in this manner was three-fold. First, and most importantly, these individuals either sext or have experienced sexting in the past, which means they have valuable insights regarding youth sexting. Secondly, these individuals comprise the older end of the youth spectrum of 18-25, which had two important advantages. They were close enough in age to younger members of the youth spectrum to more accurately reflect on their sexting experiences during their more formative years, such as in middle or high school. Furthermore, they were able to speak to their experiences, or lack of, with sexting outside of settings typically associated with 
adolescence, which provided a comparative perspective on similarities and differences between sexting along the youth spectrum. Finally, because these individuals knew each other, sampling in this way ensured a certain amount of shared lived experiences in the educational and social domain. Sampling in this manner was particularly important because it aligns with the general qualitative value of considering how individuals coconstruct their sense of reality with others. Specific to this project, it allowed me to target young people of a certain age group and richness of experience in the context of sexting.

Twenty young adults participated in this project, ranging in age from 18 to 25 with a mean and median age of 20 (see Table 1 in Appendix A for participant demographics). In total, three 18-year-olds, three 19-year-olds, six twenty-year-olds, two 21-year-olds, two 22-year-olds, three 24-year-olds, and one 25-year-old offered their stories. Seventeen of the participants were born and raised in Oregon, with the remaining three hailing from South Dakota, Missouri, and New Mexico. As discussed previously, an equal number of both males (10) and females (10) participated. Students in high school (1), college (15), trade school (1), and graduate school (1) made up a majority of the group, with two participants working in retail and hospitality and not attending school. All participants self-identified as white Caucasians. Lastly, all but one of the participants self-identify as heterosexual. James has sexting experiences in both heterosexual and homosexual relationships.

Of the 20 participants, 13 had directly participated in sexting by sending and receiving naked pictures, sexual videos, and/or sexual messages with others. The remaining seven participants had indirect experiences with sexting only. Examples of 
indirect experiences include hearing about others participating, receiving unrequested pictures from peers or strangers, or receiving requests for pictures but not acquiescing to those demands. Importantly, every participant had some form of indirect experience, which speaks to the widespread nature of the phenomenon.

\section{Procedures}

Specific sampling procedures for this study were as follows: first, I recruited the original 10 participants of a previous ethnographic project by calling each individual and asking them if they would like to take part in a new communication study. The recruitment script is listed as Appendix B. After recruiting these individuals, I asked them to recruit more individuals to participate by choosing friends whom they knew had experiences with sexting and were between the ages of 18 and 25. My recruiters enlisted the participation of others in a variety of manners: by telephone, word of mouth, text, etc. I took the first 10 individuals that agreed to take part in the study to fulfill my quota of 20 total participants.

After gathering my sample via the quota and snowball sampling techniques stated above, I collected my data using one phenomenological technique: interviews. Specifically, I used semi-structured interviews to collect data on young peoples' definitions of and feelings toward the use of the cell phone to engage in sexual communication. I conducted individual semi-structured interviews with all of my participants. By conducting individual interviews, I was able to investigate sexting from the perspective of young people in a manner that highlights their personal, uninfluenced reflection on their experiences with sexting. Justification for the interview data collection technique as well as the specifics of the research phase are discussed below. 
Justification. A research approach utilizing semi-structured, in-depth interviews offers a more open framework for getting at members' meanings and includes the advantage of triangulating themes and patterns that emerged from participant discourse for purposes of credibility. This data collection technique had two primary advantages in the context of this study. First, semi-structured interviewing permitted the generation of thick descriptions of sexting that were interpretative and not just descriptive. Second, the nature of this set-up facilitated a research process that was inherently iterative and thus inclusive of all facets of the phenomenon, and not just elements that fit into my own pre-constructed categories (Wengraf, 2011). In this manner, what is relevant in terms of context was derived from the data, as reflected by how my participants acted throughout the interview process, the language they used to talk about their experiences, the artifacts or texts that were optionally provided, and knowledge about the physical setting or environment based on its descriptions from both participants' responses and my own notes.

As noted previously, because sexting is done via the cellular phone, it cannot be readily observed, which makes it difficult to witness and describe the processes through which youth produce their own actions and interpret those of others. To mitigate the effects of excluding observation from this study, I used a research approach that is inductive in generating data and speaks to the conditions predisposing youth engagement in sexual communication via the cell phone. The research phase elicited an "emotionalist" version of interview data because it emphasized the "authentic experiences" of the interviewees (Silverman, 2006, p. 118-119). 
With the abovementioned in mind, semi-structured interviews are ideal for investigating the nature of new social phenomena, like sexting, than their more highly structured counterparts. This is because the latter type may limit the free-flow of personal narratives shared by participants as they create their views of their world. In contrast, semi-structured interviews are, by nature, characterized by "minimalist interviewer intervention" (Wengraf, 2011, p. 112), and thus allow participants to freely discuss their sexting experiences without being constrained by the nature of interview questions applied in succession.

The individual semi-structured interviews consisted of mostly participant explanations of youth sexting elicited by minimal, and often improvised, interviewer questions (see below for specific details). This form of research is designed specifically to get at key aspects of peoples' lives, such as their assumptions, feelings, and knowledge, that are difficult to access in more direct manners (Wengraf, 2011). As such, the semistructured interview design was particularly useful for investigating a phenomenon like sexting as well as youth norms governing this subculture's use of new media and technology, like the cell phone.

Finally, I utilized Guba and Lincoln's (1982) strategies of rigor to ensure the trustworthiness of naturalistic inquiry. I similarly substitute the criteria of credibility, transferability, dependability, and confirmability for the criteria of reliability (consistency in measurement) and validity (accuracy in measurement) so characteristic of rationalistic inquiry. Given the emergent design of my research method, exact replicability of this study is neither possible nor appropriate. As Guba and Lincoln (1982) note, researchers following up on my study may "choose a different path from the same data" (p. 247) 
during the course of the research process. Thus, I actively worked to achieve the criteria of naturalistic inquiry listed above instead.

Specifically, I achieved credibility by asking my participants to validate my interpretations of their explanations throughout and after the interview process. Importantly, I chose to be completely "in bed" with my data, so to speak, by conducting, transcribing, and coding all of my interviews. In this manner, I remained completely embedded in the research process throughout its entirety. While generalization is not a goal or possibility of this research, the transferability of my results is possible given certain conditions. For example, my results can be further explored in expanded contexts, such as with larger, more racially diverse groups of young people, to see if and how they stand. Lastly, I achieved dependability and confirmability by triangulating the perspectives of multiple participants, balancing the gender ratio of my respondents (10 females, 10 males), engaging in numerous reflexivity exercises to monitor my personal values and perceptions of sexting, and auditing my data to ensure that I could trace my findings back to their original sources.

Data collection. I conducted interviews in a variety of social settings within the town in which the participants lived so they felt more comfortable given the more natural (to them) surroundings. Given the sensitive nature of the study and the questions that were asked, participants were permitted to select specific interviewing sites or deferred to me for site selection. All interviews were recorded so they could be transcribed in a manner that was both faithful to interaction and available for re-analysis. Additionally, to contextualize my study as well as address any types of interview issues that I could anticipate, I specified the participants' relationships toward each other based on their 
disclosure as well as my relationship with them, either directly or indirectly. The specifics of data collection procedures for the research process are detailed below.

Individual semi-structured interviews. I conducted semi-structured, in-depth interviews with all of the participants in the study $(\mathrm{N}=20)$. The interview protocol is listed as Appendix C. All interviews began with participants reading and signing an informed consent form (see Appendix D). As previously discussed, the nature of the semi-structured interview design calls for a flexible interview protocol. This means the initial interview script was subject to spontaneous modification during the course of each interview. However, I used a standard first question at the beginning of all individual interviews to prompt participant discussion of sexting. In other words, I asked the same initial question that was open-ended and geared toward evoking some form of narration from the interviewee. Specifically, the initial question that I began each interview with was: "Can you please tell me about your first experiences of sexting via cell phones as far back as you can remember?" Participants were permitted to talk for as long as they liked to or felt the need to in the context of this initial question.

As discourse emerged, I improvised questions to probe deeper into a particular line of thought as well as access subsequent sexting experiences up to the present point in time. I also used a set of pre-constructed priming questions (all pertaining to the nature of sexting) to delve further into the details of youth sexting if preceding discourse did not touch on these facets (e.g. prevalence, why youth sext). As a "story-facilitator," I gave verbal and nonverbal cues to demonstrate active listening, such as eye-contact, nonverbal sounds, body posture, and possible mirroring of emotions to express acceptance of their own, as these are important components of successful interviews (Wengraf, 2011, p. 122). 
Interviews varied in length depending on the amount and nature of discourse that emerged during each session. In total, interviews averaged 45 minutes in length, with a range of 26-95 minutes. Immediately following each interview session, I personally debriefed by free-associating my interview experiences and producing detailed "sessionnotes" which I compared later (p. 142). I rarely took notes during the session to avoid making my participants uncomfortable or self-conscious about what I was writing in light of what they were disclosing. As mentioned previously, I recorded all interviews.

\section{Data analysis}

To analyze my participants' discourse collected in both interviews and focus groups, I first transcribed each interview in its entirety. Transcriptions included time markers at every five minutes of recorded talk, which facilitated easier perusal of the data during analysis. Participants' names were changed in the transcripts according to their previously chosen code names to preserve their anonymity and protect their privacy. Once transcribed, I open coded all of the interview cases to unearth what Luborsky (1994) calls "themes" of discourse (p. 195). Themes, in this sense, emerge from what is meaningful to participants based on what they say. I conducted open coding according to Emerson, Fretz, and Shaw's (1995) description of coding in qualitative research. This means I initially generated as many codes as possible from each interview text, then selected core themes from them to construct categories from my lists of codes. As a benchmark, I chose core themes based on their ubiquity across perspectives, meaning themes described by the majority of participants (i.e. overall, in groups, etc.) were collapsed into categories prior to focused coding (see Table 2 in Appendix E for themes and participant tallies). 
Once all of the interview texts were open-coded, I revisited all of the texts to conduct focused coding. Emerson et al. (1995) describe this analytic method: "In focused coding, the researcher constantly makes comparisons between incidents, identifying examples that are comparable on one dimension or that differ on some dimension and hence constitute contrasting cases or variations" (p. 161). In this manner, I was able to pull themes from the data as well as identify patterns and variations in the ways participants described their sexting experiences and those of others. This included a time component, as the youth who participated in this study constitute the latter half of the youth spectrum. As young adults, these individuals spoke to the nature of sexting during their formative years as well as later contexts. Ultimately, this analytic method of constant comparison permitted me to piece together a picture of youth sexting from what young people said, and involved understanding and comparing individuals' sexting experiences during their formative years versus their experiences now. Additionally, I compared categories and themes that emerged from participant discourse across gender lines to reveal similarities or differences in the ways in which these individuals experienced sexual communication via the cell phone and how they felt about engaging in this type of behavior. Finally, once I culled data from all of the interview texts, I conducted a post-study literature review to compare and contrast the results of this study with others. 


\section{CHAPTER 4: RESULTS}

Below, I discuss the results of 20 narratives on youth sexting, focusing on the patterns that emerged from participant discourse on the subject. While current and past research may generate a statistical picture of youth sexting, narratives of those who have actually experienced sexting in some form weave a more complete, detailed representation of the phenomenon. Importantly, this more holistic picture of sexting permits a more thorough examination of its interrelations with youth culture, sexual and emotional health, and privacy in the context of interpersonal relationships. More broadly, these threads culminate in a comprehensive patchwork marking the importance of technology in American society.

Various themes emerged from discourse on the nature of sexting and are separated into categories pertaining to each research question. I begin by painting a general picture of sexting from what was most commonly described by the majority of my participants. This includes discussion of themes that emerged from categories of narratives, such as what constitutes sexting, its prevalence, and the consequences experienced by participants. Next, I distinguish between two types of sexting based on the motivations driving each as well as differences in their outcomes. Finally, I conclude this section by examining themes that emerged from participants' notions of privacy as well as narratives on how sexting manifests in various types of relationships.

\section{The nature of youth sexting}

Participant definitions. Given notable discrepancies in what constitutes sexting in research on the topic, delineating the definitions set forth by actual sexters is foundational to this project. Participants were asked to describe their first experiences of 
sexting via cell phones. Furthermore, I followed up by asking participants what they thought sexting consisted of based on their personal experiences. Overwhelmingly, pictures and sexual messages, or so-called "dirty-talk," combined was the most popular definition to emerge. Fourteen of the 20 participants suggested this combination of messages and pictures explicitly. Three participants, all males, extended this definition to include sexual videos. Two participants suggested that sexting was a form of sex but did not discuss what this form involved. Only one male participant included pictures and videos but excluded sexual messages in his definition.

Finally, when asked to describe their sexting experiences, none of the participants recall referring to these types of activities as "sexting." Instead, participants used words like "nudies" or phrases like "sending pictures" to describe their experiences of "sexting," thereby suggesting that the term is one imposed by the media. Thus, establishing my participants' definition of sexting is integral to examining their perceptions of its prevalence. This is especially so when considering that my participants' assumptions regarding how many people are sexting are grounded in their understanding of what constitutes sexting as an activity.

Prevalence of sexting. Prevalence is difficult to establish given the qualitative nature of this project. Participants were often unable to articulate set numbers of people who sext, opting instead to offer general statements such as "everybody does it" or "people do it a lot." Furthermore, "it's a middle school, high school thing" or "I think people do it more when they're younger" were common assertions that imply its prevalence during participants' more formative years. For example, multiple participants suggest that sexting was a "phase" that they eventually grew out of, something younger 
people do because it is "the thing to do" in school. Indeed, 10 participants' first experiences occurred in middle school with another five occurring in high school. This is more so in the context of sexting for social gratifications, as sexting for sexual pleasure emerged as a more common motivation and occurrence for older members of this group (see later section).

Regardless of each individual's personal perception of its prevalence, their combined testimony of witnessing or hearing about mass forwards of naked pictures from within and outside of their friendship circles is highly telling of the ubiquity of the phenomenon. Notably, the oldest members of this group, ages 24-25, lacked any experience of sexting in middle school or high school. These members explain this relative absence of sexting during their teen years as the result of a lack of cell phones as well as texting and picture messaging technologies. As Lance, 19, appropriately suggests, his was the generation when "sexting was born." Taken together, the definition and prevalence of sexting according to my participants provides a crucial foundation from which to examine how sexting occurs in particular contexts.

The process of sexting. Participant narratives regarding the nature of sexting highlight the process as one that is highly contextual (e.g. grounded in relationships), motivation-based (e.g. sexual and social motives), and both preceded and followed by common forms of discussion. As such, examples of what my participants describe as the "talk" involved in the process of sexting are integral components of the practice itself. The following section begins with a brief explication of the medium(s) of sexting, explores pre and post-sexting discussion, examines the consequences described by my participants, and finishes with a description of two distinct types of sexting. Themes 
relating to the process of sexting fall under or are separated by each of the categories described above.

Evolution of a medium. The persistent evolution of the mediums used to sext emerged as a common theme in participant discourse. Aside from sexting via the short messaging system or SMS of cell phones, multiple participants referenced Snapchat as a Smartphone application typically involved in sexting. First released in November of 2012, this application allows senders to send pictures and videos to others that dissolve within 10 to 30 seconds of being seen by recipients, and is, in the words of Henry, 24, "great for sexting!" Other applications cited in the context of sexting include Words with Friends, Facebook Messaging, Whisper, OkCupid, Grindr, Windows Messenger, and Twitter, thus demonstrating the various mediums open to and used for sexual communication and expression with others.

Additionally, Henry, 24, mentioned the impending release of Teledildonics, or "telecommunicated dildo technology," by which people separated by time and space may engage in actual sexual acts with the use of their technology by inputting specific sensations they want their partners to feel. As it relates to sexting, Teledildonics may be the future of electronic sex, combining both sexual messages and actual physical pleasure in a single experience. Having established the use of these applications for sexting, I now turn to more specific, process-oriented characteristics of the practice. Importantly, participant narratives on sexting suggest commonalities in how the process begins, progresses, and ends.

Pre and post-sexting discussion. Two categories of sexting discussion emerged, with patterns of talk demonstrating the use of certain so-called "lines" used by 
respondents to sext and talk about sexts. Specifically, common sexting starters are used to begin the process of sexting. Also, post-sexting discussions, or show-and-tell sessions where mostly males show off pictures of naked girls, emerged as a common theme of these participants' sexting experiences.

Participant discourse on sexting yields numerous examples, including the texting discussions that precede and follow the sending of pictures or videos as well as the pictures and videos themselves. Participants commonly describe engaging in "everyday" conversation with their partner prior to these conversations turning sexual. For example, common sexting starters included lines like "Oh, I was wish I was there right now," "What are you wearing?," and "I really wish you were lying in bed with me." These opening lines are more casual (e.g. "How was your day") in comparison to explicit picture requests such as "Send me a pic" or "You should send me a naked pic so I can see you" that are not accompanied by prior conversation.

In conjunction with participant discourse that suggests that sexting arises somewhat organically out of typical texting conversations and rarely begins with picture requests, these lines demonstrate how sexting is embedded or contextualized in different forms of interpersonal relationships. Consider the following descriptions of male participants' initial sexting experiences in middle school and high school:

...you would text random girls — not random but you're acquaintances with them at school—and, like, you know, because texting was this new thing and it was so big everybody wanted to text everybody. It was just like you were getting to know people that you hadn't really talked to before. And so you would play games, like, "let's play the Dare game on phones." It's essentially like Truth or Dare via text messaging, or it would just be like "tell me something about you that I don't know then I'll tell you something about me that you don't know." Then eventually you would just get to "hey do you wanna...I'll trade you this [picture] if you trade me that" kinda thing. -Lance, 19 
It was mostly like just you talking to a girl and then asking for a naked picture and that was...I mean it was $7^{\text {th }}$ grade so that was pretty much where it ended right there. You'd get a naked picture. - Tex, 20

Yeah he just started out texting his friend, like talking to her and getting to know her, and then - we were middle schoolers - we thought that was cool, I guess, so ended up trying to get that [naked picture of girl]. -Milo, 18

These passages ground sexting in a particular context, specifically during the participants' middle and high school years, whereby young males may engage in casual conversation with females "to get to know" them prior to requesting naked pictures from them. Lance, Tex, and Milo's initial experiences began in middle school when, according to Lance, texting "was this new thing" and "everybody wanted to text everybody." Here, sexting emerged organically as a part of getting to know somebody, which suggests the expected natural progression of sexual information following the exchange of less personal information in interpersonal relationships. However, both Milo and Tex imply that acquiring naked pictures was the goal of initiating textual conversation with a particular girl in the first place, a motivation characteristic of a particular form of sexting that will be discussed later.

In Theo's case, his girlfriend actively participated in sexting as well, even initiating one sexting experience by asking him if he wanted to see her model her new swimsuit:

Theo: I think it started off kind of like as like "hey I got a new bikini. Do you wanna see me model it?" And it was like "well, duh, of course" and so that's how that started and so I got a couple pictures of those and she was like "oh, we should go swimming sometime blah blah blah" and then like "you should send a picture of your swimsuit" and so obviously I would do that. It was just not a problem to me "cause a girl would see me with my shirt off if we were swimming anyway. And so it just progressed slowly through that.

Interviewer: To finally naked pictures? 
Theo: Yeah.

Interviewer: Or were they always just bikini or gym shorts or something like that?

Theo: Both. In partial, like in the underwear, and then naked.

In this instance, both Theo and his girlfriend traded pictures that gradually became more and more sexual as their texting progressed. Theo's sexting experience recounted above is atypical of those described by my female participants. For them, sexting often arose from the everyday textual conversations that graduated into picture requests from males, as implied by Lance, Tex, and Milo’s experiences. As such, female participants' narratives of initial experiences follow an almost formulaic path:

...it was kinda more like "oh, what are you doing" like "oh, what are you wearing," "can I see you," like, you know, stuff like that. Being like "I wish I was with you so I could see you" and I'd be like "oh, well." So it was just kinda like being like "oh yeah, what are you wearing?" like "what are you doing?," "can I see?" and then being like "oh you look good, I wish I was there so I could be like this with you." -Anne, 19

In other cases, female participants might indirectly move a texting conversation in a sexual direction by using suggestive language:

Yeah, it's like teasing or it's implied or it's a double entendre and then they usually pick up on what I'm trying to do or where it's going. But it's usually coy. It's usually like, I'll say something like "oh I really wish I was kissing you" or like "I really wish you were lying in bed with me" or something like that. -Marina, 21

Female participants who chose not to engage in sexting by rejecting picture requests from males describe similar experiences regarding how the process begins. For example, Sally, 20, has been asked multiple times for a naked picture of herself throughout high school:

Interviewer: ... So take maybe one of those instances and take me through it. So did you guys just start texting... 
Sally: It was probably with my crush or something or a guy that liked me and I was hanging out with and we'd be talking and he'd be like "oh so how are you doing cutie?" or something like that and I'm like "fine." What are you doing?" "Oh I'm just laying in bed" or something like that and they'd be like "oh you ready to send me a picture?" and I'm like “no, (laughs) I don't know why you're asking me that?" and he's like "come on, you're in bed anyways, it's not a big deal," and I'm like "I'm not in bed to send you a picture, thank you."

Interviewer: So prior to him requesting that picture at that time, had you guys ever talked about anything like that before?

Sally: No, we hadn't. Like he'll joke around and be like "oh you're so hot" and I'll be like "thank you (laughs), I don't really know what to say, ok" and then they'll, like, casually throw it out there like a joke but completely serious at the same time if that makes sense."

Whether with an actual boyfriend or a "crush," Anne, Marina, and Sally all describe sexting instances that are grounded in their relationships with male peers. Notably, Sally's rejection of a boy's request elicits the response that sending a naked picture of herself is "not a big deal." Coupled with aforementioned participants' narratives and the initial request of "you ready to send me a picture?," the nature of Sally and her male peer's conversation is highly suggestive of the almost mundane status of sexting. Indeed, my analysis of sexting narratives indicates that males requesting pictures of females emerges as commonplace in the experiences of participants who recall sexting in middle school and high school. Requests, then, are integral precursors to the process of sexting. Participant narratives also include commonalities regarding post-sexting discourse. Discussions surrounding received pictures include lines like "Hey, look what I got," “Guess who I got a pic of," and "I got a 'nudie' from so and so." Both male and female participants described males using these lines when showing off their pictures to each other and within friendship circles. According to my participants, masturbation videos were typically more "shocking" and awe-inspiring. These also appeared to elicit the most social shaming in comparison to pictures as they were regarded as more "unattractive" 
and even "gross." Female participants who sent pictures outlined male responses to them as well, which include such lines as "You look so sexy." "Wow, you look really good!," or "You have a nice ass ;)." Both Tex, 20, and Theo, 20, corroborated their use of lines of this nature, specifically to make the girl feel "beautiful" and "confident."

The actual substance, or sexting content, of my participants' experiences, sits somewhere in between the discussions outlined above, and weaves throughout the narratives included in this project. As such, sexual messages, pictures, and videos emerge as key artifacts generated throughout the process of sexting. Given its constant emergence in participant discourse throughout this section, I briefly recount sexting content below.

Content of sexts. While I did not request to see the contents of my participants' sexting experiences, their narratives provide numerous examples of the sexual messages, pictures, and videos they have sent or received. For direct participants, explicit sexual messages or so-called "dirty talk" unanimously involved the lines "I wanna do to you" or "I want you to do to me." In some of my participants' experiences, these lines were often coupled with words of encouragement like "Oh, I like that" or other socalled "hard-core" messages like "I want to suck your cock" or "Oh, I'm getting wet." Messages of this nature were mostly exchanged for purposes of masturbation or other forms of sexual release that did not involve orgasm.

In my participants' experiences, the most common types of pictures involved in sexting were those of females' breasts or "boob shots." These could be purely topless shots or full body shots of subjects wearing underwear or bathing suit bottoms. "Teasing" or "suggestive" photos were also common, with subjects "posing" or wearing 
clothes that were partially revealing. Though cited as less common, all of the participants either received or heard about both butt shots and full-frontal nude pictures. Younger males typically sent "ab shots" to their sexting counterparts, as male genitalia is, for these participants, "ugly," "weird," and similar in appearance to a "sad elephant." All of the videos described by participants involved masturbation. Male subjects masturbated without props, while female subjects used their hands as well as a variety of objects, including a hot dog, coke bottle, and lotion bottle. Finally, direct participants unanimously admitted to including their faces in some of the pictures they sent to others, even while acknowledging that those pictures could escape the confines of their experiences.

In cases where sexting escaped the confines of the teenage experience, various forms of consequences ensued. As such, consequences must be regarded as a potential extension of the process of sexting and are explored below. Themes regarding my participants' understanding of the consequences of sexting generally fall under two categories: social and legal.

Social consequences. The most commonly discussed social consequence of sexting was that it hurts the reputations of those whose experiences go viral and thus results in emotional pain. Participants described instances where a girl or boy's pictures or videos were forwarded beyond the initial recipient, which elicited various forms of social shaming. For example, Anne's (19) college roommate sent a picture of herself wearing nothing but boots to her boyfriend when she was a sophomore in high school. The picture went viral, was mass forwarded around the school, and resulted in the girl 
being called "Boots" and other names by her peers. Theo, 20, describes a similar mass-forwarding incident of a video attained by one of his "player" friends:

He received a video of this girl and she was pleasuring herself, like it was an actual video. And then she was obviously not necessarily defined as an...I don't know...ideal 10 for a guy. She was kind of chubbier. And so obviously the video got out and then he showed it around and there was no actual to her face saying anything but the kind of whispers in the hallway kinda thing as she was walking by. So she knew he had shown it off. So I'm sure she was traumatized on the inside...I'm sure she probably cried in the bathroom stall.

In both of these cases, females were socially ridiculed, either indirectly as described by Theo or directly as in the case of Anne's friend. Only one of the forwarding incidents recalled by my participants involved a male's video. Similar to the events described by Theo, this particular person sent a video to a girl he thought was interested in him, which subsequently went viral. Phil describes this incident, coupled with what he saw in the media, as one that "played a role" in his own decision to stop engaging in sexting.

While my participants suggested that it would be "awkward" for them if their parents found out they were sexting, emotional bullying and ridicule from peers appeared to be more hurtful and consequential to them. For example, Lance's own decision to stop sexting after his sophomore year of high school was precipitated by a fellow peer's reaction to his sexting activities:

Lance: I was really good friends with a friend of mine that was a girl and when she found out about a certain sext... and actually I had been, I was tired of the sexting thing 'cause people were getting in trouble and it wasn't that exciting. It kinda developed a negative stigma.

Interviewer: Among the students?

Lance: Yeah, like "oh this guy's texting me because he wants a "nudie", or, you know, "look who's always sexting." But it would develop negative stigma for certain people and so eventually I was getting tired of it but then my friend that was a girl found out about it and she was very pissed at me for a very long time and so that was when I was like, "ok I'm not doing this anymore, I promise."

Interviewer: She was mad that you were sexting? 
Lance: Yeah. And so that was when I was kinda like I should, you know, I should stop this. It's obvious that it's offensive to a lot of people and its not necessarily a good thing, so that's when I was like "ok I'm done doing it" and that was kinda the end of it.

In this case, Lance chose to discontinue sexting after it affected his relationship with a female friend. Specifically, he realized that sexting was "offensive" to others and presumably stopped to satisfy his female friend, protect their relationship, and avoid offending others who might not view sexting in a favorable light. Similarly, Phil, 20, recalls sexting with a girl he had met from another high school when he was a freshman. He describes the experience as "awkward" and remembers ending the sexting session specifically because he realized he was "taking advantage of her body" or "mind" because he knew that she liked him more than he liked her and felt "bad." In both of the cases described above, male participants discontinued sexting in high school because of its potential to hurt themselves or others.

Likewise, female participants who chose not to send naked pictures to requesting males cited personal values and morals as well as the potential of those pictures going viral as their primary reasons for not sexting. Though not explicitly stated, these narratives imply a desire to avoid the same social shaming and emotional hurt referenced above that could result from losing control of a sexual picture or video. For example, Sally, 20, describes her feelings in response to hearing her male friends talk about sexting:

Sally: ...I've heard about it more from guys just 'cause I hung out with a lot of guys in high school so they voluntarily were like "oh did you hear, did you see this picture that I got" or something like that.

Interviewer: So, they sit around and talk about it?

Sally: Yeah.

Interviewer: What does that sound like? What do they say? 
Sally: "Dude I was texting Marissa last night and I totally got her to send me a picture" so in my head I'm hearing about this and I'm like "I don't want someone to ever say that about me" or share my picture with anyone (laughs) in this world! So I was like "that's dumb."

As demonstrated in the excerpt above, Sally gained firsthand knowledge of how males may talk about and display the artifacts (e.g. pictures) of their sexting endeavors in friendship circles while in high school. She explicitly states that her choice to not sext is due to experiences such as these, thus implying a desire to not be objectified and evaluated by her male peers. Furthermore, when asked how she felt about some of the consequences of sexting, she responded with the following:

I mean, I feel like I would just feel guilty if I did it, like, morally that would be a consequence for me but, I mean, the consequence of someone else has a picture of you and you have no idea what they're gonna do with it and what could be done with it, so that's a consequence. It's in someone else's hand. Your body is in someone else's hands and you can't take that back.

For Sally, as well as a majority of my participants, the fact that sexting can go viral is considered a "consequence" of sexting. As explained previously, the viral potential of sexting is not consequential in and of itself. Instead, participant narratives suggest that sexting gone viral is simply a precursor to the emotional consequences stemming from social shaming. Meg, 22, elaborates:

They [naked pictures] can be really damaging to reputations. You know, not only is it...it's not just a rumor because it's actually there. It's on a phone. It's evidence of what happened. And taking that whole line that's 'a picture's worth a thousand words' just imagine what people could say about a nude photo. I'm sure it's double (both laughing)... That would be the first thing that comes to my mind is just like "oh my goodness. That person's reputation." After they hear what people say about them or just the reactions that they get, you know, how are they gonna come back from that? 
In addition to previous perspectives outlining the social shaming that often accompanies mass sexting, Meg reinforces the idea that "what people say" and "reactions" from peers are most impactful in the realm of sexting consequences.

Finally, even proponents of so-called "cautious" sexting acknowledge the emotional damage that may result from experiences going viral. Sophia, 25, describes herself as an "advocate" of sexting given its potential to positively impact relationships. Other direct female participants corroborate this perspective, suggesting that sexting done within serious relationships has the ability to enhance the excitement and relational satisfaction of both partners. Furthermore, direct and indirect participants of both genders consider sexting to be a useful tool that positively impacts partner satisfaction in long-distance relationships. However, the emergence of these positive consequences of sexting pale in comparison to themes related to negative consequences. Consider Sophia's perspective:

Well, I mean if you're sexting with somebody that you don't trust and you're sending pictures, you don't know where those pictures are gonna end up. People could, you know, end up posting them to the Internet, sharing them with friends that you know, yada yada. But at the same time, personally for me, I don't care... But, at the same time, for someone who isn't an older adult, like, I think that also comes with age. I'm just nearly $26 .$. But younger people who are still developing their sense of self-confidence and everything like that, that can be devastating if something like that were to get out or even just the sex in general. Like, 'oh look at this dirty whore who is texting all these explicit things about wanting to suck a guy off.' It's like... that could be devastating to a 16-year-old and her reputation and everything like that so I definitely wouldn't say that sexting is all-around just a great thing.

Fred, 24, elaborates: “...maybe it's bad when it affects that person, like, socially, like people know, especially in a high school with everyone staring at you and laughing. I think that's when you realize the situation has turned for the worse." Again, not 
"knowing where those pictures are gonna end up" is cited as a consequence of sexting that leads to reputation damage. Notably, Sophia suggests that perspectives on the significance of sexting gone viral may be age based, with younger participants more affected by such experiences. Fred reinforces this contention by suggesting that dealing with "everyone staring at you and laughing" in high school is the ultimate cue that "the situation has turned for the worse."

Taken together, the passages included here suggest that social consequences of sexting are predominately peer-based, such as the emotional pain that may result from social shaming or the loss of friendships. In extreme cases, emotional pain may lead to suicide, as in some participants' references to media coverage on the consequences of sexting. Though uncommon, some of the participants who refuse to sext cite personal consequences, such as damage to their values or morals as individuals and the feelings of "guilt" that would follow. Interestingly, legal consequences often followed social consequences in participant narratives or had to be introduced in order to elicit discussion. This fact further distinguishes the latter as more significant and impactful for these individuals during their formative years.

Legal consequences. The extreme nature of legal consequences and respondents' lack of awareness regarding those consequences emerged as two common themes of participant discourse within this particular category. For example, 17 of the 20 participants used words like "extreme" or "harsh" to describe the legal consequences of sexting (e.g. child pornography charges, sex offender registration) for young people, particularly if both parties have consented to partake and exploitation is not involved. James, 20, elaborates: "The question is, did you consent to make that action [sext]?" In 
the latter cases, prosecuting teens is considered "ill-fitting" and not in tune with the fact that "kids are gonna be kids" or "guys are guys." As Sophia, 25, explains it, science proves that teenagers' brains “are not fully developed and they're incredibly impulsive because they don't understand the consequences of their actions." Phil reinforces this perspective:

'Cause I mean, at least younger guys or guys in general don't think about the future generally all that much from my experience. So they're just like "we're going to do this right now. We're not gonna care about a month from now what is gonna get me in."

Milo agrees: "In my experience, the guys don't really think of the consequences at the time. It's just, “yeah, I'm gonna see a girl naked!” Sophia, Phil, and Milo's suggestions are corroborated by the fact that 14 participants were not aware of the potential charges, such as child pornography, accompanying youth sexting when they were in middle school or high school. Furthermore, all of the participants with direct experience cite not thinking about the fact that their sexting could go viral when "in the moment" and actually engaging in the practice with others.

Thus far, participant narratives on sexting experiences present a basic outline of youth sexting. My participants' outline includes: a more comprehensive definition of sexting than previously suggested in research on the topic and in the media; a perception of high prevalence in both middle and high school; a process of sexting that includes common forms of pre and post-sexting discussion as well as content (e.g. pictures of females' breasts); and an emphasis on the social consequences of sexting at the expense of knowledge regarding the legal consequences. With this outline in mind, I now turn to the two types of sexting that emerged from participant narratives on the topic. Each type 
of sexting houses various subthemes particular to why participants sext, what they do with sexting artifacts (e.g. naked pictures), and the outcomes of the practice.

Forms of sexting. Two distinct pictures of sexting emerge from the narratives of these young adults: sexting for social gratifications and sexting for sexual gratifications. While males may text females for several hours or even days to retrieve a naked picture, sexting for purposes of sexual pleasure are described by all direct participants as typically lasting one hour or until orgasm is achieved. Notably, the motivations for participating in sexting appear to change over time. For example, participants 18-20 who engage in sexting unanimously describe sexting as a means of fulfilling individual needs. Even indirect participants speculate that the purpose of sexting is for the same reasons. Just two of the younger participants, Tex (also the most avid sexter of this age group and James) had engaged in both types of sexting (e.g. sexting for social and sexual gratifications). As such, sexting for social gratifications emerged as more prevalent in middle school and early high school, although it may extend into late high school, college, and beyond.

In contrast, participants ranging in age from 20 to 25 who also sext discuss it as a means of fulfilling sexual desires together. This is not to say that those who sext for sexual gratifications only do so with selfless intentions. Rather, the stories told by this older group often involve sexual exploration, fulfilling fantasies, and achieving orgasms with a partner of some type. Both forms are discussed in detail below.

Sexting for social gratifications. The more prominent of the two types, sexting for social gratifications is typically one-sided. For example, males request multiple pictures from multiple females for the purpose of collecting trophies to show off and 
compare with each other. Similarly, females send pictures to males to receive positive feedback on their appearance as well as try to foster a relationship with them.

Importantly, this form of sexting mostly occurs amongst peers in a particular institutional setting. Consider the following passages:

It kind of was more of a game back then [when younger], like you had a mission to do it and you had to be careful with the step you took to get to that [naked picture of girl] so it was kind of...I don't know how to explain it. Like, a rush kind of. If you really played all of your cards right you would get this trophy, I guess, and that was fun. - Tex, 20

When you do get those pictures you are cool. It doesn't really make sense looking back. I think it's probably pretty childish but in high school it was like that's how you were cool. Or, like, within the closeness of your group of friends, you know, 'I got three nudies yesterday so I'm obviously the shit' (laughing), like 'what? I'm obviously pretty cool,' or 'I got it going on. I can work it.' -Theo, 20

Well, from what I heard it was just... anytime a guy gets a picture from a onenight stand or a girl they're like 'oh, check this out' and so, I mean, that's been my experience of it...it's a symbol of having gone out and conquered something. -Henry, 24

There's quite a large [male] ego. So how that conversation would be brought up is probably just in any sort of context of trying to one-up a group of friends, like 'oh I did this' or 'oh I met this girl' or guys talking about girls and they're like 'oh so and so sent me a picture of her tits.' They would say that... that was just how it was. -James, 20

I think it's just a dick-measuring contest, like 'I can one-up you.' Just like it would be any other thing you are trying to compete in. It's just an expression of power probably to be able to get what you want. -George, 22

These passages sufficiently articulate the desires of what James calls the "large male ego" in the context of sexting. Milo, 18, elaborates: "It kind of seemed like it was a big old contest because whoever would have the one's [pictures] of the better looking girls were probably the coolest guys." Here, young males may go to great lengths to persuade and even manipulate their female counterparts into sending naked pictures or "trophies" to 
them, which are then used as material manifestations of male genitalia in so-called “dick-measuring contests." Manipulation may include "leading the girl on" by implying that a relationship was likely to follow their sexting activities or requesting a "trade" or "pic for pic" deal that males do not honor. Interestingly, females suggest that the primary reason males request pictures is because they are "horny." While this may be true, males themselves appear to have more social motives for these pictures within the context of sexting for social gratifications. On the contrary, being "horny" is the main motivation of sexting for sexual gratifications, as discussed later.

Showing off naked pictures of girls in circles of male friends is not merely a common occurrence but, rather, it is done with dedication and purpose. For example, George's first experience with sexting involved him waking up to a bus full of fellow baseball players cheering over one teammate's acquisition of a naked picture of a girl. The uproar was apparently in light of the fact that it took this individual several hours to persuade the girl that she should send the picture to him and that it would stay within the confines of their purely sexual relationship. Once received, this player passed his phone around the bus to whoever asked to see the picture. The occurrence of mass forwards of pictures and videos that go "viral" demonstrate both the prevalence of the phenomenon itself as well as the desire of males, in particular, to show their so-called "conquests" to others. Thirteen of the 20 participants recalled instances such as these, as well as the social shaming of the girl, or guy in one instance, following the outbreak.

Furthermore, every female participant experienced instances of being asked for a picture of themselves by either or both random males or people they were in relationships with. One girl, Anne, recalled being in the same room with one of her girlfriends and 
both of them receiving the same picture request from the same boy at the same time, thus validating others' contentions that males ask multiple girls at once to see how many they can get. Beyond personal experiences, every female participant also had a friend or friends who were asked, further delineating the ubiquity of male requests. Finally, all participants suggested that, predominately, males ask for pictures and females send them with very little reciprocation involved. The variety of angles implicating males as the initiators of picture requests suggest that males want and thus fish for pictures and videos of naked females, presumably for the purposes outlined above.

All male participants unanimously describe post-sexting show-and-tell as a common element of guy talk and interaction. Theo notes that 'guy code' requires that any individual who receives a naked picture must show that picture to other males in his vicinity and, if it is sufficiently interesting or "hot," save it to show others absent at the time of receipt. In this sense, sexting for social gratifications for males involves partaking in "games" to collect pictures to then show off for purposes of "one-upping" other males and increasing social "status." Finally, both males and females suggest that males request pictures and show them off because they are funny to them, similar to the manner in which males may flaunt their naked bodies in locker rooms or partake in games to try to get others to walk in on them with their balls exposed. As Milo notes, “guys think it's not a big deal and girls think it's a huge deal when other people see them naked because guys actually do that [show off their genitalia] all the time."

In contrast, girls send pictures to seek attention and sexual flattery from the opposite sex. Fifteen of the 20 participants suggested that girls send pictures because they have low self-esteem and require attention from the opposite sex, specifically in the 
form of compliments of their bodies or expressions of desire to have sex with them, to feel valued. Consider Rose's response to the question of why she thinks her friends sext:

"Because she wants the attention, and she wants people to tell her that she is beautiful.

She's not confident in herself, so she needs the approval of other people." Rose's

contention is further reinforced by girls who do and do not sext themselves:

I think they do it to get attention...I feel like they wanna send them a picture to be like 'oh I trust you' type of thing but at the same time like 'look at me. Look what I have. Look what I can offer you' type of thing. And I just think they're really insecure because they need and want them to reinforce that and say like 'yeah, you look really great. I love you.' -Ariel, 19

Although Ariel does not feel the need to sext her boyfriend, her suggestion that girls use their bodies to attain male attention and desire is thus validated by Marina, who has sexted both random and non-random guys via cell phone and through applications like Whisper: "I think it's hot. Like, it makes me feel wanted and it kinda makes me feel powerful too that this person wants me this badly to put themselves in a vulnerable position to express that." Marina describes her motivation to sext as a "very superficial, self-esteem-based thing" and notes how her desire to do so dwindles when trumped by having actual, physical relationships. Even Fran, 21, who refuses to engage in sexting, recalls her mixed emotions toward being asked for a picture on two separate occasions by two different male peers:

Interviewer: Ok. So thinking back on those two experiences how did it make you feel in the moment to be asked for a picture?

Fran: I don't know. It just, like it was kinda nice to feel like they must want me but at the same time I was like "how many people are you asking for picture right now" or like "what are you gonna do with this later?"

Male sexters validate the perspectives described above via their actions, specifically using flattery to increase both their odds of acquiring pictures and the amount 
and variety of pictures they receive. For example, Tex describes how he gives girls both attention and confidence by "telling them how beautiful they are" after they send him naked pictures of themselves in various poses. As mentioned previously, Theo likes to compliment girls on their "curves" and uses "winky-faces" to convey his approval of the pictures he receives. Similarly, Anne has also sexted within and outside of serious relationships and, when engaging in the practice outside of relationships, does so to get guys to take interest in her and not "put them off" by saying no to their requests: "You don't wanna be like 'oh no' just 'cause you don't want him to be like 'well, fine. Bye." Finally, Olivia's experiences of sexting further corroborate these suggestions. Several of her encounters with men from online dating sites whom she sexted "too quickly" required her to, as she sees it, "perpetuate those sexual messages to keep those people interested in me" even though the focus on sex and not her as a person was often a cause of her emotional distress.

Combined, these perspectives and actual experiences suggest that girls do, in fact, use sexting as a vehicle to feed their desire for attention and approval from members of the opposite sex. Oftentimes, girls believe they will start a relationship with the boy they are sexting, although this is often described by both sexes as a ruse used by the boy to convince the girl to send pictures. Importantly, female participants denied the use of male pictures for showing off or bragging rights within friendship circles, although several of them suggested that girls may show each other the pictures they get if they are "funny," if the boy sending them is physically endowed, or if they receive them while with others like in a "sleepover" setting. 
Sexting for sexual gratifications. Six of the seven direct participants explicitly described using sexting as either a form of foreplay leading into actual physical intimacy or a form of sex to aid masturbation or relieve sexual tensions without orgasm. For the three youngest of the six, ranging in age from 20-21, sexting for pleasure evolved out of an initial foundation of sexting for social purposes, whether the goal was self-esteem or pictures for bragging rights. The remaining three participants, ranging in age from 23-25, have primarily sexted within the context of some form of relationship and specifically to communicate sexually and have fun with their partner. Notably, sexting for pleasure is a joint endeavor whereby two people actively participate in sexually stimulating each other. These efforts are often coupled with masturbation if orgasm is the end goal, or simply involve releasing sexual tensions/frustrations through hour-long sessions of erotic texting. In all cases but one discussed by participants who do it, the latter form eventually leads to meeting up and having sex. Most importantly, sexting for pleasure for this group occurs within the confines of some form of interpersonal relationship.

Sexting for pleasure is sexually motivated as opposed to a cure for boredom or challenge to attain trophies. Consider the following passage regarding one of James' experiences:

Interviewer: Did your partner send you pictures that were...nude or full nude? James: No, actually. Interestingly.

Interviewer: But the purpose of that type of session, for instance, was because both of you were...

James: Yeah, turned on.

Interviewer: Turned on. And was there an end result, like orgasming or anything like that?

James: No, actually, or nothing that was explained as an end result. I'm sure there were for both parties. There was no need to get to an end result. It was just kind of like an outflow of sexual expression. Yeah. 
Although masturbation was inferred, James explains that facilitating orgasm was not the central goal of sexting in this particular instance. Instead, this sexting experience was firstly about sharing, as his contention that it was an "outflow of sexual expression" suggests. James' participation in sexting with his partner to jointly express their sexual desires and motivations is mirrored by the experiences of the remaining participants in this smaller group. For example, Sophia often sexts her "longest standing friends-withbenefits" to better prepare for actually having sex in person, while both her and Marina may sext their partners to keep their relationships exciting:

...you know it's always good, the more information you know about a partner before you end up being sexually intimate is better...also we discussed what was off limits and stuff like that. I mean, I'm big into communication. Communication makes great sex and so that was just one of the ways that we communicated. -Sophia, 25

It can be really fun to get a nasty, dirty text in the middle of the day. It's like this element of excitement that gets added to your day kinda thing. -Marina, 21

Additionally, George and his girlfriend of several years sext to maintain the sexual excitement of their long-distance relationship:

I don't see my girlfriend very often, but when we are together we generally have a pretty healthy sexual relationship. So that was just cut off, but the feelings of wanting to have sex don't just go away so, for me, it's just a way to feed that desire.

Whether it leads to sex, masturbation, or emotional sexual release, in the situations considered, sexting for pleasure emphasizes the desire to work with and please the other partner in the endeavor. As such, it has the potential to enhance various types of relationships by generating excitement and even improving individuals' abilities to please their partners physically. Additionally, although Henry chooses to only sext in novelette form with another writing partner, his goal is to use his knowledge of what his 
partner likes in order to impress her. In doing so, Henry and his partner jointly create sexual scenarios to explore and satisfy both their sexual fantasies and literary standards.

In this particular case, the short, back and forth messages typical of sexting are not enough, as demonstrated by the following excerpt:

Interviewer: Can I ask you how you feel about those one-sentence type things 'cause it's not coming out of your body language right now? (both laughing) Henry: Well, I think the human capacity for literature and expression is boundless.

Interviewer: Which excites you and is why you're always seeking these challenges?

Henry: And so why would I want to make someone feel that the entire extension of my passion and imagination can be summed up in "man, I wanna fuck you so bad." I feel like there is more that a person can offer...

Finally, in the case of shy individuals such as Olivia, sexting offers a medium that mitigates her communication apprehension and allows her to better express her sexual desires with her partners:

...I've always been very introverted and shy and I like writing 'cause I feel like, when I'm writing, I can be a lot more confident and articulate...so, one thing for me, even during sex I really like dirty talk. It's very arousing for me to hear it but I've never been able to actually speak it because I get flustered, like, I don't really know what I want to say or how to say it when you're in the middle of having sex or whatever. But when it's sexting and you have more time to sit there and think about what you wanna say or how you wanna come across in this message, I like that. I like being able to think that out. -Olivia, 24

While it is necessary to distinguish between these two types of sexting given their inherently dissimilar nature, it is also important to note that personal motivations for sexting weave throughout both forms. As such, factors that play into the motivation to sext are not mutually exclusive of and often bleed into one another.

The varying nature of sexting outlined above has important implications for youth notions of privacy within and outside of interpersonal relationships. Indeed, answering the first research question regarding the nature of youth sexting inevitably proffers 
answers to the remaining two. Because privacy emerged from participant narratives as a factor interwoven with and oftentimes dependent on the relationship context, the remaining section addresses the themes regarding notions of privacy and sexting in relationships together. Specifically, the ambiguous nature of sexting as private and public, so-called "naïve" notions of trust and privacy in relationships, and sexting as more comfortable and justifiable within relationships emerged from participant narratives as three predominate themes regarding the second and third research questions.

\section{"What we're doing is private": Sexting, privacy, and relationships}

Privacy within sexting. Despite the fact that my respondents continuously described stories in which they or others shared sexting content with individuals outside of their initial sexting contexts, they still considered sexting to be private. For example, 15 of the 20 participants consider sexting to be a form of private communication, with nude pictures and videos of masturbation as private objects and acts. Three male participants suggested that sexting was simultaneously private and non-private, and the remaining two male participants explained that it was not, in any way, private given the medium used for engaging in the practice.

Participant discourse on the nature of privacy in the context of sexting is as confused as the expectation of information transmitted electronically always remaining between senders and their intended recipients. For example, respondents clearly suggest that sexting is private despite its capacity to go viral. Olivia, 24, explains: "Yeah. I would consider it [sexting] all private. And I would consider the photos a lot more private than the words." Milo agrees: "I think that they [nude pictures] should be private 
obviously because why would you want someone to see you nude other than the person

you are trying to show?" Sophia, 25, elaborates:

...what we're doing is private. It's a private conversation between the two of us. I mean, I have a lock on my phone. I don't want people to necessarily see that even though I don't care and some of my friends know that I sext. It's completely different between knowing that I do it and then seeing the actual result of it.

Others attempt to characterize sexting based on a seemingly soft distinction between personal and private:

In my opinion it would be something personal that, if I were to send it to someone, I would only want that one person to see it. I wouldn't want a lot of people. But I think for some people it's a very personal thing but I think for others they know it's gonna get shown to other people. -Sara, 18

I mean, I think everything's only as private as you choose to make it...I mean, I think it's a very personal, like it's [sexting] somewhat personal and like I said I wouldn't go talking to strangers about my sex life unless maybe I was really drunk...It's kind of like a 2-way street and I think, like we've talked about before, it's kind of like this implied privacy thing where I assume other people have talked about having sex with me because I've talked about having sex with them. I'm sure it's going both ways but I'm assuming that they're not plastering it everywhere. -Marina, 21

Lance, 19, furthers these attempts: "Depends on the people. Sometimes it's private, sometimes people keep it a secret. Sometimes it's not. Most of the time it's not. It's a personal thing that's not always private." Still others negate the possibility of sexting being private:

It isn't private technically. Let me rephrase that. A person may think it is, but it's not because once you put it out there it is to the open public and anybody can get their hands on it. Obviously it may start with just one, but that one can turn into 2, to the Internet, which is so expanded now that anybody can get their hands on it. Cecil, 20

I guess you just figure that's something really intimate that you share with that person and that should be private and sexting isn't super private considering it can be sent to other people. -Ariel, 19 
The passages outlined above demonstrate the equivocal nature of sexting as a practice involving information that is considered "personal" by my participants but is sent in a manner that readily lends itself to the public eye. This ambiguity is especially evident when participants describe sexting as private while also sharing stories in which naked pictures and videos go viral without the permission of the original sender. Realistic or not, all of the perspectives included above demonstrate a desire for sexting to be a private act between two people, which implies that my respondents consider sexual information to be private as well.

Notably, both female participants who refuse to sext and male participants in general are seemingly far more realistic about sexting and privacy within and outside of interpersonal relationships. The fact that sexting endeavors can spread is often cited as a primary reason why select participants do not sext. For the female participants with indirect experiences only, this fact is coupled with issues of morality and values regarding their body, which prevent them from sexting even within serious relationships. For the male participants in this study, participation and understandings of privacy depend on the type of sexting they are engaging in. For example, James sexts with partners he knows and feels comfortable with for purposes of pleasure only but acknowledges that, no matter what, the information he sends out no longer belongs to him:

I'm constantly battling 'do I care? Do I not care?' ... It [sexting forms] shouldn't be exposed to other people, although I realize that at the point at which I send something, that information no longer becomes my own and it can be used in any way, form, for or against me. So I am conscious of that decision. My care for it is really just kind of what is always in the bounds of things.

Henry is similarly aware of this reality: 
I think that, because people don't talk about privacy because it's something that everyone just wants to assume is theirs as a right, is a case where humanity isn't catching up with technology. "It can happen" is all you need to say...someone's gonna steal your phone. Someone's gonna take it and once it's on the Internet, it's there forever. If you say something in public and someone has a phone in their hand, you are responsible for everything you just said. Just imagine you're telling it to everybody in the entire world in perfect clarity. It's something that everyone's just gonna have to understand.

George furthers this notion of the impossibility of privacy via technology. He has sexted within the context of his 3-year relationship with his girlfriend and explains that he trusts her not to spread their endeavors, but is realistic of the potential for their pictures and messages to spread in other ways:

My phone is locked and I don't let anyone else touch it. If I show anyone something on my phone, I don't put it in their hand and not pay attention to what they're doing. I'm very private about who is seeing my phone and what they are doing when I'm showing them something...I mean, anyone who has a Smartphone has something to lose on it. That's just the age we live in.

Tex agrees with these ideas and explicitly accepts responsibility for his sexting activities: "I mean, like I said with the whole consequence thing, it would suck if it went around but I mean I'm making that choice and I know that that's a possibility." These four participants are distinctly aware of privacy issues in the current techno social climate, and are far more expressive of their understanding. For example, while male participants who still sext or have sexted note that they know pictures have the capacity to spread, they are not worried about the few images they have sent of themselves for two reasons: male nudity is not a big deal to them and they do not include pictures of their faces with pictures of their "junk." The former sentiment is expressed by both males and females in this study and, as discussed previously, reflects the possibility that men and women may view the seriousness and personal nature of sharing nudity, and thus sexting, differently. 
Naïve notions of trust and privacy. Regardless of these differences in

perception, all of the participants suggested that young people, like themselves when they were in middle school and high school, do not want their sexting endeavors to go beyond their intended recipients but are simultaneously "naïve" about trust and relationships at that age. Consider the following passages regarding sexting in high school:

...I'm sure people that send them most of the time think "oh I'm with this person. He respects me. He won't do that." But, I mean, unfortunately not all guys are really nice and there's always gonna be the assholes that are like (in mocking voice) "oh yeah, she sent me this" and then goes to show his friend and then that friend's like "hey look" and then it ends up just spreading like wildfire unfortunately. -Ariel, 19

...I think that a lot of younger people think that just because they're sending it to one other person or maybe a couple of people that they feel really safe with, I think that they have a mindset that it is private between them and those people. Meg, 22

Here, Ariel and Meg suggest that young peoples' expectations of sexting staying private are unfounded given the consistency of naked pictures going viral in youth culture.

Undeniably, sexts often break the bounds of the relationships they were initially contrived within. Milo, 19, notes the recurring drama of such instances in high school: "When somebody was dating somebody. Then when they got a picture from their girlfriend, they showed one of their friends. It usually broke them up and it ended badly for everyone." Similarly, Sara describes the aftermath of one forwarding incident of a girl's picture she experienced in early high school. In Sara's mind, the girl should have known the picture could get out regardless of her relationship status with her boyfriend:

She probably thought like "oh they were in love" and all these things and "he's gonna keep my picture and he's not gonna show it to anyone else" like "why would he do that?" But, I mean, boys are boys and girls are girls and things get sent. 
Participant discourse in this context, then, reflects an apparent disconnect between the reality of the youth sexting experience and the expectations young people may have regarding the role of sexting and privacy within relationships. My respondents suggest that young people in particular are prone to naïve notions of trust within teenage relationships, despite evidence all-around them that reflects the prevalence of sexting endeavors going viral.

Furthermore, despite considering sexting to be "personal," all of the female participants who sext now or have sexted in the past admit to not thinking about their pictures or videos going viral when actually sexting their partners. It is, according to Marina, 21, something that "is always in the back of my mind" or an "afterthought" but does not interfere with her sexting activities in the moment. Similarly, Olivia, 24, recalls hearing about a picture of a woman's breasts going viral around her small community and having one of her friends show her the picture with the comment 'she should've at least cut her head out of the breast picture.' This experience precipitated Olivia to recall the numerous times she had sent one of her previous partners pictures: “And then again I'm thinking like 'oh my God, I've done similar pictures to that and it didn't cross my mind to cut my face out." Sophia, 25, while admitting that she does not ask what her male sexting partner has done with her photos, is confident that he would not spread them around because "he hasn't done anything to imply that he would" and is "honest" in all aspects of his life. However, Sophia is also cognizant of one of her so-called "flaws," which involves assuming that others think like her when it comes to morality and privacy or, as she puts it, “This is something I wouldn't do so I assume someone else wouldn't do it." 
Additionally, while at least three of the four women recall using some form of verbal safeguard (e.g. "This is for your eyes only) when sexting, all of them suggest that privacy is more of an unspoken expectation in their sexting relationships. Similarly, male participants who sext or have sexted also suggest that trust is implied or, as Cecil puts it, an "unspoken law." For my respondents, then, attempts to protect their sexual information are minimal even as their distrust of others remains high. For example, my respondents often expressed skepticism about human nature, suggesting that male individuals' desires to see others naked as well as show off pictures or talk about their sexual conquests with other males trumped their allegiance to protecting the privacy of their sexting partners.

Thus, the experiences outlined above demonstrate several key aspects of privacy within the context of sexting. First, sexting may be understood as personal, but cannot be mistaken as completely private given the nature of the medium used to engage in the practice and the consistency in respondents' stories of sexts gone viral. Second, a majority of the respondents do not think about protecting nor actually take measures of some form (e.g. verbal safeguarding, checking partners' phones) to protect the sexual information they send over their phones. Finally, this lack of safeguarding suggests that participants feel comfortable sexting with their partners and/or have naïve notions of trust. This latter component extends into a discussion of sexting within relationships.

Sexting within relationships: Comfortable and "justified." Two dominant themes emerged from participant discourse on sexting within relationships: comfort level and justification. For both direct and indirect participants, sexting within a relationship is 
or would be more comfortable and less worrisome than outside of one. Additionally, my participants consider sexting to be more justifiable within the confines of a relationship.

Each of the participants is quick to note that they sext within very particular forms of relationships and only with people they trust. Anne, the youngest direct female participant at age 19, elaborates:

I feel like I'm just hesitant in general about it because I'm like "I don't want other people seeing that. That's my business. That's my private body and if I feel comfortable enough to share it with you then I expect it to just be you." I wouldn't want every other person to see it just because you're like "ohhh, look. This girl sent me a pic." I wouldn't ever want that and so that's why I try to stay on a more, like, comfort level with someone throughout my relationship and stuff like that.

Anne's reflections on her ideas of privacy and decision-making in the context of sexting are telling of the contradictory nature of sending private pictures over a medium that can go viral in a matter of seconds. This passage suggests that Anne is cognizant of that potential, considers her body to be private, and is selective in who she sends pictures to. Indeed, throughout her interview she describes only sexting within the context of a longstanding relationship or with individuals that she is interested in and would like a relationship with. She suggests that she will only send suggestive pictures in the latter situation, with pictures becoming gradually sexual if and only if a relationship is impending.

Importantly, both groups of respondents who do participate in sexting as well as those who do not suggest that they would be more comfortable doing so within the bounds of a meaningful relationship. All of the direct participants have sexted within and outside of emotional relationships at some point and recall being more hesitant and 
cautious in the latter case, potentially employing verbal safeguards or refusing to include their face or specific body markings (e.g. tattoos) in their pictures. However, as discussed previously, safeguarding is rare. For example, while Olivia does not worry about the suggestive picture she once sent to a boyfriend of several months, this comfort does not extend outside of deeper interpersonal relationships where she might be a "bit more concerned" they could escape. Regardless, this has not prevented her from impulsively sexting within a purely sexual relationship or with guys she was not in a relationship with at the time. In her words, "Who fucking knows where those photos are right now."

Both Olivia and Anne suggest that they feel more comfortable and less worried about sexting within relationships. Their feelings are validated by male perspectives and experiences as well. Fred has never personally sexted but, like the majority of my respondents, exhibits the same intuitions regarding privacy in "committed relationships":

I think if you're in a committed relationship, if that person is faithful to you, the photo will stay with them or they'll just delete it afterwards. But you never know with any other random person where it's gonna go, you know.

Male respondents who have participated agree based on their personal experiences. Consider George's explanation when asked about why he thinks sexts go viral:

The only context of what I have heard this [sexting gone viral] about is guys doing it with girls they don't care about, or say that they don't care about. I've never heard of a guy who is in a long-term relationship with a girl that they could see themselves being with for a long time or marrying or whatever ever showing pictures like that.

George's description echoes the "girlfriends off limits" mantra that Theo references when describing his sexting experiences within relationships: 
Well, sexting with a girlfriend I feel was different just 'cause, I don't know, you can kind of know about that and you obviously care about that person so you don't want to show it off to your guy friends. You don't want them to know about it.

Both George and Theo propose that males do not show off pictures of girlfriends they

"care" about. Accordingly, all of the male participants who have directly sexted within a serious relationship say they have never shown to others the pictures they received from their significant others. Breaking the "girlfriends off limits" mantra, as Milo suggests in a previous passage, results in break-ups because girls expect their pictures to stay within the bounds of their relationship. Referring back to Anne's story of her friend's "boots" picture going viral, Anne recalls her friend being surprised that the picture got out "because they were in a relationship."

The existence of this "girlfriends off limits" mantra supports my respondents' notions that sexting is more "justified" within relationships. As Anne explains, sexting with her boyfriend was "okay" because they were "together." Indeed, even those who do not directly participate in sexting promote this assumption. Rose explains: "I've been taught that it's not ok, and that's why I don't think that it is ok. But if you are in a long distance relationship, it could be ok." Others echo these contentions:

I don't know. I mean, it's the same but different I guess. I feel like it could be a little more justified because if you're in the intimate relationship and say you guys have had sex, they've seen it anyways. I don't think it's really that necessary but I mean it's a little bit different then sending a picture to someone you don't really know that well. Who you don't trust per se. Who you aren't even with. I think that's more risky and frowned upon as to where if you're in a relationship with the person you've been with and you trust and you feel like that's something that's okay between the two of you, I can see where people can justify that more. In my head, I guess, I'm just like 'well it's just not necessary' but if it was gonna happen I would rather, like, if I was gonna do it, I would rather be in a relationship with someone, you know, rather than with some guy I have a crush on and we're seeing where things are going. -Sally, 20 
Fran: Um...I would like to hope most of them...like if they're just honestly doing it with their boyfriend it's a little bit better than a girl just sending it to random guys.

Interviewer: And why is that?

Fran: I don't know. 'Cause, like, if they're actually together and having sex it's different than just some random guy you're gonna send a picture to. Like, there's a difference.

Interviewer: Right. But why do you think that that's different?

Fran: Ok, this is gonna sound probably bad but most people would call a girl that doesn't have a boyfriend and sent it to other random people a 'slut' but if it's a girl with a boyfriend it's not a big deal.

Combined, participant perspectives advocate the appropriateness of sexting within relationships. For Rose, sexting is not "ok" but "could be ok" given the nature of the relationship in which it is occurring (e.g. long distance relationship). While Sally does not view sexting as necessary, she would "rather be in a relationship with someone" if she were to sext. Finally, Fran's excerpt extends these contentions by including social shaming as a potential end result to sexting outside of relationships, specifically for girls. Again, the takeaway from both direct and indirect participants alike is the common assertion that sexting within relationships is more normal, expected, and justifiable and sexting outside of relationships is more risky and worrisome.

Unsurprisingly, perspectives on the interrelations amongst sexting, privacy, and relationships are mixed. However, some common threads emerge from participant narratives, such as the comfortable, more justifiable nature of sexting within serious relationships, the increased caution or worry used or felt by participants outside of serious relationships, and the acknowledgement of the capacity of sexting to go viral coupled with the absence of some form of safeguard, verbal or otherwise. Most salient here, the majority of my participants consider sexting to be a private act. This is problematic given 
the fact that they participate via a medium that is, by nature, not private. James makes an important distinction here: "It's [sexting] personal in terms of what the action means as, like, a gesture to that person that 'I'm willing to trust you with this kind of information although I know it's not private.'”

\section{Summary}

The abovementioned themes of youth sexting that emerged from participant narratives are foundational to understanding the phenomenon. The majority of my participants define sexting as both sexual messages and pictures, thus extending the primary definition (i.e. naked pictures only) used in both the media and academic circles. My respondents' stories further suggest that sexting is ubiquitous, especially in middle and high school, and involves a specific and almost formulaic process. Social consequences (e.g. emotional bullying) appear to surpass legal consequences for my respondents who firstly describe the social impacts of sexting prior to discussing legality, if they do so at all. Importantly, the emergence of two distinct forms of sexting best demonstrates the dynamic nature of the phenomenon, as the motivations for and outcomes of sexting within each are inherently different and must be treated as such.

Furthermore, participant narratives reveal important themes regarding how sexting manifests in interpersonal relationships, how it goes viral, and how young people view and understand notions of privacy in the so-called "age of technology." Most notably, my participants consider sexting to be private even as they describe recurring instances of sexting gone viral. Themes of comfort and justification regarding sexting within relationships speak to this tension, as sexting is more likely to impact relationships in a positive manner when mutual participation and trust is involved. Importantly, the 
negative impact of sexting appears most consequential in young peoples' formative years, which is also the time that individuals are mostly engaging in sexting for social gratifications. These ideas, coupled with the absence of education on technology and access, have important implications for sexting in both interpersonal relationships and the greater context of society, all of which will be discussed in the following chapter. 


\section{CHAPTER 5: DISCUSSION}

The theoretical and practical implications of the themes generated over the course of this project are discussed below. I begin by exploring how my findings regarding the nature of youth sexting (i.e. perceptions of definitions, prevalence, type, etc.) may precipitate an "everybody's doing it" mentality and social pressure to partake in the practice. This includes my participants' consideration of the role of media in actualizing and reinforcing social expectations and pressures to sext. Additionally, two types of sexting emerged over the course of this project. As such, I explain the implications surrounding these differences in type and how they necessitate a more holistic understanding of how and why sexting manifests.

Next, I discuss the theoretical implications of my respondents' notions of privacy within the context of sexting in the electronic age. I examine the significance assigned to sexting within various forms of interpersonal relationships and how expectations of trust may be independent of important social factors like age and relationship status. Finally, I consider how the results of this project can be applied to current attempts to educate young people about sexting in order to mitigate the social and legal consequences attached to the phenomenon. I conclude this section by discussing the limitations of this project as well as avenues for future research.

\section{Nature of youth sexting: What, how often, and why}

Generally speaking, the mobile phone, though far more advanced and perpetually evolving, maintains its place as the cornerstone of youth culture (Bond, 2011; Bosch, 2011; Oksman \& Turtiainen, 2004; Thompson \& Cupples, 2008; Thulin \& Vilhelmson, 2007; Yoon, 2006). Particular to this study, the cell phone exemplifies both Bond's 
“prop" (2011, p. 599) of adolescent performance and Bosch's “space for play” (2011, p. 75), specifically for sexual displays. For my younger participants (i.e. 18-21), owning a mobile phone during their formative years signified their social importance and belonging to a techno-savvy culture. Furthermore, the mobility of the phone combined with advances in picture and video technologies "escalated" sexting during middle and high school by making it easier to do. Although secondary to this project, my results corroborate the social importance of technology, specifically cell phones, in youth culture today. As such, understanding the significance of mobile technology in young peoples' lives provides context for a discussion of the results of this study.

Definitions. First, according to my participants' definitions, sexting manifests as a virtual form of sex that is primarily driven by sexual texts and pictures. Because this definition of sexting emerged from the participants' narratives, it stands as a more grounded version of the actual practice. Furthermore, sexting that includes both sexual messages and pictures is more inclusive than the definition supplied by both the media and a majority of academic projects on the subject. As noted previously, media and academic definitions are limited to the sending and receiving of naked pictures. The lone male participant that excluded sexual messages from his definition may have done so because his personal experiences only involved sending pictures. In contrast, the majority of my participants have experienced sexting in a manner that is more diverse and less exclusive than previous definitions suggest.

Above all, my participants' narratives regarding how to define sexting demonstrate the subjective nature of the practice, a result that implies a need for more openness to the emics of youth sexting in various socio-cultural contexts. With numerous 
studies limiting the act of sexting to the sending of sexually explicit images (Draper, 2012; Lenhart, 2009; Strassberg et al., 2012; Walker et al., 2011), research may not be generating a clear picture regarding the prevalence of youth sexting. Similarly, definitions that stretch to include videos (Gordon-Messer et al., 2013; Hurdle, 2009) and sexual content sent over social-networking sites and other technological mediums (Bailey \& Hanna, 2011) may be too expansive for certain groups of people. For example, individuals without Smartphone technologies may experience, and thus understand, sexting differently than individuals with Smartphones. Additionally, incorporating participant language (e.g. I got a "nudie" today; Did you get any pics?) into research protocols can help develop a more grounded understanding of what constitutes sexting and how definitions vary based on personal experiences as well as access to technology.

Specifying the nature of sexting content is also critical. My participants' descriptions of sexting content include both suggestive and sexually graphic pictures of themselves or others in various poses. Importantly, content may vary based on the type of sexting, with topless pictures most characteristic of sexting for social gratifications and full body pictures and masturbation videos more characteristic of sexting for sexual gratifications. Additionally, the recurring nature of application references implies the multi-modal nature of sexting and its capacity for evolving further. As many of my participants suggest, being curious about and exploring sex is not new. However, the mediums used by individuals to engage in these activities are always evolving.

Nuances such as these may impact both research on and general understandings of sexting in a variety of ways and must be carefully considered when developing future modes of inquiry in order to produce results that are reflective of the actual experiences 
of participants. Ignoring the nuances of sexting may continue to fuel one-size-fits-all social policies generated to deal with the consequences of the practice. With few exceptions, research on sexting lacks the complexity necessary to adequately explore sexting. Thus, Stone's (2011, p. 267) contention that sexting is an "unsatisfactory" term for a wide "spectrum of behaviors" is both correct and consequential, at least for the participants in this study for whom sexting manifests in a least two distinct forms.

Prevalence, peer pressure, and sex in the media. Secondly, my participants' reflections regarding the prevalence of sexting reveal two important ideas. Namely, young people think that a majority of their peers and individuals in general are engaging in the practice and more so during their more formative years (i.e. in middle and high school). These perceptions contrast statistical research reflecting a tendency for sexting rates to increase post-high school (Gordon-Messer et al., 2013; The National Campaign, 2008). Again, definitions may come into play here. For example, The National Campaign (2008) study revealed an increase in sexting statistics among young adults when suggestive content was included in the definition of sexting. Nuances in definitions should be explored among younger populations as well. Though lacking explicit numbers, my respondents' narratives most directly support research implying gendered sexting, with females sending more images than males and high numbers of males viewing sexual images of their female peers (Barkacs \& Barkacs, 2010; The National Campaign, 2008; Walker et al., 2011, 2013). Ultimately, the results of this study, in conjunction with previous research, reveal a gender divide in youth sexting. This divide may be intertwined with differences in individuals' assessments of social expectations, 
specifically those championed by the actions of fellow peers and media representations of sex.

In this context, males and females may sext for very different reasons, but their motivations to do so come from the same place (e.g. pressure from peers and the media). The media is a relevant and consequential actor within my participants' cultural landscape because sex and sexting in the media emerge from participant narratives on the prevalence of sexting. In this manner, the perceived ubiquity of sexting connects to media representations of sex and social pressures to sext. For example, perceptions of the ubiquity of sexting may engender very specific expectations, namely that, in my participants' words “everybody's doing it" and thus everybody should sext to keep up with social norms of coolness. Consider the following perspectives regarding sexting, sex, and the media:

I think it's [sexting] just more common. I think you just hear about it more. There's even movies about it now on TV and so I think it just...I mean it's sad to think that girls have to prove themselves through a text message. -Fred, 24

I feel like a lot of it also comes from like you hear things, I mean, the whole Kardashian family became super famous of a sex tape thing that goes on. And, I mean, I think you kinda correspond with that leaking type of thing, like, people do that. Like, I don't understand necessarily why people always do what they do, like that's their own business and everything, but I think you kinda correlate with "oh these people, they need to draw attention to themselves" and I don't think...I don't know...I guess the people that you would correlate doing that would be people that are kinda like higher up on the food chain sorta to say. Like, girls that know that they're hot stuff and they can get a guy versus the super awkward wallflower girl, like, she wouldn't do that but someone that was full of themselves probably would. -Ariel, 19

For these participants, the perceived ubiquity of sexting is fueled by both personal experiences and media hype. Both Fred and Ariel implicate the media as a key player in perpetuating both the popularity of sexting or "leaking" of sex tapes as well as the 
expectations that females must use their bodies through these vices to "prove" or "draw attention" to themselves. The majority of my female participants corroborates Ariel's contention that popular girls are more likely to send naked pictures to others than "the super awkward wallflower girl". Furthermore, the majority of male participants suggests that popular people are the ones sexting by describing the practice as prominent in their own social circles. For example, Cecil explains that "cool" males may exert their social "power" by requesting and receiving naked pictures from girls. Intuitively, Ariel's suggestion fits nicely with the idea that popularity is achieved by satisfying mainstream social expectations and norms regarding beauty and sexuality. For those who desire the attention and fame that celebrities like Kim Kardashian have achieved through sexual display, sexting is a powerful tool for achieving those ends.

Females, in particular, appear to be buying into this mentality by taking and posting pictures that highlights their breasts, or so-called "Duck Face Photos." Rose explains:

Girls will let their boobs completely hang out and just take a picture with their phone over their head so you can practically see their boobs but no nipples or anything. So it's technically cleavage, but still you can see your whole area.

When asked how she felt to be asked for a naked picture by her boyfriend at the time, Meg also references cleavage shots and further connects females taking and sending/posting them to self-esteem issues:

Interviewer: So, how did you feel when he asked you?

Meg: In one word, and this may be really over-exaggerating, I kind of felt cheap. Interviewer: Interesting.

Meg: Just because I don't look at that sort of thing as having high self-esteem of like sending a nude photo of yourself. I don't know if that make sense.

Interviewer: Explain it a little bit. 
Meg: If I were to get a nude photo of somebody, I wouldn't look at that as beautiful or handsome. I would just look at that as "wow. What do you think of yourself? What are you trying to portray?" I guess. The whole thing is just really confusing to me (laughs). And it just seems like you would have low self-esteem. I mean it reminds me of those girls on Facebook or MySpace that take the Duck Face Photos with, you know, putting their phone in the air and having their chest hang out of their shirt, you know. I'm just like "what are you doing? You're beautiful the way that you are." As cheesy as that sounds, you don't need to take off your clothes and send pictures.

For Meg, girls take "Duck Face Photos" and post them on social networking sites like Facebook and MySpace because they think they will be considered beautiful in light of their displays. Meg's question of "What are you trying to portray?" grounds the activity of sexting as one of self-representation and thus identity construction. Sexting, then, gains its power from female participants' desires to mock the sexual displays they see in the media as well as in everyday encounters with peers who sext.

Furthermore, James extends the role of the media to include power issues between males and females. Below, he describes a conversation he had with his father and younger sister regarding why young girls send naked pictures to others:

It was about understanding how images in the media frame our identities and how we then transpose our own identities through other people, if you will, and through our relationships with other people. So, if you're seeing some sort of ad, you know in my opinion, that is consistently telling you to devalue your body or that you're not perfect enough, you're always going to be trying to attain that value through whatever means possible. In that context of how people attain that attention if you will, I guess, or approval is a better way of saying it, is usually just through the patriarchy - that I think still is super, super prevalent - of how male and female roles are still super engendered and that, especially young girls and the way the media portrays things is still that women are, in some cases within the media, submissive to men and that they need their approval to otherwise go and do things. And you see that in young relationships still with like asking their boyfriends of like "oh can I go do this?" It's like "yeah, you can go do this even without him." (laughing). -James, 20 
This conversation was in response to an incident in James' sister's high school where a group of boys posted to the Internet hundreds of pictures of naked girls that they had received while sexting. Once discovered, these so-called "DropFiles" became the subject of media scrutiny, further reinforcing notions of both the prevalence and danger of youth sexting. Here, sexting is simply another manifestation of technological advances blending with deep-seated patriarchal norms that continue to influence and guide American social relations. Specifically, James suggests that the recurrent devaluation of the female body in the media prompts young girls and women alike to seek evaluation and approval from males. Sexting, then, is another way that young people, girls in particular, may showcase their bodies to retrieve that feedback. Consequently, in the context of this study, social evaluation then shapes the subsequent actions of individuals, thus perpetuating this cycle and reinforcing the power of peer pressure in the media and institutional settings like schools. James also extends media pressure to the context of couple interaction, specifically suggesting that sexting is "expected within relationships":

Yeah, I like drawing on the media for my examples of just like MTV, of how MTV will like, you'll see shows and they'll have couples sexting on there and you're like "do you understand what the fuck is happening and how this translates to young people's lives?" So when those precedents are set within social media, within generations of high schoolers, it kinda just sets a precedent for young people in relationships I think.

Interestingly, Marina acknowledges the existence of James' "patriarchy" but

suggests that her sexting actions flip the power structure on its head:

I think, like for me, I feel like there's power that comes out of it. Like in such a male dominated society, it can be nice to kind of feel that position of power in the sense of, like I said earlier, they [males] kind of put themselves in a very vulnerable position and you technically have the power to stop it at any point and just stop responding or not send pictures or not do what they want. Both people can be in that control but I think, as a woman, I feel like I probably notice it more 
than guys do or that's more of a reality for me than guys do. But for me, a large part of it's the power that you can have and just knowing that someone wants you. I think girls tend to have lower self-esteem and just knowing that like "oh this person wants me in a sexual way" can be really flattering and really boost your self-esteem even if it's momentarily and I know that's played into it for me before too.

Marina's perspective is significant for several reasons. First, Marina suggests that she is taking back power in a "male-dominated society" by showing off her body and receiving flattery from the opposite sex. However, she generates her "power" from male approval, which suggests that she needs to feel wanted in a "sexual way" in order to feel valued. As such, Marina may be inadvertently perpetuating the importance of more superficial aspects of the individual persona by playing within, instead of fighting, a system that is flawed. In other words, Marina is simply playing out her, in James's word, "engendered" social role as a sexualized woman and slave of male approval. This adoption of what Bailey and Hanna (2011, p. 414) describe as "pre-packaged conceptions of femininity and sexuality as keys to social success" is seemingly pervasive in light of emic narratives. As such, emergent themes regarding motivations to sext support both adolescent behavior experts' and young peoples' descriptions of sexting as a sexualization issue (Walker et al., 2011, 2013). Furthermore, both young people and expert perspectives implicate media as a key player in promulgating a hypersexualized cultural landscape.

Both sexes acknowledge media's role in encouraging sexual displays that may be achieved via sexting. For example, six participants mentioned media portrayals of both sex and sexting when discussing sexting's prevalence or consequential nature. More importantly, these perspectives were unprovoked. In other words, respondents first proposed ideas regarding sex in school or in the media without being asked. Consider the 
following excerpts in which participants' initial contentions that "sex is everywhere" prompt a follow-up question:

Interviewer: So when you say that "sex was everywhere" what do you mean by that?

Meg: Well, I mean it just seemed like everyone was doing it, you know. And there was kind of that pressure, like if you didn't do it, you were uncool or inexperienced or just kind of, you know, like you were looked down on. You weren't really held in high regard like the cool people in the school. 'Cause my school was super clique-y and, you know, it just seemed like if you weren't going to the parties or partaking in any of their extra-curricular activities (sarcasm) then, you know, you weren't valued.

Interviewer: When you said earlier that "sex is everywhere," what do you mean by that?

Phil: I mean it's in the media. Kids are talking about it. They wanna hook up with this girl at a party or something or this girl's coming over, I mean, all the Carl's Jr. ads with Kate Upton, all those. The MotoX, all those girls are wearing bikinis and it's just, I mean, it's all around.

For both Meg and Phil, peer pressure to have or gain "experience" in order to be "valued" emerges from both what individuals are talking about and what they see on TV.

Discourse implicating the role of the media in perpetuating sex and sexting is especially powerful when coupled with narratives exposing the consequential nature of youth sexting for social gratifications. Ultimately, these perspectives unveil the social pressures that fuel individuals' desires or compulsions to sext. As demonstrated above, these pressures come from a variety of sources, namely peers and media representations of men and women. Thus, participant narratives depict a potent sexual landscape based on the hypersexualization of youth.

In this sense, it appears that Brown et al. (2009) are only partially correct in their contention that sexting has the potential to normalize objectification of self and others. Holistically speaking, sexting manifests as both a product of a culture that normalizes 
objectification and a vehicle through which that normalization is reified. Sexting content, then, is both the goal driving pre and post-sexting discussions as well as the product of the process itself. In this manner, the process of sexting is iterative, with sexting content (e.g. naked pictures) generating post-sexting discussion that inspires others to engage in the practice too. Because female desires for attention are grounded in males' desire to gaze at the female body, the power of sexting ultimately derives from cultural constructions of pleasure. Importantly, the desire to gaze and be gazed at is reinforced by media mechanisms previously acknowledged, which means sexting is both a result and supporting agent of this desire.

In this manner, the practice of sexting speaks to traditional notions of attaining sexual pleasure through gazing while simultaneously transforming the way individuals seek and achieve that pleasure. Here, the vehicle of sexting modifies gazing in important ways, namely by making the practice more personal. For example, sexting locates gaze on a specific, known subject (e.g. males asking female peers for pictures) instead of on a stranger (e.g. actresses and models). While principles regarding pleasure and gaze were not primary foci of this project, their manifestation in the narratives of my participants is both noteworthy and foundational for future sexting research. Importantly, the positive or negative impacts of sexting on individuals may depend on the type they engage in, including their motivations and goals for sexting.

Social versus sexual sexting. Thirdly, two types of sexting emerged from my participants' narratives on their direct and indirect experiences. Sexting for social gratifications involves individuals using naked pictures to boost their self-esteem in a variety of ways that differ based on gender. For example, males may request pictures 
from girls for show-and-tell with their friends so as to demonstrate their capacity to acquire pictures and be, as Theo suggests, "the shit." Similarly, females may send pictures of themselves to satisfy the males who pursue them as well as acquire positive feedback about their bodies. In both cases, the goal is to gratify the social expectations of fellow peers. In this manner, individuals generate capital in youth culture, which reflects Curnutt's (2012) contention that youth remediate their sexuality through sexting expressly to demonstrate their ability to belong and, by extension, achieve popularity.

Perhaps most importantly, participant narratives indicate that the importance assigned to sexting differs for males and females, particularly within the context of sexting for social gratifications. In my participants' words, males ask for pictures because they are "horny" and their desire to see females naked is purely "human nature." As such, males do not view the significance of sexting, or nudity in general, as highly or as seriously as their female counterparts. In contrast, females may send naked pictures of themselves precisely because they assign undue importance to the request. For them, sexting, picture requests specifically, may indicate that a male is interested in them or "likes" them. Also, as Theo notes, girls may "see some weird connection girl-thing" in males' desire to sext or "be vulnerable" with them when, in reality, males simply want to see females naked.

Tex, the most avid sexter of the group, offers the most telling narrative that speaks to this reality. When contemplating the idea of his future children sexting, he explained that he would not want his daughter to send pictures of herself to boys specifically because she should "respect" her body. Consider the following passage: 
Tex: ...I would not like my daughter to do the same thing if I ever had a daughter. Like, that's your body, respect it. And it's kind of losing respect for your body to show people that "cause that could be sent around and then your body's not going to be as special I guess "cause everyone has seen it."

Interviewer: Ok. So it's no longer private.

Tex: It's like an apple. I mean, if everyone holds that apple it's not going to be as fresh and stuff as if just one person holds it.

Interviewer: So you wouldn't want your daughter to sext?

Tex: No. I would not.

Interviewer: Interesting. So whereas for you, you see it's benefits, you enjoy it, but you wouldn't want your daughter to do it. What about your son?

Tex: I wouldn't want...I'm very sexist when it comes to that.

Interviewer: That's okay.

Tex: I mean, for guys, I don't want him to do it but I feel like it's gonna happen and it's not as big of a deal for the guy to sext as it is for the girl. I mean obviously it takes two of them to do it but I would be more lenient on my son doing it than my daughter doing it.

Interviewer: And explain a little bit why that is. Why do you think it's more, it's deeper, whatever it is for the girl?

Tex: Just because, like, the intentions of the guy are it's a goal to reach and the intentions of the girl is it's...she wants that attention and stuff and for the girl I feel like there's better ways to get attention and the guys, I mean, obviously there's better goals to reach and stuff but, I mean, that's, I feel like in human nature is kind of, like they wanna learn more and their gonna hurt the girl more in that. There's potential to hurt the girl and the guy's not going to get as hurt. So I wouldn't want my daughter to be hurt and have the wrong intentions with that.

Here, the combination of males wanting to learn about females in sexual ways (i.e. what they look like naked) and females wanting to garner attention from males results in females disrespecting and even diminishing the "special"-ness of their bodies. Tex directly acknowledges the increased potential for females to "be hurt" by sexting. Furthermore, he specifies why this is the case by clearly implicating the difference in "intentions" between males and females. Coupled with both male and female narratives on why males ask for and females send naked pictures, Tex's explanation bolsters the idea that sexting is a gendered activity with different implications and consequences for different genders. Importantly, females invest more in the process of sexting (i.e. naked 
pictures) and assign more weight to their actions. Thus, females have more to lose than their male counterparts. Henry furthers this idea:

I think, personally for men, there's less of a consequence because then they just look like dufusses [if they send pictures of their penises to others]. Like, to a girl, they're just gonna be like "this guy's an idiot." But, as we all know, the pornography rating of people on the Internet is men much higher than women so the propensity for a woman to specifically go on a website to find some guy's dick - some idiot in the shower taking a picture of himself in the mirror, like "this is exactly what I want"-is very little. The only people who are gonna see it is another guy that's like "this guy's an asshole." Whereas for women, it's different. It's almost like a predator/prey system that goes on. It's like "oh, yah, I wanna get the hottest girl and show her pictures to everybody and then everybody will know that I got this hot girl" and then it's huge shaming for her so it's not the same thing as a guy.

Henry's "predator/prey" system comes to life in the countless participants' narratives of males working to gain females' trust prior to requesting naked pictures and subsequently showing them off to others. Indeed, my participants only described stories highlighting the "huge shaming" of female peers. Male nudity, in contrast, elicits little more than laughter and possibly shock.

Thus, the motivations that feed sexting for social gratifications are similar to those that feed actual physical intimacy, particularly for young individuals wanting to live up to social expectations engendered in media contexts (see previous paragraphs). The potency of media influence in this context makes sense in light of statistics demonstrating how much time per day youth invest in media (Brown et al., 2009). Indeed, my participants' narratives reflect the social importance of technology generally and the consequential nature of sexting for youth culture specifically.

In contrast, sexting for sexual gratifications manifests in more selfless ways, whereby individuals may use sexting as a form of foreplay to increase the excitement of 
physical relationships. Also, sexting for pleasure can enhance long distance relationships where physical intimacy is difficult to achieve on a daily, weekly, and even monthly basis. This latter type manifests as a more consensual form of sexual exploration. For my participants, sexting for pleasure occurs in sexual relationships where both individuals are aware of the nature of the relationship and want to participate. The nature of sexting for sexual gratifications, then, upholds the positive functional utilities of sexting (e.g. initiate relationships, enhance relational and sexual satisfaction, and gain sexual experience) within intimate relationships previously established by Drouin and Landgraff (2012), Lenhart (2009), and Parker et al. (2013).

Perhaps unsurprisingly, individuals who participate in this form of sexting demonstrate increased awareness of the potential for their experiences to go viral and increased accountability for their actions if they do. Furthermore, this enhanced perception of the reality of privacy within sexting may beget greater acceptance of and resilience toward the social consequences of sexting gone viral. Notably, both males and females who sext for pleasure are typically older and no longer worried about legal consequences like producing and distributing child pornography. However, they also exhibit superior ability to, in Marina's words, "get over it" if their pictures or videos go viral.

Importantly, sexting for sexual gratifications emerges as a positive form of sexting when individuals do so with a full understanding and acceptance of the process and potential consequences of the practice. What is especially problematic is the fact that, according to my participants, young people are not mentally or emotionally capable of comprehending the magnitude of sexting's impact on themselves or others. Regardless, 
participant narratives reveal a high participation rate, thus demonstrating the power welded by social expectations and peer pressure in institutional settings such as middle and high school.

Ultimately, the differences separating these two types of sexting revolve around commitment. In sexting for social gratifications, individuals' actions demonstrate higher commitment to gaining and maintaining social status, prioritizing self-gain over the feelings and experiences of their partners. Furthermore, females who send naked pictures to others do so to gain attention and flattery. In doing so, females boost their self-esteem and use their bodies to attract potential boyfriends. In contrast, sexting for sexual gratifications emphasizes commitment to some form of relationship and the needs of the partner within that relationship. Knowing these differences is crucial for young people today. Specifically, understanding the social pressures that drive sexting for social gratifications may increase both male and female individuals' capacity to resist those pressures or be, as Sally explains below, more confident in their ability to say no:

Sally: ...if I was to go back to high school and be young or in those situations, I think I would handle them differently and from probably a more mature standpoint then what I did.

Interviewer: How would you handle them differently?

Sally: I would probably just say, like, I'd just be blunt and be like "you know, girls deserve to be treated better than being asked for pictures like that and it's really demeaning when you ask a girl for a picture and think that they're just going to send one to you because you don't need it at all (laughs)," you know, or just be like "I'm sorry but I honestly think this whole concept is dumb."

Interviewer: You'd just be honest and up front.

Sally: Yeah instead of being like "no not today" or, you know, because sometimes it's just weird and you don't want to be rude. It goes back to that whole theory. I would just be upfront, like "if you're going to ask me for that, we're probably not going to work out." 
Perhaps the most significant advantage of interviewing young people fresh out of high school is the ability to tap into their reflections regarding their actions during their more formative years. Sally's perceptions recounted above demonstrate her emergence from the pressures of youth culture encapsulated in the institutional setting. Statusincreasing actions, such as sexting to one-up others (males) or gain approval (females), are no longer hallmarks of her social experience or, if they are, manifest in ways no longer framed by caveats of youth culture. Direct and indirect participants (i.e. those who sext versus those who only hear about sexting from others) alike view sexting for social gratifications as "childish" and suggest that their engagement in it was mostly out of "immaturity" or because "everybody" was doing it. However, participant discourse suggests that sexting is "okay" within relationships and has the potential to positively enhance those relationships.

Indeed, the general emergence of two forms of sexting demonstrates the fluid nature of sexting as a communication phenomenon. As such, sexting for sexual gratifications, characterized by mutual participation and consent, emerges as an entirely different category and cannot be contextualized in the same manner as sexting for social gratifications. Subsequently, the self-esteem variable may vary in accordance with type of sexting. For example, my participants repeatedly suggest that individuals with low self-esteem sext in order to feel better about themselves, results that directly contradict prior quantitative research (Gauz \& McGraw, 2011). However, Gauz and McGraw’s (2011) study does not differentiate between different types of sexting, which means the form of sexting that is practiced may impact certain psychological variables (e.g. selfesteem) amongst participants of a given sample and vice versa. 
Participant narratives on the nature of sexting offer insight into young peoples' perceptions of privacy within and outside of relationships in the electronic age. Below, I discuss the implications of discourse regarding the nature of privacy in the context of sexting. Because relationships of some form house sexting experiences and expectations of privacy, I examine the interrelations amongst privacy, sexting, and relationships together.

\section{Privacy, sexting, and relationships: Expectations versus reality}

Analysis of themes regarding my participants' narratives on privacy in the context of sexting indicates that young people have unrealistic notions of privacy in the electronic age. This is especially apparent in the existence of two conflicting facts. First, the majority of my participants consider sexting to be a form of private communication. Secondly, they assert this even after recalling numerous instances where sexting goes viral without the permission of the original senders. Importantly, participants suggest that sexting within various types of relationships is more comfortable and justifiable because trust is established and involved. Again, these themes emerge in light of stories of individuals breaking up over one of the partners showing off or forwarding naked pictures of the other partner. Furthermore, the theme of young people having naïve notions of trust is constantly explicated and reiterated by both direct and indirect participants throughout their narratives.

Participant discourse validating sexting within relationships conjures up more traditional notions of the appropriateness of engaging in sexual relations with a committed partner as opposed to outside of the relationship context. The fact that sexting is more justifiable when it is done between two people within a relationship manifests in 
the use of social shaming that Fran references, whereby girls are more likely to be called names if they are sexting random guys. Additionally, male discourse emphasizing the "girlfriends off limits" mantra further validates the assumed safety of sexting within relationships, even if that safety cannot be fully guaranteed.

Importantly, both themes of comfort and justification within relationships reflect the potential impacts sexting may have on relationships. By nature, individuals' feelings regarding their actions predict positive outcomes. Indeed, direct participants who described their sexual relationships as mutual and their partners as trustworthy also cited the positive impacts of sexting. As discussed previously, sexting for sexual gratifications is typically a mutual endeavor with both partners engaging in various forms of sexual expression to satisfy each other's sexual desires. For example, all of my direct participants recall sexting within intimate relationships because it is "exciting" or "fun." In these instances, sexting enhanced interpersonal relationships in positive ways, such as giving participants a better idea of what was sexually pleasing to their partners. Furthermore, direct participants describe sexting as both a form of foreplay leading into actual physical intimacy and an instrument of sexual expression without some form of physical manifestation (e.g. orgasm). Speaking to the latter function, George, Marina, Olivia, and James have sexted within long-distance relationships or ones in which time spent together in-person was minimal. These individuals suggest that sexting allowed them to express their sexual desires for their partner without being physically intimate and thus combatted some of the frustrations characteristic of long-distance relationships. In contrast, sexting can negatively impact interpersonal relationships when sexts go viral. This is particularly the case within the context of sexting for social 
gratifications where individuals' desires to seem cool and popular may trump their inclination to protect the privacy of others. Indeed, Milo's earlier contention that males showing off pictures of their girlfriends often led to break-ups and "drama" in high school demonstrates the potential for sexting to end relationships. Moreover, sexting has the potential to jeopardize friendships, especially if direct participants have friends who disagree with the practice. It is important to note, however, that even as sexting for social gratifications can ruin the relationships between sexting partners, it can simultaneously enhance the rapport individuals have with their fellow peers with whom they share sexting content.

Finally, the role of sexting as a potential relationship starter is demonstrative of its grounding in the relationship context. As previously discussed, individuals (mostly males) may mislead their partners into thinking sexting will precede an imminent relationship so as to acquire naked pictures or videos from them. Partners (mostly females) will then acquiesce to these individuals' requests in the hopes of starting said relationship. Regardless of whether or not the promised relationship is fulfilled, the use of sexting as a form of sexual manipulation speaks to the nature of young peoples' expectations regarding sex and relationships. In Olivia's case, sexting too soon can perpetuate relationships where sex, and not companionship or love, is the sole focus. In this regard, sexting with the hopes of beginning a relationship is reminiscent of individuals engaging in physical sexual acts to achieve the same end.

Taken together, themes of comfort and justification within relationships do not mix well with the overarching theme of naïve notions of trust. This combination of discourse suggest that younger people lack realistic expectations of what will and will not 
remain private between two partners within a relationship. These assertions contrast Van Manen's (2010) notions of ubiquitous Momus technology-use destroying “inner values of the private" (p. p. 1024) because my participants consider their sexts to be private and feel most comfortable when sexting with people they trust. In this sense, it appears that my participants maintain traditional expectations of privacy but live and act in an age where that privacy is difficult to control. This reality suggests that young people, in particular, are either not fully aware of the nature of the medium they are using to sext or are too impulsive in their decisions to trust their partners. Specifically, their actions do not demonstrate an understanding of two things: privacy has shrunken considerably in light of American society's increased dependence on satellite-based communications systems and young people may prioritize personal status over the feelings of others, especially during their more formative years.

Additionally, privacy management is not occurring within or outside of relationships in the context of sexting. Consistent lack of safeguards and efficacy of the few that are employed prove this. Considered within Petronio and Durham's (2008) communication privacy management, youth sexting exhibits high amounts of boundary turbulence precisely because the protection of private information is expected but NOT adhered to. This is particularly evident in participant narratives recounting situations where males and females alike experience their pictures and videos going viral or being showed to others without their consent. Boundary turbulence manifests in various ways, including break-ups between couples over pictures gone viral and individuals attempting to navigate social backlash when this occurs. Importantly, advancements to cell phone technology naturally increase the boundary permeability, or "amount of access or 
openness within a privacy boundary" (Petronio \& Durham, 2008, p. 315), of sharing sexual information via sexting.

Despite this ongoing clash between what is expected and what is happening, privacy rules appear under-developed within the context of sexting. The "girlfriends off limits" mantra espoused by both direct and indirect participants in this study stands as the sole exception to young peoples' sharing of sexts. Perhaps, then, sexting not going viral is the ultimate sign of true love and devotion, as kissing and telling occurs when individuals do not feel obligated nor compelled to protect the privacy of their sexting partners. Notably, participant narratives suggest that ex-girlfriends are not given the same consideration.

However, the emergence of a "trust" rule based on comfort level develops independent of relationship status, as participants invoke this rule even with people they are interested in but know little about. The emergence of Lenhart's (2009) third category (sexting between people where at least one person hopes to be in a relationship with the other) in this study implicates a possible social compulsion to sext. For example, female participants like Olivia and Anne described sexting to initiate and maintain a sexual or romantic relationship with others. Similarly, male participants like Theo, Cecil, and Milo previously suggested that girls send pictures to "get" or "keep" guys. Taken together, these experiences and perspectives may validate research suggesting that attachment anxiety may predict a greater likelihood to sext for certain individuals based on how they perceive and cater to social expectations regarding sex and sexting (Weisskirch \& Delevi, 2011). For these individuals, culturally engendered expectations regarding sex and sexuality may trump contextual criteria based on trust within relationships. 
Furthermore, my participants' narratives expand Lenhart's (2009) 3-category typology of sexting contexts (i.e. between partners; between partners and shared with others; between people where at least one person hopes to be in a relationship with the other) to include at least two more: sexting between acquaintances and sexting between "friends with benefits." Both of these categories demonstrate the increased sharing of socalled private information with others prior to or completely outside of serious relationship contexts. Here, motivational criteria may be at play (e.g. wanting to see girls naked or wanting attention from the opposite sex). However, because these motivations emerge as culturally established (e.g. pervasiveness of hypersexual media representations), it is illogical to separate motivational and cultural criteria.

Thus, the results of this study extend CPM theory by exploring the disclosure of sexual information within a particular, as-of-yet unexplored terrain. Participant narratives regarding privacy allow for a preliminary understanding of how youth share and regulate the sharing of their sexual displays (e.g. naked pictures and videos). Notably, privacy rules manifest as under-developed, with motivational criteria (perhaps perpetuated by cultural criteria) trumping both contextual and accurate assessments of risk-benefit ratio criteria. The apparent under-development and lack of implementation of privacy rules described by my participants demonstrates young peoples' need for increased education on the consequences of prematurely disclosing sexual information via sexting.

\section{Youth sexting: Conclusions and practical applications.}

As demonstrated by the results of two different types of sexting, the positive or negative impact of sexting on interpersonal relationships varies based on individuals' 
motivations for engaging in the practice. Participant narratives show that sexting for sexual gratifications enhances intimate relationships, especially when distance is involved. However, sexting for social gratifications, like other activities that individuals engage in to satisfy social pressures, warrants deeper consideration of the nature of youth culture today. As expected, young people are exploring their sexuality and using technology, such as cell phones, SMS, and picture/video messaging, to facilitate those explorations. Importantly, though, research suggests young people are exploring their sexuality in potentially harmful ways (Dake et al., 2012; Farber et al., 2012; Ferguson, 2011; Hua, 2012; Reyns et al., 2013; Walker et al., 2011, 2013; Wolak et al., 2012), a proposition that is at least partially corroborated by my participants' narratives regarding the social consequences (e.g. social shaming and emotional hurt) of sexting.

Furthermore, my participants' narratives regarding privacy management begin to uncover how and why youth reveal or conceal sexual information in the context of sexting. According to my participants, social norms regarding sex and sexuality appear to be generated and maintained in unhealthy ways via media representations and peer pressure. Specifically, my respondents repeatedly implicate low self-esteem and the desire to be "cool" or "popular" as motivators for sexting for social gratifications. Theoretically speaking, then, attacking the culprits of low self-esteem amongst young people through education and open discussion would begin the process of discouraging the premature sexualization of self and others. Ideally, these efforts would be coupled with continued pressure on media organizations to change the hypersexualized nature of media representations. 
Thus, those concerned must ask several key questions: Why are levels of selfesteem among youth so low? How can manifestations of "guy code" as well as female notions of self-worth be rewired to reflect greater respect for self and others? Why are understandings of privacy in the age of technology so far behind the times? How can we educate young individuals on how to practice safe sexting? Though oftentimes unprovoked, participant narratives offer a potential solution to the youth sexting dilemma: Talking.

Results in practice: Sexting education. Taken together, the key elements that emerged from my participants' narratives demonstrate a clear need for in-school and inhome education on both the nature of sexting as a practice and the nature of privacy over mediums like cell phones. This lack of understanding the legal consequences of sexting may be due to the fact that only Ariel, 19, recalls learning about sexting consequences in middle school:

The first thing I remember was $7^{\text {th }}$ grade and we had to have some people come into the middle school and talk to us because people were sending around pictures of people. I don't actually remember who all it was, but I remember they had to talk about it and the police were there and they were like 'hey we wanna let you guys know that this is a criminal act. You know, it's child pornography to be sending this around.'

Ariel's testimony is rare. While two girls remember briefly hearing high school teachers tell students not to sext, the remaining participants do not recall any form of school education on the topic and suggest instead that it was something "ignored" by faculty members rather than confronted. Furthermore, only three of the girls involved in this study recall talking about sexting with their parents. 
Ultimately, the perspectives included here demonstrate an absence of meaningful and effective education on the potential social and legal consequences of youth sexting. This is particularly alarming given the same peoples' perceptions of the ubiquity of the practice, especially among teenagers. Here, education on the subject is far outpaced by the activity itself, leading to a significant gap in teenager awareness of the laws involved in its regulation. For example, when asked if she thought young people knew about child pornography laws in relation to sexting, Sara responded, "I think they may have heard it cross paths at some point, whether they heard it on TV or news from other stories. But I don't think it's something that's constantly in their mind when they're receiving it, like 'oh my gosh. I have porn on my phone,' or whatever.” Similarly, Anne asserts that young people need to know how sexting can impact others' lives, especially since her and her boyfriend engaged in the practice ignorant of the fact that he "could go to jail or get penalized to be a pedophile." Furthermore, Fred suggests that young people who sext may do so without adequate understanding of what could happen with their pictures:

I think that people just need to realize maybe that...do they know what they're gonna get themselves into? Do they know what could happen? I mean, there's pros and cons for every decision you make but do you really know what's gonna happen with that photo? So I guess it really just comes down to, is it really a good idea? Is it really worth doing in the end?

This passage is reminiscent of my participants' perspectives on privacy in the electronic age. As discussed previously, respondents' descriptions of the ambiguity of privacy in the context of sexting do not appear to impact direct participants' decisions to sext. In the context of sexting for social gratifications, in particular, individuals may send pictures 
to requesting others without truly understanding the impact of their actions on

themselves or others or while falsely expecting those pictures to remain private.

This lack of sexting education in schools and families does not go unnoticed. A majority of my participants said that educating kids about the consequences of their actions, specifically by talking about sexting in schools, was necessary:

I'd take the money you would use on prosecuting [kids who sext] and educate some kids. Schools have sex-ed classes, and schools gotta adapt to the times. Sex-ed programs are so out of date, and they are already so late in kids' education that most of them have already had sex. Our teaching systems are way too far behind our culture, and I think the only way is through an education program. It's like the DARE program. Have a cop go in there that's certified and scare them. They're kids. Teach them, but also show them the real world consequences. George, 22

Fran echoes these contentions in the following excerpt:

Fran: We should educate our kids better.

Interviewer: Ok. About sexting specifically or life in general?

Fran: Yeah. Life in general, sexting, and then just the whole topic around sex "cause people are always so closed-minded, like "wait "til marriage" or "we're not gonna talk about it."

Indeed, the majority of participants in this study suggest that talking to young people about the consequences of sexting is needed and would be more effective then simply punishing them.

The fact that my participants do not recall knowing the legal consequences of sexting while in middle or high school demonstrates an important disconnect between the implementation and communication of social policies amongst those most impacted by them. Teenagers are sexting without knowing they can be prosecuted for their actions. Furthermore, teenagers that are sexting with so-called "naïve" notions of trust may be aware of the potential legal consequences but cannot imagine their actions escaping the 
confines of their relationship. Thus, current social policies do not appear to align with realistic understandings of youth culture.

Most importantly, my analysis of the results of this study validates the need for serious and open discussions regarding both forms of sexting in manners similar to those proposed by Dake et al. (2012), Theodore (2011), and the adolescent health experts in Walker et al.'s (2011) study. Instead of encouraging students to simply abstain from sexting, as is traditionally done with sex as well, parents, educators, and youth mentors should focus their discussions on the nature of sexting for social gratifications to adequately demystify the practice. In practice, these discussions should distinguish between both types of sexting (social versus sexual gratifications), encourage awareness of the motivations driving sexting for social gratifications as well as the legal and social consequences that may follow sexting gone viral. Including the positive functions of sexting for sexual gratifications within intimate relationships in these discussions will enhance young individuals' abilities to differentiate between both forms and feel empowered in their decisions to sext responsibly if they so choose. Ideally, educational materials (i.e. presentations, pamphlets, etc.) regarding sexting would use the language of its target audience as well as real-life examples of pre, during, and post-sexting talk to make the practice and its potential consequences more relatable to the experiences of young people.

Concretely, sexting education materials may take a number of different forms. George's suggestion to incorporate DARE-like classes into youth curricula, especially in elementary and middle schools, could be a useful foundation for continuing sexting education into high school. Sexting classes could involve role-playing of typical sexting 
scenarios and ways to decline participation. Within high schools, in-class

presentations and school assemblies could utilize the perspectives and performances of young people from the latter end of the youth spectrum (e.g. 18-25) who sext or have sexted to present a more realistic and relatable picture of youth sexting.

Importantly, my participant narratives demonstrate concrete connections between media representations of sex and sexuality, peer pressure, and sexting for social gratifications. Sexual ethics, in general and specific to sexual communication via technology, appear relatively absent in the narratives of my participants. As such, sexting classes must include round-table discussions of the importance of respecting others by respecting their bodies, including how to establish and communicate personal boundaries as well as respect the boundaries of others.

The interrelations between what is seen in the media, how young people are engaging with each other in sexual ways via new technologies, and the harmful consequences of sexting for social gratifications demand more extensive in-class and inhome discussions regarding the negative impacts of self and other-objectification. Developing curricula that addresses these connections and allow young people to form and discuss associations they have seen or developed on their own is a key step in allowing individuals to formulate their own opinions and corresponding actions. In this vein, sexting classes should expose power dynamics and abuses as experienced by young people to help them construct their own ways of dealing with peer pressure. Walker et al.'s (2013) recommendation of using the "bystander approach," whereby young men learn to recognize and curb violence against women, is especially salient here, as participant narratives across cultures implicate the potency of peer pressure in promoting 
self and other objectification. However, strategies specific to the "bystander approach" should not be exclusive to males, as both young men and women partake in forwarding sexts and discussing them with their peers.

Finally, researchers should develop speaking guides for parents to use within inhome discussions. These guides should include ample information regarding both forms of sexting and their potential consequences. Notably, parent materials should emphasize both the benefits and harms of sexting and include speaking scripts or starters that do not frame sexting in an abstinence-only lens. Instead, sexting scripts should reflect parents' understandings of the social pressures involved in youth sexting coupled with cues that encourage children to talk to parents about their sexting experiences. Ultimately, the goals of sexting education must prioritize encouraging open discussions between educators, parents, policy makers, and youth to forego harmful one-size-fits-all social policies to deal with youth sexting.

Limitations. The limitations of the present study are typical of qualitative research. Twenty participants contributed their perspectives to this project, allowing for a more in-depth examination of these individuals' sexting experiences. Accordingly, the sexting picture generated from these narratives and subsequent thematic data are rich in concentration but limited in scope. Thus, my results are not generalizable beyond the members of my sample.

Furthermore, all of the respondents self-identify as white Caucasians, which demonstrates a need for exploring sexting from the perspectives of a more racially diverse sample. Also, just one of the participants in this study is homosexual. While no differences in sexting experiences emerged based on sexual orientation, increasing the 
SEXTING UNLEASHED

amount of perspectives of individuals from all walks of life would better enhance academic and social understandings of the phenomenon. Fortunately, these limitations are prospective opportunities for expanding the sexting knowledge base. From here, future research may take multiple forms.

Future research. Given my participants' expansion of both media and academiaespoused definitions of sexting, future studies should seek to test and standardize this definition if it proves representative of the experiences of larger samples. Additionally, future research should explore both forms of sexting separately, combined, and more indepth utilizing both quantitative and qualitative methodologies. In general, more qualitative research is needed among populations further down the youth spectrum to see if younger individuals corroborate and/or negate the reflections included in this project regarding such themes as the perceived ubiquity of sexting, the existence of social shaming, and the lack of education on sexting within schools and homes to name a few. Furthermore, investigating younger populations may shed light on whether or not sexting has leaked into elementary school and social pressures similar to those explicated here are at play.

Researchers should continue to examine perceptions of social expectations regarding sex and sexting amongst young people. These types of studies should focus on the role of various social pressures on individuals during their formative years and see if differences in gender exist. For example, the results of this project demonstrate that both genders are pressured to sext and predict that girls are more likely to feel pressure to send pictures of themselves to others while boys are more likely to feel pressure to ask for and show off pictures. Furthermore, true critical assumptions emerge from this project. 
Specifically, younger people are simultaneously encouraged to recklessly display their bodies for social evaluation and punished for these actions. Also, sexual politics drive the process of sexting for social gratifications at the expense of both sexes. Research focusing on these themes is critical for better understanding and working with the members of youth culture today. Clearly, gender blaming (e.g. males are preying on females and females are only victims) undercuts the sexual agency of all genders and will only subvert attempts to educate on the positive or negative consequences of sexting.

Lastly, my results demonstrate a crucial need for more up-to-date and engaging sexting education. Researchers should utilize the perspectives of young people, in conjunction with the results of studies such as this, to craft educational materials and implement programs on sexting. These endeavors should open forums on youth sexting within various institutions to shed light on the potential social and legal consequences of not protecting self and others' private information. Perhaps more importantly, these forums should explore the exploitative nature of youth culture and create strategies that encourage respect for others and enhance individuals' abilities to combat negative social pressures.

By collaborating with young people to construct a more holistic picture of youth sexting, I was able to generate new insights into the phenomenon. Specifically, the motivations for and importance assigned to sexting for social gratifications are gendered according to my participants' experiences. Also, the two forms of sexting (social versus sexual) that emerged from my participants' narratives underscore the importance of exploring the nuances of various types of sexual communication like sexting prior to developing both educational materials and social policy on these practices. As such, this 
project is foundational in opening the door to future discussions and research on sexting. Ultimately, pursuing and further clarifying the diverse foci offered here may aid in evaluating and changing the harmful nature of youth's current socio-cultural landscape. In turn, we may collectively mitigate the emotional bullying experienced by the realworld Dina Van Cleave's of any gender, race, and age, as well as encourage more positive forms of communication, sexual and otherwise. 


\section{References}

Ahmed, M. (2013, January 2). Sexting fears over app that causes photo to self destruct in seconds. The London Times. Retrieved from http://www.thetimes.co.uk/.

Bailey, J., \& Hanna, M. (2011). The gendered dimensions of sexting: Assessing the applicability of Canada's Child Pornography Provision. The Canadian Journal of Women and the Law, 23, 405-441.

Barkacs, L., \& Barkacs, C. (2010). Do you think I'm sexty? Minors and sexting: Teenage fad or child pornography? Journal of Legal, Ethical and Regulatory Issues, 13(2), 23-31.

Barry, E., \& Harris, E. (2012, October 20). Sexting scandal: Elite private school kids in video wildfire. The Herald Sun. Retrieved from http://www.heraldsun.com/.

Becker, H. (2001). The epistemology of qualitative research. In R. Emerson, Contemporary Field Research ( ${ }^{\text {nd }}$ Ed.). (pp. 317-330). Prospect Heights, IL: Waveland Press.

Bertrand, H. R. (2006). Research methods in anthropology: Qualitative and quantitative approaches. Lanham, MD: AltaMira Press.

Blumer, H. (1969). The methodological position of symbolic interactionism. In H. Blumer, Symbolic Interactionism (pp. 1-60). Englewood Cliffs, NJ: Prentice Hall.

Bond, E. (2011). The mobile phone = bike shed? Children, sex, and mobile phones. New Media \& Society, 13, 587-604.

Bosch, T. (2011). Young women and 'technologies of the self': Social networking and sexualities. A genda: Empowering women for gender equity, 25(4), 75-86.

Brown, J. D., Keller, S., \& Stern, S. (2009). Sex, sexuality, sexting, and sex-ed: Adolescents and the media. The Prevention Researcher, 16(4), 12-16.

Child, J. T. \& Agyeman-Budu, E. A. (2010). Blogging privacy management rule development: The impact of self-monitoring skills, concern for appropriateness, and blogging frequency. Computers in Human Behavior, 26, 957-963.

Cumming, P. E. (2009). Children's rights, voices, technology, sexuality. Paper given at 'Youth, Sexuality, Technology', a joint session of the Association for Research in Cultures of Young People (ARCYP) and the Association of Canadian College and University Teachers of English (ACCUTE) at the Congress of the Humanities and Social Sciences, Carleton University, Ottawa. 26 May. Available at: http://www.yorku.ca/cummingp/research.html. 
Curnutt, H. (2012). Flashing your phone: Sexting and the remediation of teenage sexuality. Communication Quarterly, 60(3), 353-369.

Dake, J. A., Price, J. H., Maziarz, L., \& Ward, B. (2012). Prevalence and correlates of sexting behavior in adolescents. A merican Journal of Sexuality Education, 7(1), $1-15$.

Davis, C. S., Gallardo, H. L., \& Lachlan, K. A. (2010). Straight talk about communication research methods. Dubuque, IA: Kendall Hunt.

Draper, N. (2012). Is your teen at risk? Discourses of adolescent sexting in United States television news. Journal of Children and Media, 6(2), 221-236.

Drouin, M \& Landgraff, C. (2012). Texting, sexting, and attachment in college students' romantic relationships. Computers in Human Behavior, 28(2), 444-449.

Dvorak, P. (2013, February 5). Teenage quest for fame spells trouble. The Washington Post. Retrieved from http://www.washingtonpost.com.

Farber, B. A., Shafron, G., Hamadani, J., Wald, E., \& Nitzburg, G. (2012). Children, technology, problems, and preferences. Journal of Clinical Psychology: In Session, 68(11), 1225-1229.

Ferguson, C. J. (2011). Sexting behaviors among young Hispanic women: Incidence and association with other high-risk sexual behaviors. Psychiatric Quarterly, 82(3), 239-243.

Emerson, R. M., Fretz, R. I., \& Shaw, L. L. (1995). Writing ethnographic fieldnotes. Chicago, IL: The University of Chicago Press.

Gauz, J. and McGraw, J. (2011). Am I "sexty" enough? Self-esteem as a predictor of sexting behavior. Paper presented at the meeting of NCA, Orlando, FL.

Gordon-Messer, D., Bauermeister, J. A., Grodzinski, A., \& Zimmerman, M. (2013). Sexting among young adults. Journal of Adolescent Health, 52, 301-306.

Guba, E. G. \& Lincoln, Y. S. (1982). Epistemological and methodological bases of naturalistic inquiry. Educational and Technology Journal, 30(4), 233-252.

Hasinoff, A. (2010). No right to sext? A critical examination of media and legal debates about teenage girls' sexual agency in the digital age. (Unpublished doctoral dissertation). University of Illinois at Urbana-Champaign, Urbana.

Hasinoff, A. A. (2012). Sexting as media production: Rethinking social media and sexuality. New Media \& Society, 0(0), 1-17. 
Hua, L. L. (2012). Sexting and social media in today's adolescent: Peer norms, problems, and provider responsibility. The Brown University Child and Adolescent Behavior Newsletter, 28(4), 4-6.

Hudson, H. (2011). Factors affecting sexting behaviors among selected undergraduate students. (Unpublished doctoral dissertation). Southern Illinois University, Carbondale.

Hurdle, J. (2008). US judge rules for teen girls in 'sexting case.' Electronic document. Retrieved from http://www.reuters.com/article/mediaNews/idUSN.

Karaian, L. (2012). Lolita speaks: 'Sexting,' teenage girls and the law. Crime, Media, Culture, 8(1), 57-73.

Kiesbye, S. (2011). Sexting. Greenhaven Press.

Lenhart, A. (2009). Teens and mobile phones over the past five years: Pew Internet looks back. Pew Internet and A merican Life Project. Retrieved from http://authoring.pewinternet.org/reports/2009/14-teens-and-mobile-phones-datamemo.aspx

Lithwick, D. (2009, February 23). Teens, nude photos and the law: Ask yourself: Should the police be involved when tipsy teen girls e-mail their boyfriends naughty Valentine's Day pictures? Newsweek, 153(8), 18-19.

Lowry, P. B., Cao, J., \& Everard, A. (2011). Privacy concerns versus desire for interpersonal awareness in driving the use of self-disclosure technologies: The case of instant messaging in two cultures. Journal of Management Information Systems, 27(4), 163-200.

Luborsky, M. R. (1994). The identification and analysis of themes and patterns. In J. F. Gubrium \& A. Sankar (Eds.), (2004), Qualitative methods in aging research (pp. 189-210). Thousand Oaks, CA: Sage Publications.

Lumby, C. \& Funnell, N. (2011). Between heat and light: The opportunity in moral panics. Crime, Media, Culture, 7(3), 277-291.

Metzger, M. J. (2007). Communication privacy management in electronic commerce. Journal of Computer-Mediated Communication, 12, 1-27.

Moody Independent (Producer). (2012). Sexting in suburbia [Made for TV movie]. Available from the Lifetime Network.

National Campaign to Prevent Teen and Unplanned Pregnancy (2008) Sex and Tech: Results from a Nationally Representative Survey of Teens and Young Adults. 
Available at: http://www.thenationalcampaign.org/sextech/

Oksman, V. \& Turtiainen, T. (2004). Mobile communication as a social stage: Meanings of mobile communication in everyday life among teenagers in Finland. New Media \& Society, 6(3), 319-339.

Parker, T. S., Blackburn, K. M., Perry, M. S., \& Hawks, J. M. (2013). Sexting as an intervention: Relationship satisfaction and motivation considerations. The A merican Journal of Family Therapy, 41, 1-12.

Patton, M. Q. (2002). Qualitative research and evaluation methods ( ${ }^{\text {rd }}$ Ed.). Thousand Oaks, CA: Sage Publications.

Petronio, S. \& Durham, W. T. (2008). Communication privacy management theory: Significance for interpersonal communication. In L.A. Baxter and D.O. Braithwaite (Eds.), Engaging theories in interpersonal communication: Multiple perspectives (pp. 309-322). Thousand Oaks, CA: Sage Publications.

Reyns, B. W., Burek, M. W., Henson, B., \& Fisher, B. S. (2013). The unintended consequences of digital technology: Exploring the relationship between sexting and cybervictimization. Journal of Crime and Justice, 36(1), 1-17.

Silverman, D. (2006). Interpreting qualitative data: Methods for analyzing talk, text and interaction ( $2^{\text {nd }}$ Ed.). Thousand Oaks, CA: Sage Publications.

Stone, N. (2011). The sexting quagmire: Criminal justice responses to adolescents' electronic transmission of indecent images in the UK and the USA. Youth Justice, 11(3), 266-281.

Strassberg, D. S., McKinnon, R. K., Sustaita, M. A., \& Rullo, J. (2013). Sexting by high school students: An exploratory and descriptive study. A rchives of Sexual Behavior, 42, 15-21.

Theodore, S. (2011). Developments in the law: Technology and social media in the $21^{\text {st }}$ Century: Solutions for minimizing the risk to children: An integrated response to sexting: Utilization of parents and schools in deterrence. Journal of Contemporary Health Law and Policy, 27, 1-33.

Thompson, L. \& Cupples, J. (2008). Seen and not heard? Text messaging and digital sociality. Social \& Cultural Geography, 9(1), 95-107.

Thulin, E. \& Vilhelmson, B. (2007). Mobiles everywhere: Youth, the mobile phone, and changes in everyday practice. Nordic Journal of Youth Research, 15(3), 235-253.

Thurlow, C. (2003). Teenagers in communication, teenagers on communication. Journal 
of Language and Social Psychology, 22(1), 50-57.

Thurlow, C. \& McKay, S. (2003). Profiling "new" communication technologies in adolescence. Journal of Language and Social Psychology, 22(1), 94-103.

Van Manen, M. (2010). The pedagogy of Momus technologies: Facebook, privacy, and online intimacy. Qualitative Health Research, 20(8), 1023-1032.

Walker, S., Sanci, L., \& Temple-Smith, M. (2011). Sexting and young people: Expert's views Youth Studies A ustralia, 30(4), 8-16.

Walker, S., Sanci, L., \& Temple-Smith, M. (2013). Sexting: Young women's and men's views on its nature and origins. Journal of Adolescent Health, 52, 697-701.

Waters, S. \& Ackerman, J. (2011). Exploring privacy management on Facebook: Motivations and perceived consequences of voluntary disclosure. Journal of Computer-Mediated Communication, 17, 101-115.

Weiss, R. \& Samenow, C. (2010). Smart phones, social networking, sexting and problematic sexual behaviors-A call for research. Sexual Addiction \& Compulsivity, 17, 241-246.

Weisskirch, R. and Delevi, R. (2011). "Sexting" and adult romantic attachment. Computers in Human Behavior, 27, 1697-1701.

Wengraf, T. (2011). Qualitative research interviewing. Thousand Oaks, CA: Sage Publications.

Wolak, J. D., Finkelhor, D., \& Mitchell, K. J. (2012). How often are teens arrested for sexting?: Data from a national sample of police cases. Pediatrics, 129(1), 4-12.

Wolf, T. (2000). Hooking Up. New York: Farrar Straus Giroux.

Wortham, J. (2013, February, 9). A growing app lets you see it, then you don't. The New York Times. Retrieved from http://www.nytimes.com.

Wysocki, D. K. and Childers, C. D. (2011). "Let my fingers do the talking": Sexting and infidelity in cyberspace. Sexuality \& Culture, 15, 217-239.

Yoon, K. (2006). Local sociality in young people's mobile communications: A Korean case study. Childhood, 13(2), 155-174. 
Appendix A

Table 1: Participant Demographics

\begin{tabular}{|c|c|c|c|c|c|}
\hline $\begin{array}{c}\text { Participant } \\
\#\end{array}$ & Code Name & Gender & Age & Work Status & Birth State \\
\hline & & & & & \\
\hline 1 & Anne & $\mathrm{F}$ & 19 & College Student & $\mathrm{OR}$ \\
\hline 2 & Ariel & $\mathrm{F}$ & 19 & College Student & OR \\
\hline 3 & Cecil & $\mathrm{M}$ & 20 & College Student & OR \\
\hline 4 & Fran & $\mathrm{F}$ & 21 & College Student & OR \\
\hline 5 & Fred & $\mathrm{M}$ & 24 & Hospitality & OR \\
\hline 6 & George & $\mathrm{M}$ & 22 & Retail Sales Rep & NM \\
\hline 7 & Henry & $\mathrm{M}$ & 24 & College Student & OR \\
\hline 8 & James & $\mathrm{M}$ & 20 & College Student & SD \\
\hline 9 & Lance & $\mathrm{M}$ & 19 & College Student & OR \\
\hline 10 & Marina & $\mathrm{F}$ & 21 & College Student & OR \\
\hline 11 & Meg & $\mathrm{F}$ & 22 & College Student & $\mathrm{MO}$ \\
\hline 12 & Milo & $\mathrm{M}$ & 18 & College Student & OR \\
\hline 13 & Olivia & $\mathrm{F}$ & 24 & Graduate School & OR \\
\hline 14 & Phil & $\mathrm{M}$ & 20 & College Student & OR \\
\hline 15 & Rose & $\mathrm{F}$ & 18 & College Student & OR \\
\hline 16 & Sally & $\mathrm{F}$ & 20 & Trade School & OR \\
\hline 17 & Sara & $\mathrm{F}$ & 19 & High School Student & OR \\
\hline 18 & Sophia & $\mathrm{F}$ & 25 & College Student & OR \\
\hline 19 & Tex & $\mathrm{M}$ & 20 & College Student & OR \\
\hline 20 & Theo & $\mathrm{M}$ & 20 & College Student & OR \\
\hline
\end{tabular}




\section{Appendix B \\ Recruitment Script}

Recruitment Script: To use via phone, in person, or over e-mail

"Hello

I am calling/writing/visiting to ask you if you would be willing to participate in a research study that I am conducting for my Master's Thesis. I am interested in your experiences with cell phones and sexting. You would participate in interviews and focus groups, each lasting 30 minutes or longer. Would you like to take part in my study? (If "yes," I will take down individuals' contact information so that I can set up research times with them in the future). Thank you!"

Snowball sampling script: For initial participants to use to recruit friends

"Hey

I am taking part in a study on cell phones and sexting. We need more participants, though, and I know that you could contribute to the study because of your age and experience with sexting. You would participate in interviews and focus groups with me and some of our other friends. Would you like to take part in this study? (The recruiter would then take down the new recruit's contact information and send it to me). Thank you! Jessie, the lead researcher, will get in touch with you to set up research times." 


\section{Appendix C Interview Protocol}

Introduction: Used as an icebreaker for participants.

"Go ahead and have a seat (gesture to chair). How are things going with you in (whatever context is relevant for them; work, school, baseball, volleyball, etc.)? Very cool. Well, this interview should be lots of fun (mildly sarcastic tone). No difficult questions, I'm just curious about your experiences with sexting. Answer however you want, all I ask for is honesty."

Question 1: Used first with all participants to induce narrative on first experiences with sexting.

"Can you please tell me about your first experience of sexting via cell phones."

Complementary questions: These will come from the discourse that emerges during the interview. Some potential firestarter-type questions that I may use if certain aspects of sexting are not addressed are listed below. Interview questions (IQs) are arranged in terms of the research question (RQs) they are constructed to address. This list is not exhaustive as I cannot anticipate the full range of probing questions I will need.

\section{RQ1) What is the nature of the youth sexting experience?}

IQ1: "What is sexting to you? Like, how would you define it based on your experiences with it?"

IQ2: "How often do you sext?" "How long do you sext when you sext?"

IQ3: "Why do you sext?"

IQ4: "Do you think there are differences in sexting based on gender? Like, do girls sext differently than guys or for different reasons?"

IQ5: "What about your observations of other people sexting?"

IQ6: "How do social responses to sexting fit with your experiences of sexting? (e.g. what parents, legislators, authority figures think about sexting)."

IQ7: "Are there any benefits to sexting?"

IQ8: "How do you feel about some of the consequences of sexting?"

IQ9: "Please describe your experiences with sexting via cell phones now. Are these different from when you were younger?" 
RQ2) What is the youth perspective on privacy in the context of sexting?

IQ1: "What is private information to you?"

IQ2: "Do you think sexting is private communication?"

IQ3: "What about issues of privacy? How come you/others sext if it can be spread to lots of other people?"

IQ4: "Given the potential legal consequences, like going to jail or having to register as a sex offender, why do you/others sext?"

\section{RQ3) How does sexting manifest in interpersonal relationships?}

IQ1: "Tell me about a time when you sexted your significant other."

IQ2: "Do you sext in your current relationship? Have you in past relationships? How does that work?"

Note: It is not possible to specify which of these questions will be used per interview or in what order, as their use will be dictated solely by the nature of the interview and how it is going. 
Appendix D

Informed Consent

Hello! , 2013

With your help, I would like to conduct communication research among various individuals to satisfy the research component of my Master's Thesis at Portland State University. I will conduct this study under the close supervision of my thesis advisor, a professor at PSU.

The purpose of this research is to explore the use of cell phones for various forms of communication, specifically sexting. Participants in this study will be asked to discuss their thoughts on mobile communication issues in both individual interviews and focus groups with other participants. All interviews and focus groups will be audio-recorded.

There are no foreseeable risks of any kind that could be incurred by participating in this research. However, the benefits of such will involve expanding present-day knowledge of digital communication more broadly and sexting specifically.

Your involvement in this research is completely voluntary, and refusal to participate will have no negative repercussions nor will it affect your relationship to Portland State University or any relevant department. Also, you may discontinue participation at any time without consequences. In short, your participation in this research would be very much appreciated, but whether or not you would like to participate is completely up to you.

Furthermore, your participation will be kept completely confidential in both research and within the written project itself. I will keep and protect all information (interview and focus group audios, etc.) obtained during my data collection. Participants will choose their own "Code Name" to use within the written project in lieu of their names. All information will not be disseminated to others in any way without your acquired consent.

Once research is completed, I will be available to discuss the end results of my work and take questions, comments, and concerns. Each participant will have my phone number and may contact me at any time during or after research to discuss how they feel about the project. The final written project will be available to any interested participant upon request.

To give your consent to participate, please sign your name below. Signing indicates that you have read the information above and have voluntarily decided to participate! Thank you!

Participant Signature of Consent: Date:

CONTACT INFORMATION: jes22@pdx.edu; Cell: (971) 409-0774 
SEXTING UNLEASHED

Appendix E

Table 2: Theme Tallies

\begin{tabular}{|c|c|c|c|c|}
\hline $\begin{array}{l}\mathbf{R Q /} \\
\text { Category }\end{array}$ & $\begin{array}{l}\text { Theme/ } \\
\text { Subtheme }\end{array}$ & Definition and/or examples & $\begin{array}{l}\text { \# of } \\
\text { Participant } \\
\text { Narratives in } \\
\text { which Theme } \\
\text { Emerged }\end{array}$ & $\begin{array}{l}\text { Participants } \\
\text { (See \# } \\
\text { designations } \\
\text { from Table 1) }\end{array}$ \\
\hline $\begin{array}{l}\text { 1/ } \\
\text { Definition }\end{array}$ & $\begin{array}{l}\text { Dirty talk + } \\
\text { Pictures }\end{array}$ & $\begin{array}{l}\text { Sexting includes sexually explicit } \\
\text { messages and pictures }\end{array}$ & 14 & $\begin{array}{l}1,2,3,9,10, \\
11,12,13,14, \\
15,16,18,19, \\
20\end{array}$ \\
\hline $\begin{array}{l}\text { 1/ } \\
\text { Prevalence }\end{array}$ & $\begin{array}{l}\text { Sexting as } \\
\text { common } \\
\text { activity for } \\
\text { youth }\end{array}$ & $\begin{array}{l}\text { "Everybody does it" / "Epidemic" } \\
\text { / "Happens a lot" / "Common" }\end{array}$ & 16 & $\begin{array}{l}1,2,4,5,7,8, \\
9,10,12,13, \\
14,15,16,17, \\
19,20\end{array}$ \\
\hline $\begin{array}{l}/ \\
\text { Prevalence }\end{array}$ & Mass forwards & $\begin{array}{l}\text { Participants narratives including } \\
\text { descriptions of sexts being } \\
\text { forwarded on or showed en masse } \\
\text { to others }\end{array}$ & 20 & $1-20$ \\
\hline 1/Process & $\begin{array}{l}\text { Evolution of } \\
\text { Sexting } \\
\text { Medium }\end{array}$ & $\begin{array}{l}\text { Participants describing how the } \\
\text { medium used for sexual } \\
\text { communication has changed and } \\
\text { will change }\end{array}$ & $\begin{array}{c}8 / 13 \text { direct } \\
\text { sexters; } 3 / 7 \\
\text { indirect sexters }\end{array}$ & $\begin{array}{l}3,6,7,8,9, \\
10,11,13,14, \\
15,17\end{array}$ \\
\hline 1/Process & $\begin{array}{l}\text { Common } \\
\text { sexting starters }\end{array}$ & $\begin{array}{l}\text { Pre-sexting talk that is indirect } \\
\text { and progresses to sexual } \\
\text { communication (ex. "I really miss } \\
\text { you." / "What are you up to right } \\
\text { now." }\end{array}$ & 18 & $\begin{array}{l}1,2,3,5,6,7, \\
8,9,10,11, \\
12,13,14,15, \\
16,18,19,20\end{array}$ \\
\hline 1/Process & $\begin{array}{l}\text { Post-sexting } \\
\text { show and tell }\end{array}$ & $\begin{array}{l}\text { Participants describe post-sexting } \\
\text { discussions involving people } \\
\text { showing off naked pictures and } \\
\text { videos they have received of } \\
\text { others (ex. "Hey look what I got." } \\
\text { / "Guess who I got a picture } \\
\text { from") }\end{array}$ & 20 & $1-20$ \\
\hline 1/Process & $\begin{array}{l}\text { Content/Boob } \\
\text { shots }\end{array}$ & $\begin{array}{l}\text { Common type of sext involving } \\
\text { topless females }\end{array}$ & 12 & $\begin{array}{l}1,2,6,8,9, \\
10,12,13,17 \\
18,19,20\end{array}$ \\
\hline 1/Process & $\begin{array}{l}\text { Content/Dirty } \\
\text { talk }\end{array}$ & $\begin{array}{l}\text { Common type of sext involving } \\
\text { sexually explicit messages }\end{array}$ & 12 & $\begin{array}{l}1,3,6,7,8, \\
10,12,13,15 \\
16,18,19\end{array}$ \\
\hline 1/Process & $\begin{array}{l}\text { Content/ } \\
\text { Suggestive pics }\end{array}$ & $\begin{array}{l}\text { Common type of sext involving } \\
\text { clothed individual posing in a } \\
\text { sexual manner }\end{array}$ & 12 & $\begin{array}{l}1,2,7,8,9, \\
10,13,15,16 \\
18,19,20\end{array}$ \\
\hline 1/Process & $\begin{array}{l}\text { Content/ } \\
\text { Masturbation } \\
\text { videos }\end{array}$ & $\begin{array}{l}\text { Common type of sext involving } \\
\text { video of individual masturbating } \\
\text { with or without various objects } \\
\text { (ex. lotion bottle, coke bottle) }\end{array}$ & 11 & $\begin{array}{l}1,3,6,8,9 \\
10,12,14,15 \\
19,20\end{array}$ \\
\hline 1/Process & $\begin{array}{l}\text { Content/Pics \& } \\
\text { videos include }\end{array}$ & $\begin{array}{l}\text { Sexual pictures or videos that } \\
\text { include individuals' face }\end{array}$ & 12 & $\begin{array}{l}1,2,5,6,7,8 \\
9,10,13,18\end{array}$ \\
\hline
\end{tabular}




\begin{tabular}{|c|c|c|c|c|}
\hline & face & & & 19,20 \\
\hline 1/Process & $\begin{array}{l}\text { Consequences/ } \\
\text { Social shaming }\end{array}$ & $\begin{array}{l}\text { Participant narratives include } \\
\text { descriptions of individuals whose } \\
\text { sexts went viral being ridiculed } \\
\text { by peers and references to } \\
\text { "reputation" damage }\end{array}$ & 14 & $\begin{array}{l}1,5,9,10,11 \\
12,13,14,15, \\
16,17,18,19 \\
20\end{array}$ \\
\hline 1/Process & $\begin{array}{l}\text { Consequences/ } \\
\text { Legal charges } \\
\text { as "extreme" }\end{array}$ & $\begin{array}{l}\text { Participants referring to legal } \\
\text { consequences of sexting as } \\
\text { "extreme," "harsh," "archaic," } \\
\text { "inappropriate," etc. }\end{array}$ & 17 & $\begin{array}{l}1,2,4-14,17- \\
20\end{array}$ \\
\hline 1/Process & $\begin{array}{l}\text { Lack of sexting } \\
\text { education }\end{array}$ & $\begin{array}{l}\text { Participants describing a lack of } \\
\text { sexting education in schools }\end{array}$ & 19 & $1,3-20$ \\
\hline $\begin{array}{l}\text { 1/Forms of } \\
\text { Sexting }\end{array}$ & $\begin{array}{l}\text { Sexting for } \\
\text { Social } \\
\text { Gratifications/ } \\
\text { Self-esteem } \\
\text { based }\end{array}$ & $\begin{array}{l}\text { Individuals who engage in this } \\
\text { form of sexting have low self- } \\
\text { esteem = Females achieve self- } \\
\text { esteem by sexting and getting } \\
\text { attention, feeling desired; Males } \\
\text { achieve self-esteem by showing } \\
\text { off acquired naked pictures and } \\
\text { increasing their "coolness" and } \\
\text { social status }\end{array}$ & $20 / 17$ & $\begin{array}{l}1-20 / 1-3,5-12 \\
14,16-20\end{array}$ \\
\hline $\begin{array}{l}\text { 1/Forms of } \\
\text { Sexting }\end{array}$ & $\begin{array}{l}\text { Sexting for } \\
\text { Social } \\
\text { Gratifications/ } \\
\text { Self-esteem } \\
\text { based }\end{array}$ & $\begin{array}{l}\text { Males primarily ask for } \\
\text { pictures/Females primarily send } \\
\text { pictures }\end{array}$ & 16 & $\begin{array}{l}1-4,6,9-13 \\
15-20\end{array}$ \\
\hline $\begin{array}{l}\text { 1/Forms of } \\
\text { Sexting }\end{array}$ & $\begin{array}{l}\text { Sexting for } \\
\text { Sexual } \\
\text { Gratifications/ } \\
\text { Partner-based }\end{array}$ & $\begin{array}{l}\text { Individuals who engage in this } \\
\text { form of sexting do so to sexually } \\
\text { communicate and bond with their } \\
\text { partner, add excitement to } \\
\text { relationship, and achieve sexual } \\
\text { pleasure in some form }\end{array}$ & $\begin{array}{l}\text { 7/7 direct } \\
\text { sexters }\end{array}$ & $\begin{array}{l}6,7,8,10,13 \\
18,19\end{array}$ \\
\hline $2 /$ & $\begin{array}{l}\text { Sexting as } \\
\text { private }\end{array}$ & $\begin{array}{l}\text { Participants consider sexting to be } \\
\text { private communication with sexts } \\
\text { as private objects }\end{array}$ & 15 & $\begin{array}{l}1-2,4-6,10- \\
13,15-20\end{array}$ \\
\hline $2 /$ & $\begin{array}{l}\text { Lack of } \\
\text { safeguards }\end{array}$ & $\begin{array}{l}\text { Participants describe not using } \\
\text { safeguarding measures to protect } \\
\text { their sexting information (ex. } \\
\text { "unspoken trust") }\end{array}$ & 15 & $\begin{array}{l}1-3,6-10,13 \\
15-20\end{array}$ \\
\hline $3 /$ & $\begin{array}{l}\text { Naïve notions } \\
\text { of trust }\end{array}$ & $\begin{array}{l}\text { Participants suggest young people } \\
\text { are naïve in trusting their partners } \\
\text { to not show off their sexts }\end{array}$ & 20 & $1-20$ \\
\hline $3 /$ & $\begin{array}{l}\text { More } \\
\text { comfortable to } \\
\text { sext within } \\
\text { relationships }\end{array}$ & $\begin{array}{l}\text { Participants describe sexting } \\
\text { within relationships as more } \\
\text { "comfortable" and "less } \\
\text { worrisome" }\end{array}$ & 13 & $\begin{array}{l}1,3,4,8,10 \\
11,13,14,16 \\
17,18,19,20\end{array}$ \\
\hline $3 /$ & $\begin{array}{l}\text { "Justified" or } \\
\text { "expected" to } \\
\text { sext within } \\
\text { relationships } \\
\end{array}$ & $\begin{array}{l}\text { Participants describe sexting } \\
\text { within relationships as "justified" } \\
\text { and "expected" }\end{array}$ & 13 & $\begin{array}{l}1,4,5,8,10 \\
11,14,15,16 \\
17,18,19,20\end{array}$ \\
\hline
\end{tabular}

